\title{
Steady State and Dynamic Modeling of the Modified Claus Process as part of an IGCC Power Plant
}

\author{
Dustin Douglas Jones \\ West Virginia University
}

Follow this and additional works at: https://researchrepository.wvu.edu/etd

\section{Recommended Citation}

Jones, Dustin Douglas, "Steady State and Dynamic Modeling of the Modified Claus Process as part of an IGCC Power Plant" (2011). Graduate Theses, Dissertations, and Problem Reports. 4736.

https://researchrepository.wvu.edu/etd/4736

This Thesis is protected by copyright and/or related rights. It has been brought to you by the The Research Repository @ WVU with permission from the rights-holder(s). You are free to use this Thesis in any way that is permitted by the copyright and related rights legislation that applies to your use. For other uses you must obtain permission from the rights-holder(s) directly, unless additional rights are indicated by a Creative Commons license in the record and/ or on the work itself. This Thesis has been accepted for inclusion in WVU Graduate Theses, Dissertations, and Problem Reports collection by an authorized administrator of The Research Repository @ WVU. For more information, please contact researchrepository@mail.wvu.edu. 
Steady State and Dynamic Modeling of the Modified Claus Process as part of an IGCC Power Plant

Dustin Douglas Jones

Thesis submitted to the College of Engineering and Mineral Resources

at West Virginia University in partial fulfillment of the requirements

for the degree of

Master of Science

In

Chemical Engineering

Dr. Richard Turton, Chair

Dr. Joseph Shaeiwitz

Dr. John Zondlo

Dr. Debangsu Bhattacharyya

Department of Chemical Engineering

Morgantown, West Virginia

2011

Keywords: Modified Claus Process, IGCC, Optimization, Control 


\section{ABSTRACT \\ Steady State and Dynamic Modeling of the Modified Claus Process as part of an IGCC Power Plant}

\section{Dustin Douglas Jones}

The Modified Claus Process is one of the most common methods for sulfur recovery from acid gas streams. An extensive survey of the open literature has been carried out to collect rate expression and experimental data for the reactions of the Claus reaction furnace. For the instances that no rate expression could be found, rate expressions were derived from the available published experimental data. Additionally, data fitting of the rate parameters of key reactions in the Claus furnace was carried out. This resulted in a significantly better agreement of the model with the published industrial data in comparison to the available models in the open literature. With these and other rate expressions, a steady-state model of the Claus plant and hydrogenation unit was developed. With this kinetic model, an optimization study was carried out to minimize the power requirement in the Claus unit and other associated units as a result of the Claus unit operation. The optimization study shows that for low costs of hydrogen sulfide recovery, optimal $\mathrm{H}_{2} \mathrm{~S} / \mathrm{SO}_{2}$ ratio is larger than two so as to maximize hydrogen production. As the cost of hydrogen sulfide recovery is increased, optimal $\mathrm{H}_{2} \mathrm{~S}_{/} \mathrm{SO}_{2}$ ratio nears two, increasing single-pass conversion. This steady state model then served as the basis of a dynamic pressuredriven simulation of the Claus and hydrogenation units. With this simulation, models where identified between the oxygen flow to the Claus furnace (input) and $\mathrm{H}_{2} \mathrm{~S} / \mathrm{SO}_{2}$ ratio (output) and between the $\mathrm{H}_{2} \mathrm{~S}$ concentration in the feed to the Claus unit (disturbance)) and the $\mathrm{H}_{2} \mathrm{~S} / \mathrm{SO}_{2}$ ratio. With these identified models, a feedforward control strategy was developed and implemented in Aspen Plus Dynamics. This control strategy resulted in a much improved dynamic performance than conventional PI control under changing acid gas composition. 


\section{Contents}

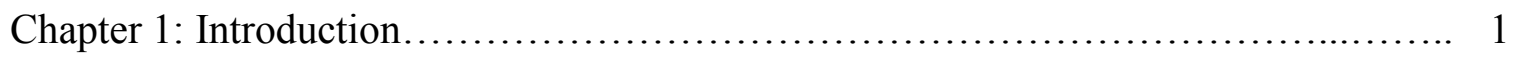

Chapter 2: Literature Review................................................... 10

2.1. Combustion Reactions........................................................ 10

2.2. Equilibrium Reactions................................................ 12

2.3. Ammonia Destruction.................................................... 14

2.4. Methane Destruction..................................................... 15

2.5. Carbonyl Sulfide Formation........................................... 16

2.6. Catalytic Reactions..................................................... 17

2.7. Hydrogenation Reactions................................................ 18

Chapter 3: Data Analysis................................................................ 19

3.1. Sulfur Dioxide and Ammonia Reaction................................... 19

3.2. Thermal Cracking of Ammonia.......................................... 23

3.3. Combustion of Hydrogen Sulfide....................................... 27

Chapter 4: Model Methodology................................................ 30

4.1. Zone Analysis................................................................ 30

4.2. Parametric Optimization................................................. 32

Chapter 5: Steady State Optimization............................................ 43

5.1. Problem Description................................................... 43

5.2. Results.................................................................. 45

Chapter 6: Control Studies.................................................... 50

6.1. Simplifying Assumptions and Development of Dynamic Model............... 50

6.2. Regulatory Controls................................................... 51

6.3. Control Strategies..................................................... 55

Chapter 7: Conclusions ........................................................ 60

Chapter 8: Recommendations for Future Work................................ 62

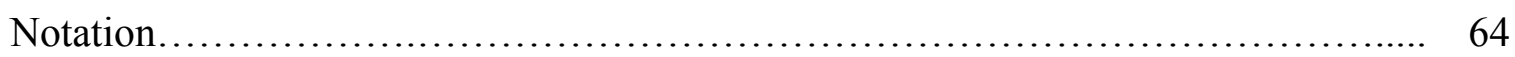

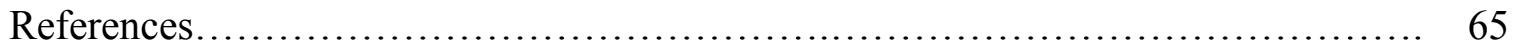

Appendix A..................................................................... 68 


\section{List of Tables}

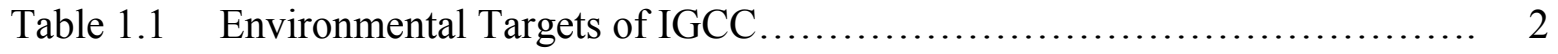

Table 1.2 Western Research correlations for yields from Claus Reaction .............. 6 furnace by Sames and Paskall [13]

Table 4.1 Comparison of measured plant data to that of equilibrium ................. 33 predictions[13]

Table 4.2 Summary of feed conditions......................................... 34

Table 4.3 Summary of feed compositions (mole percent, dry basis)................. 35

Table 4.4 Comparison between published rate parameters and adjusted ................ 38 rate parameters

Table 4.5 Comparison between published rate parameters and adjusted rate............ 39 parameters

Table 6.1 Time-integral performance criteria

\section{List of Figures}

Figure 1.1: Block Flow Diagram of IGCC Power Plant with Carbon .................. 2 Capture [21]

Figure 1.2: Diagram of straight-through Claus reaction furnace [14] .................. 3

Figure 1.3: Split-Flow Configuration of Claus Furnace [24] ........................ 3

Figure 1.4: Connectivity of Claus Unit with Other IGCC Unit....................... 5

Figure 1.5: $\mathrm{H}_{2}$ : Equilibrium results vs. empirical correlation and .................... 7 plant data [13]

Figure 1.6: Sulfur: Equilibrium results vs. empirical correlation and .................. 7 plant data [13]

Figure 3.1: Arrhenius plot for ammonia and sulfur dioxide reactions................... 22

Figure 3.2: Model Predictions vs. Experimental Data................................. 23

Figure 3.3: Arrhenius plot of thermal cracking of ammonia in the.................... 25 absence of water and hydrogen sulfide

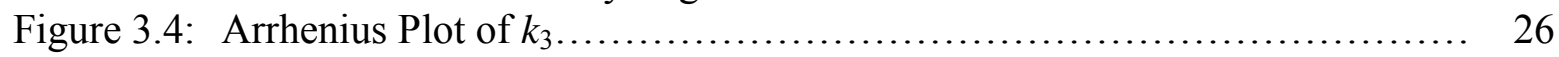

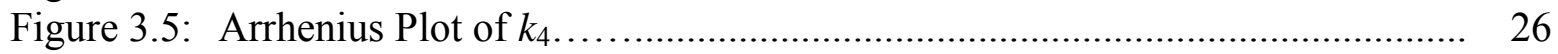

Figure 3.6: Model Predictions vs. Experimental Data................................ 27

Figure 4.1: Zone Analysis of the Claus Reaction Furnace......................... 31

Figure 4.2: Simplified Flowsheet of 2-Stage Claus Process......................... 32

Figure 4.3: Comparison of Model Prediction with Plant Data Set 1.................. 35

Figure 4.4: Comparison of Model Prediction with Plant Data Set 2.................. 36 
Figure 4.5: Comparison of Model Prediction with Plant Data Set 3................ 36

Figure 4.6: Comparison of Model Prediction with Plant Data Set 4................ 37

Figure 4.7: Comparison of Model Prediction with Plant Data Set 5................ 37

Figure 4.8: Model Comparisons Case 1........................................ 39

Figure 4.9: Model Comparisons Case 2 ...................................... 40

Figure 4.10: Model Comparisons Case 3 ....................................... 40

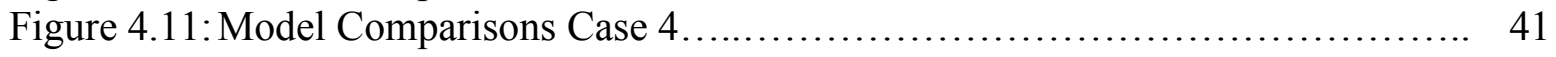

Figure 4.12: Model Comparisons Case 5.................................... 41

Figure 4.13: Comparison of the Model with TSweet ${ }^{\circledR} \ldots \ldots \ldots \ldots \ldots \ldots \ldots \ldots \ldots \ldots \ldots . . . \ldots 2$

Figure 5.1: Effect of oxygen flow on hydrogen and hydrogen sulfide flow in tailgas... 45

Figure 5.2: Effect of oxygen flow on Claus power production and power produced.... 46 by steam turbines minus power requirement of tailgas compressors

Figure 5.3: Effect of Selexol power requirement on optimal oxygen flow............ 47 and objective function value

Figure 5.4: Effect of Selexol power requirement on optimal $\mathrm{H}_{2} \mathrm{~S} / \mathrm{SO}_{2}$ ratio........... 47 at the inlet of the hydrogenation unit and $1^{\text {st }}$ Claus Reactor

Figure 5.5: Effect of Selexol power requirement on optimal power................. 48 generation of steam turbine and requirement of tailgas compressor and single pass conversion

Figure 6.1: Simplified Flowsheet of Modified Claus Process ..................... 52 with Controls

Figure 6.2: Block flow diagram of a feedforward-augmented feedback.............. 56 control scheme

Figure 6.3: Process response and fitted model to a 13\% step decrease.............. 57 in oxygen flow

Figure 6.4: Process response and fitted model to a 27\% step decrease............... 58 in hydrogen sulfide concentration in Selexol acid gas

Figure 6.5: $\mathrm{H}_{2} \mathrm{~S} / \mathrm{SO}_{2}$ ratio and oxygen flow for feedforward-augmented............. 59 feedback and feedback control for a $27 \%$ step decrease in $\mathrm{H}_{2} \mathrm{~S}$ concentration in Selexol gas 


\section{Chapter 1}

\section{$\underline{\text { Introduction }}$}

Integrated gasification combined cycle (IGCC) is a promising technology for generating clean, affordable, and secure power. However, a coal-fed IGCC power plant has lower net plant efficiency compared to a conventional natural gas combined cycle (NGCC) power plant. A recent NETL study shows that the net plant efficiency of a coal-fed IGCC plant with a General Electric Energy (GEE)type gasifier is $38.2 \%$ compared to $50.8 \%$ efficiency for NGCC plants [20]. The net plant efficiency of the IGCC plant further decreases to $32.5 \%$ when the $\mathrm{CO}_{2}$ capture option is considered. In order to make IGCC technology more competitive, efforts must be exerted to improve its efficiency. Recently, an optimization study was carried out for improving the efficiency of IGCC plants with $\mathrm{CO}_{2}$ capture [21]. The typical plant layout for IGCC is shown in Figure 1.1. The study considered a GEE-type entrained flow gasifier mainly because of its high carbon conversion rates and environmental advantages [21, 22]. In high-temperature gasifiers, such as the GEE-type, the gasifier efficiency increases and the size of downstream equipment is reduced when oxygen, instead of air, is used in the gasifier [23]. Figure 1 shows that the shifted syngas from the gasifier goes to a Selexol ${ }^{\mathrm{TM}}$ solvent unit for acid gas removal. Hydrogen sulfide removed is sent to the Claus unit and carbon dioxide is sent for compression and sequestration. Environmental targets for the IGCC are shown in Table 1.1 [20]. 


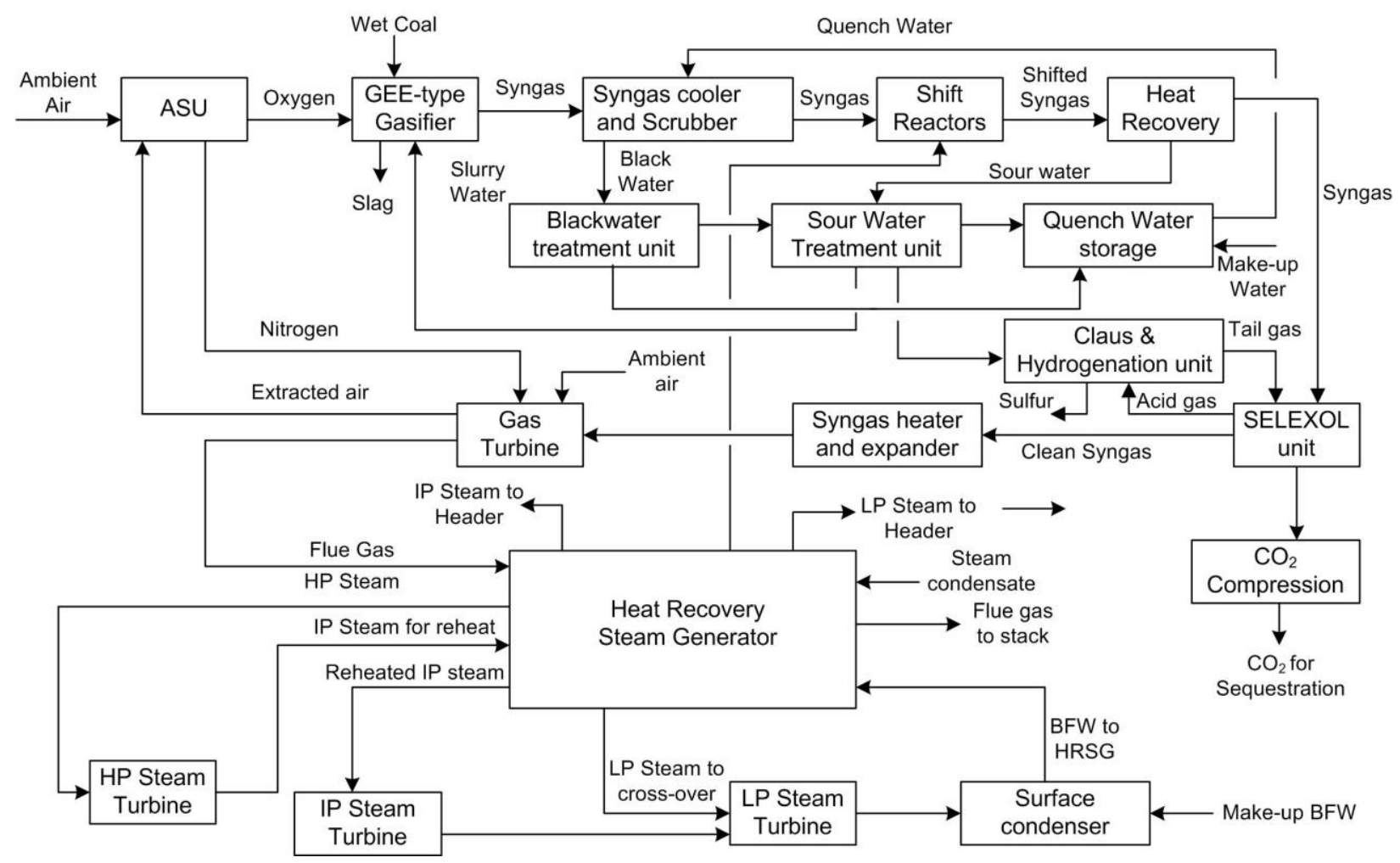

Figure 1.1: Block Flow Diagram of IGCC Power Plant with Carbon Capture [21]

Table 1.1 Environmental Targets of IGCC

\begin{tabular}{|c|c|}
\hline Pollutant & Environmental Target \\
\hline $\mathrm{NO}_{\mathrm{x}}$ & $15 \mathrm{ppmv}(\mathrm{dry}) @, 15 \% \mathrm{O}_{2}$ \\
\hline $\mathrm{SO}_{2}$ & $0.0128 \mathrm{lb} / \mathrm{MMBTU}$ \\
\hline Particulate Matter & $0.0071 \mathrm{lb} / \mathrm{MMBTU}$ \\
\hline Mercury & $90 \%$ Capture \\
\hline
\end{tabular}

The process begins with the Claus reaction furnace, Figures 1.2 and 1.3, also referred to as the thermal stage. In the reaction furnace, one third of the hydrogen sulfide contain in the acid gases is combusted to form sulfur dioxide, reaction (1.1). This gas then passes through a waste heat boiler (WHB) to generate MP steam to be used for heating duties required in the process. The process gas is then further cooled to condense the sulfur formed during the thermal stage. The gas is then reheated and sent to the first of two catalytic stages where hydrogen sulfide 
and sulfur dioxide react in a 2:1 ratio to form sulfur and water, reaction (1.2). The overall sulfur chemistry of the Claus process is often shown as reaction (1.3).

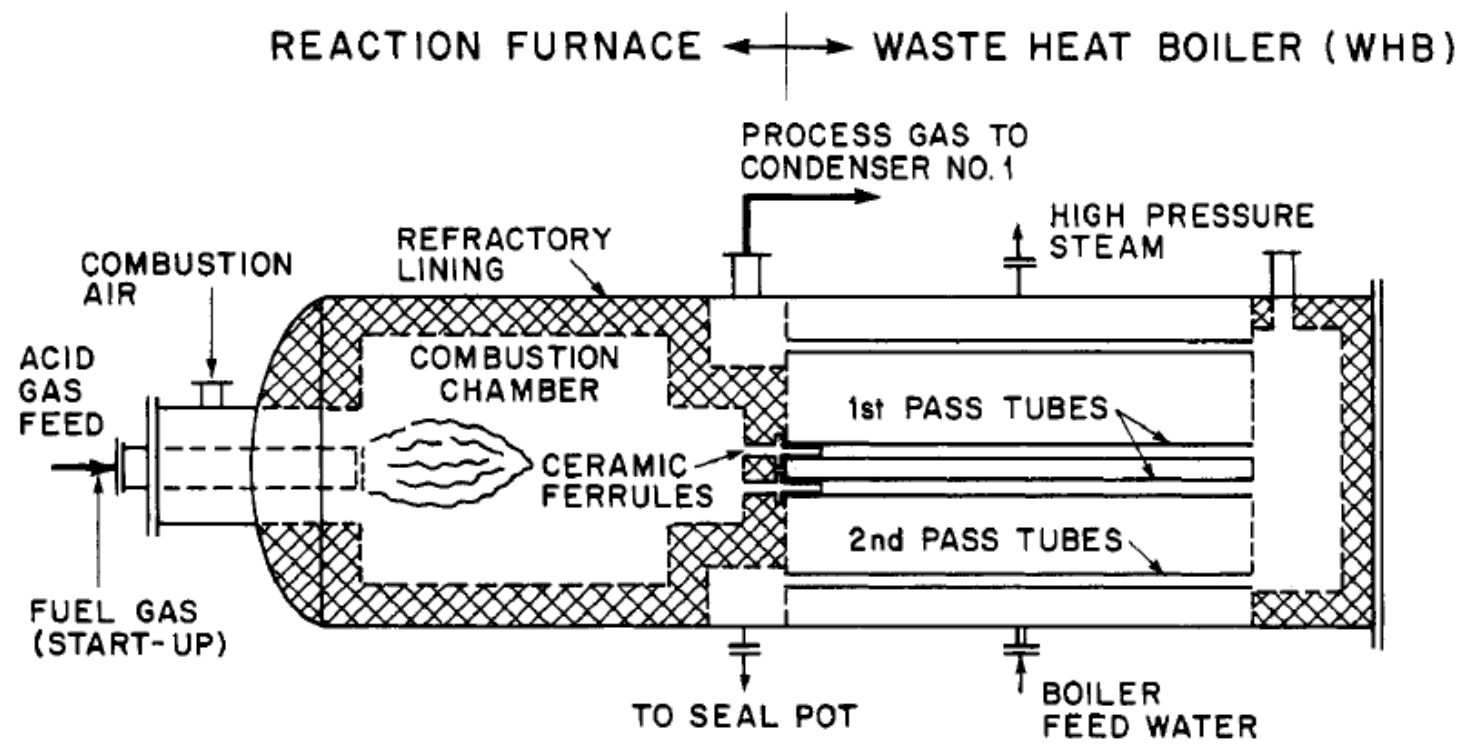

Figure 1.2: Diagram of straight-through Claus reaction furnace [14]

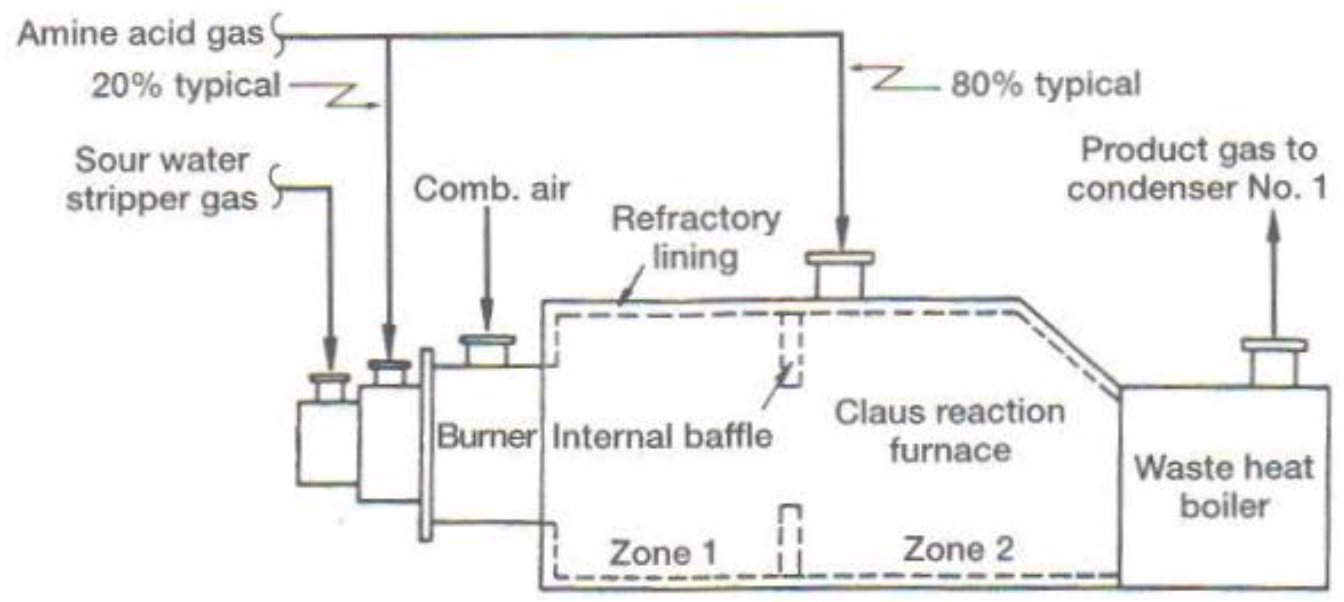

Figure 1.3: Split-Flow Configuration of Claus Furnace [24]

$$
\begin{gathered}
3 \mathrm{H}_{2} \mathrm{~S}+\frac{3}{2} \mathrm{O}_{2} \rightarrow 2 \mathrm{H}_{2} \mathrm{~S}+\mathrm{SO}_{2}+\mathrm{H}_{2} \mathrm{O} \\
2 \mathrm{H}_{2} \mathrm{~S}+\mathrm{SO}_{2} \longleftrightarrow 2 \mathrm{H}_{2} \mathrm{O}+\frac{3}{n} \mathrm{~S}_{n} \\
\mathrm{H}_{2} \mathrm{~S}+\frac{1}{2} \mathrm{O}_{2} \rightarrow \frac{3}{n} \mathrm{~S}_{n}+\mathrm{H}_{2} \mathrm{O}
\end{gathered}
$$


The Claus unit's primary function in the operation of an IGCC power plant is the recovery of sulfur from acid gases. In addition, it is required to destroy ammonia that is generated in the IGCC. Figure 1.4 shows the connectivity of the Claus unit with other unit operations of the IGCC. For operations with acid gases whose hydrogen sulfide composition is greater than $50 \mathrm{~mol} \%$, a straight-through configuration is generally chosen [24], shown as Figure 1.2. However, for operations with acid gases whose hydrogen sulfide concentrations are less than 50 mol\%, a split-flow configuration is generally required, shown as Figure 1.3. This is due to the requirement that the adiabatic flame temperature must be greater than $1,700^{\circ} \mathrm{F}$ for flame stability [24]. In addition, a split-flow configuration is also sometimes required when processing a sour water stripper gas, due to its high concentration of ammonia. This is generally required to ensure the combustion of ammonia [24]; although Clark et al. [10] claim that the more likely path for ammonia destruction is with its reaction with sulfur dioxide in the high temperature flame region. 


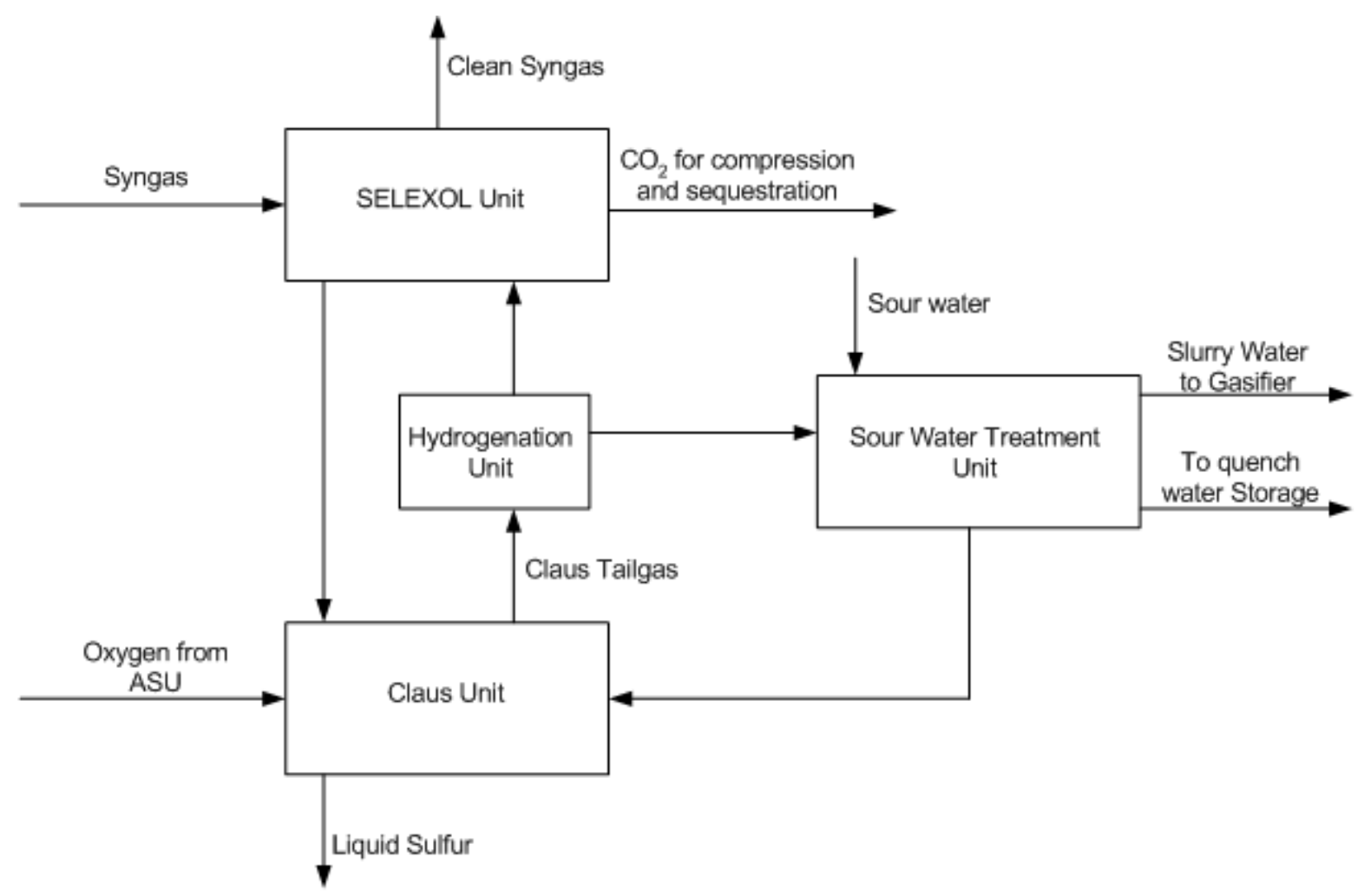

Figure 1.4: Connectivity of Claus Unit with Other IGCC Unit

Challenges arise when hydrogen sulfide concentrations in the acid gas are low and when there is a high flow of ammonia to the furnace. Since high temperatures are required for complete ammonia destruction, to prevent plugging in downstream reactors [17], to ensure flame stability, and since there exists a limit on the amount of acid gas that can be bypassed, due to the need to combust a third of the hydrogen sulfide to form sulfur dioxide for downstream catalytic reactors, other options are often required [24]. The options considered here are preheating of all feed streams and the use of an oxygen-enriched stream instead of oxygen. Due to these modifications to the conventional Claus process, this process is also called a modified Claus process.

Computational approaches for predicting Claus furnace product distribution vary from equilibrium models, restricted equilibrium models, and correlations. Often used correlations from Western Research are given in Table 1.2. The results of 
these correlations and equilibrium predictions are compared with plant data in Figures 1.5 and 1.6.

Table 1.2: Western Research correlations for yields from Claus Reaction furnace by Sames and Paskall [13]

$R \mathrm{CO}=$ fraction of furnace inlet carbon that forms $\mathrm{CO}$

$$
=0.002 A^{0.0345} \exp 4.53 A
$$

$R \mathrm{H}_{2}=$ fraction of furnace inlet $\mathrm{H}_{2} \mathrm{~S}$ that cracks to $\mathrm{H}_{2}$

$$
=0.056 \pm 0.024
$$

$R \operatorname{COS}=$ fraction of furnace inlet carbon that forms COS

$=0.01 \tan (100 A)$, for $0 \leq A \leq 0.86$

$=0.143$, for $A \geq 0.86$

$R \mathrm{CS}_{2}=$ fraction of furnace inlet hydrocarbon that forms $\mathrm{CS}_{2}$

$=2.6 A^{0.971} \exp -0.965 A$

$R \mathrm{~S}=$ fraction of furnace inlet $\mathrm{H}_{2} \mathrm{~S}$ that forms elemental $\mathrm{S}$

$$
=1.58 A^{1.099} \exp -0.73 A
$$

where $A=$ mole fraction of $\mathrm{H}_{2} \mathrm{~S}$ in the acid gas feed on a dry basis. 


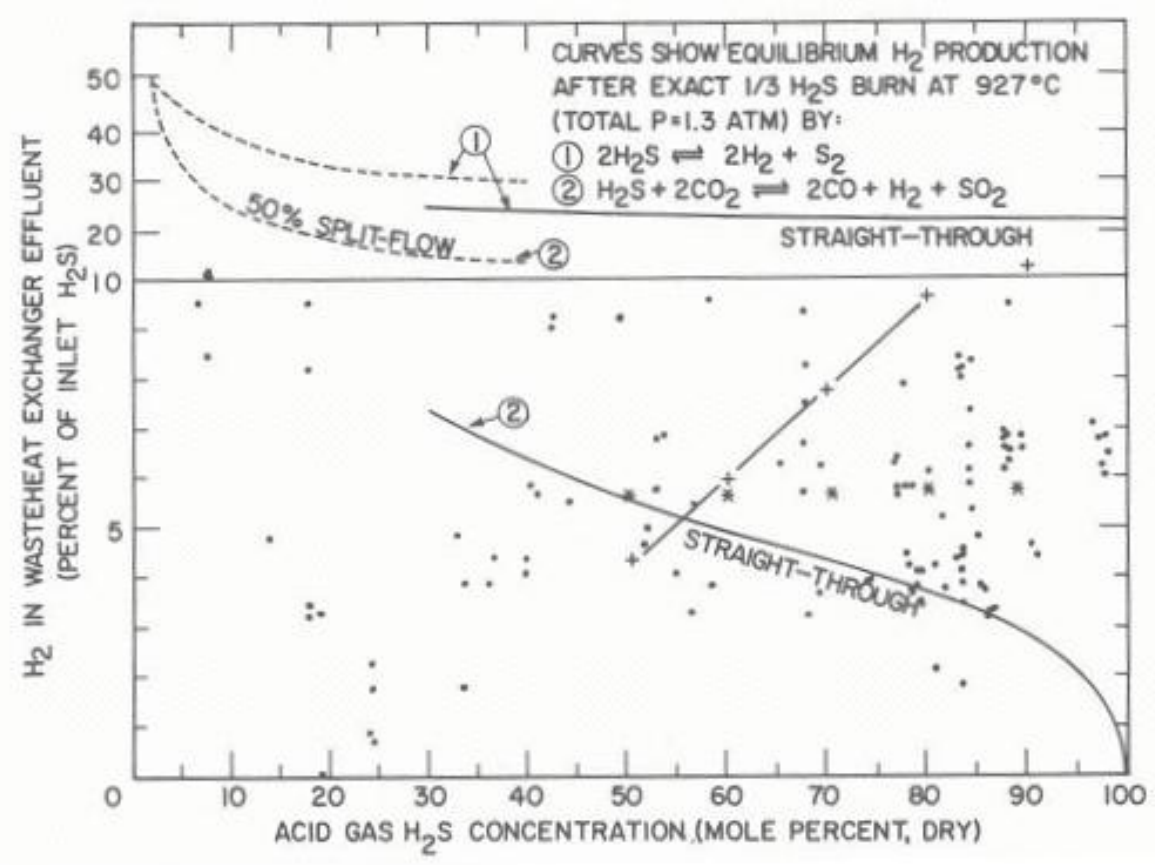

Figure 1.5: $\mathrm{H}_{2}$ : Equilibrium results vs. empirical correlation and plant data [13] $\bullet$ = Plant Data

$+=$ Equilibrium (adiabatic flame temperature)

$*=$ Western Research correlation

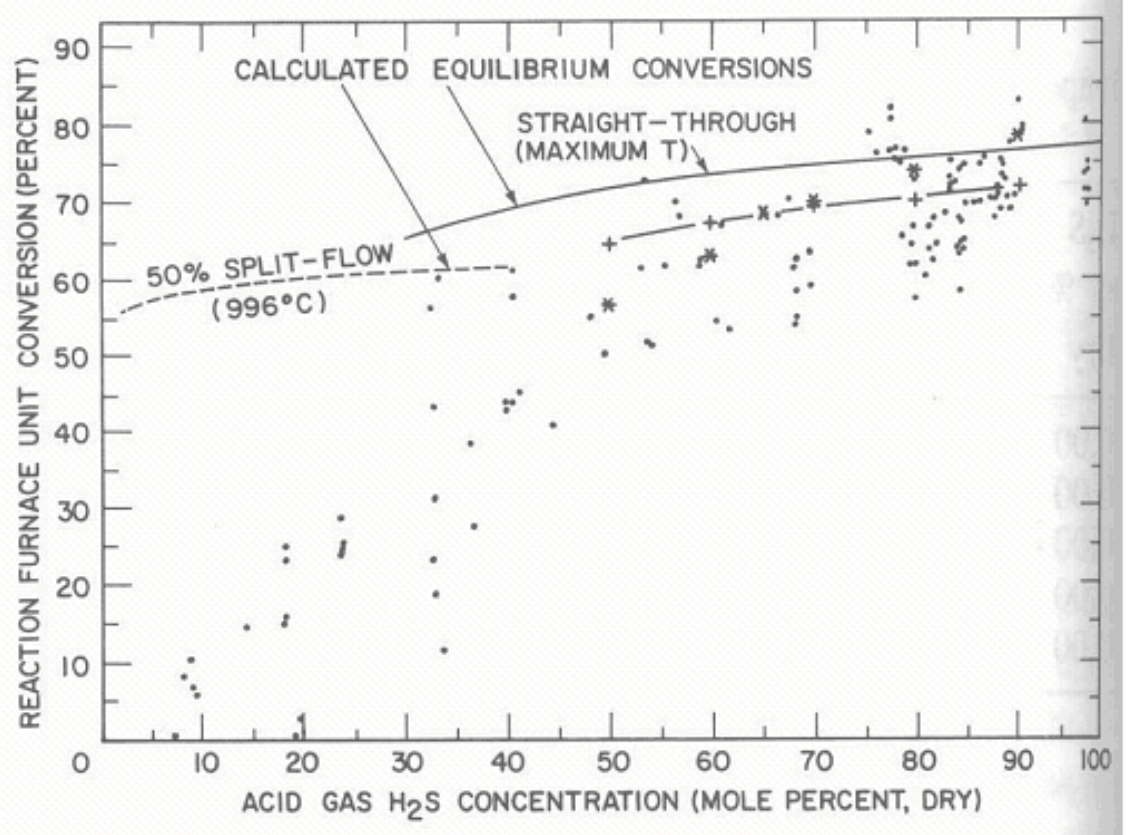

Figure 1.6: Sulfur: Equilibrium results vs. empirical correlation and plant data [13]

$\bullet$ = Plant Data

$+=$ Equilibrium (adiabatic flame temperature)

$*=$ Western Research correlation 
From Figures 1.5 and 1.6, it is apparent that both the correlation and equilibrium models do not capture the behavior of the Claus furnace over a wide range of operating conditions. The equilibrium models can be used, with some accuracy, to describe the product distribution for a single Claus furnace by using the temperature approach to equilibrium as tuning parameters; however, these methods cannot accurately describe furnaces with changing operating conditions, feed conditions, or flowrates.

The process gas that exits the waste heat boiler passes to a cooler to condense and separate the sulfur. The process gas is then reheated and sent to the first of two catalytic reactors where hydrogen sulfide and sulfur dioxide react in a 2:1 ratio to form sulfur and water. After reacting in the catalytic reactor, the gas is then cooled to condense and remove the formed sulfur and sent to the second catalytic stage. After the second stage, the tailgas is sent to a hydrogenation unit. This unit converts remaining sulfur species to hydrogen sulfide. This gas is then cooled to remove the water and compressed and recycled to the Selexol unit.

The purpose of this work is the development of a model of the Claus process based on reaction kinetics and unit operations that will accurately represent the Claus process across a wide range of operating conditions. This model developed is then used as the basis for a dynamic, pressure-driven simulation of the Claus process, which shows the transients of the system under changing operating and flow conditions that may occur in the operation of an IGCC plant. Finally, several control strategies for the Claus furnace are formulated and compared. 
During the course of this research, work was done on the optimization of an air separation unit as part of an IGCC plant. Though this work will not be discussed in the body of this paper, the manuscript of the work is attached as appendix A. 


\section{Chapter 2}

\section{Literature Review}

Although the Claus process is a mature and widely used technology, detailed understanding of its chemistry is still not available. There is much disagreement about dominant pathways for the destruction/formation of components, rates of reactions, inhibition of reactions by other components within the feed, etc. An extensive literature review was required to ensure an accurate model of the Claus furnace.

\subsection{Combustion Reactions}

Accurately predicting the extent of each combustion reaction is an important issue in the lean-oxygen environment of the Claus furnace. Although it is often thought that the primary pathway for the destruction of methane, ammonia, and other impurities in the acid gas feed is through oxidation, the actual extent of these reactions is minimal due to the much faster oxidation rate of hydrogen sulfide [1]. Reactions (2.1-2.4) describe possible hydrogen sulfide combustion reactions and reactions (2.5-2.7) describe other possible combustion reactions.

$$
\begin{gathered}
\mathrm{H}_{2} \mathrm{~S}+\frac{3}{2} \mathrm{O}_{2} \rightarrow \mathrm{SO}_{2}+\mathrm{H}_{2} \mathrm{O} \\
2 \mathrm{H}_{2} \mathrm{~S}+\frac{5}{2} \mathrm{O}_{2} \rightarrow 2 \mathrm{SO}_{2}+\mathrm{H}_{2} \mathrm{O}+\mathrm{H}_{2} \\
\mathrm{H}_{2} \mathrm{~S}+\frac{1}{2} \mathrm{O}_{2} \rightarrow \frac{1}{2} \mathrm{~S}_{2}+\mathrm{H}_{2} \mathrm{O} \\
2 \mathrm{H}_{2} \mathrm{~S}+\frac{1}{2} \mathrm{O}_{2} \rightarrow \mathrm{S}_{2}+\mathrm{H}_{2} \mathrm{O}+\mathrm{H}_{2} \\
\mathrm{CH}_{4}+2 \mathrm{O}_{2} \rightarrow \mathrm{CO}_{2}+2 \mathrm{H}_{2} \mathrm{O}
\end{gathered}
$$




$$
\begin{gathered}
\mathrm{NH}_{3}+\frac{3}{4} \mathrm{O}_{2} \rightarrow \frac{3}{2} \mathrm{H}_{2} \mathrm{O}+\frac{1}{2} \mathrm{~N}_{2} \\
\mathrm{H}_{2}+\frac{1}{2} \mathrm{O}_{2} \rightarrow \mathrm{H}_{2} \mathrm{O}
\end{gathered}
$$

The primary issue with the combustion reactions is not the extent of reactions (2.5), (2.6), or (2.7) but with the extent of reaction of the four possible hydrogen sulfide combustion reaction, $(2.1-2.4)$ [1]. These reactions can be used to explain the higher than expected sulfur yields of the Claus furnace that are often observed because these reactions are not equilibrium limited. In addition, the oxygen requirements for each of these reactions vary greatly, with $\mathrm{H}_{2} \mathrm{~S}: \mathrm{O}_{2}$ ratios varying between 0.66 and 4. Furthermore, these reactions have a dramatic effect on the temperature profile within the furnace, due to the large differences in their heats of reaction, ranging from $\Delta H_{R}=-2.23 \times 10^{5} \mathrm{Btu} \mathrm{bmol}^{-1}$ for $(2.1)$ to $\Delta H_{R}=1.29 \times 10^{8} \mathrm{Btu}^{\mathrm{bmol}}{ }^{-1}$ for (2.4). Although it has been suggested by Clark [1] that reactions (2.2) and (2.3) may also occur when oxygen concentration becomes very low, these reactions have not been included in the current model due to the lack of data or rate expressions.

The kinetic expressions for reactions (2.1), (2.5), (2.6), and (2.7) obtained from Hawboldt [2], Lindberg and Hermansson [3], Monnery et al. [4], and Molnar and Marek [5], respectively, are:

$$
r\left[\frac{\mathrm{kmol}}{\mathrm{m}^{3} . \mathrm{s}}\right]=1.4 \times 10^{9} \exp \left(\frac{-11.0\left[\frac{\mathrm{kcal}}{\mathrm{mol}}\right]}{R T}\right) P_{\mathrm{H}_{2} S} P_{\mathrm{O}_{2}}^{1.5} \mathrm{~atm}
$$




$$
\begin{gathered}
r\left[\frac{\mathrm{kmol}}{\mathrm{m}^{3} . \mathrm{s}}\right]=348 \exp \left(\frac{-3.77\left[\frac{\mathrm{kcal}}{\mathrm{mol}}\right]}{R T}\right) C_{C H_{4}}^{0.62} C_{O_{2}}^{0.55} \\
r\left[\frac{\mathrm{kmol}}{\mathrm{m}^{3} . \mathrm{s}}\right]=4.43 \times 10^{6} \exp \left(\frac{-40.0\left[\frac{\mathrm{kcal}}{\mathrm{mol}}\right]}{R T}\right) P_{\mathrm{NH}_{3}} P_{O_{2}}^{0.75} \mathrm{~atm} \\
r\left[\frac{\mathrm{kmol}}{\mathrm{m}^{3} . \mathrm{s}}\right]=7.63 \times 10^{10} \exp \left(\frac{-48.2\left[\frac{\mathrm{kcal}}{\mathrm{mol}}\right]}{R T}\right) C_{H_{2}}^{0.229} C_{O_{2}}^{0.771}
\end{gathered}
$$

\subsection{Equilibrium Reactions}

Although it is often assumed that all the reversible reactions taking place in the Claus furnace reach equilibrium, it has been shown that equilibrium predictions of the Claus furnace do not accurately predict product distributions $[1,2,13]$. In addition, the shifting equilibrium within the waste heat boiler (WHB) causes this to become a kinetically controlled regime. This is largely due to relatively slow kinetics and alternative pathways for reactions.

$$
\begin{gathered}
\mathrm{CO}_{2}+\mathrm{H}_{2} \longleftrightarrow \mathrm{CO}+\mathrm{H}_{2} \mathrm{O} \\
\mathrm{H}_{2}+\frac{1}{2} \mathrm{SO}_{2} \longleftrightarrow \mathrm{H}_{2} \mathrm{O}+\frac{1}{4} \mathrm{~S}_{2} \\
\mathrm{H}_{2} \mathrm{~S}+\frac{1}{2} \mathrm{SO}_{2} \longleftrightarrow \frac{3}{4} \mathrm{~S}_{2}+\mathrm{H}_{2} \mathrm{O} \\
\mathrm{H}_{2} \mathrm{~S} \longleftrightarrow \mathrm{H}_{2}+\frac{1}{2} \mathrm{~S}_{2}
\end{gathered}
$$


As an example to illustrate the need for kinetics to predict product distributions, it is often thought that the primary pathways for sulfur production in the Claus furnace are by means of the Claus reaction (2.14) and/or the thermal cracking of hydrogen sulfide $(2.15)[1,13,15]$. However, it has been shown that sulfur production can exceed the equilibrium conversion predicted when considering these reactions as the primary pathway for sulfur production [1]. It has been suggested by Clark [1] that the major pathway for the production of sulfur is not by reactions (2.13 - 2.15), but rather by reactions (2.3) and (2.4). However, with longer residence times, the reverse reactions $(2.14-2.15)$ decrease sulfur yield.

Another important equilibrium reaction that has a major impact on the performance of the modified Claus process is the water-gas shift reaction (2.12). This reaction is not only a large source of the hydrogen produced in the furnace but also the major source of the carbon monoxide that is produced $[6,7,14]$. This is particularly important because the major pathway for the formation of carbonyl sulfide is the reaction of sulfur and hydrogen sulfide with carbon monoxide [1, 2, $6]$.

Kinetic expressions for reactions (2.12), (2.14), and (2.15) obtained from Karan et al. [6], Monnery et al. [8], and Hawboldt et al. [9], respectively, are:

$$
\begin{aligned}
& r\left[\frac{\mathrm{kmol}}{\mathrm{m}^{3} . \mathrm{s}}\right]=3.95 \times 10^{10} \exp \left(\frac{-62.03\left[\frac{\mathrm{kcal}}{\mathrm{mol}}\right]}{R T}\right)\left(C_{C O_{2}} C_{H_{2}}^{0.5}-\exp \left(-4.72+\frac{4800}{T}\right) \frac{C_{C O} C_{H_{2} O}}{C_{H_{2}}^{0.5}}\right) \\
& r\left[\frac{\mathrm{kmol}}{\mathrm{m}^{3} . \mathrm{s}}\right]=1.6 \times 10^{7} \exp \left(\frac{-49.9\left[\frac{\mathrm{kcal}}{\mathrm{mol}}\right]}{R T}\right)_{H_{H_{2}} P_{S o_{2}} P^{0.5}} \text { atm }-5.1 \times 10^{5} \exp \left(\frac{-44.9\left[\frac{\mathrm{kcal}}{\mathrm{mol}}\right]}{R T}\right) P_{S_{2}}^{0_{2}^{0.55}} P_{H_{2} O} \text { atm }
\end{aligned}
$$




$$
r\left[\frac{\mathrm{kmol}}{\mathrm{m}^{3} . \mathrm{s}}\right]=5.26 \times 10^{6} \exp \left(\frac{-45.0\left[\frac{\mathrm{kcal}}{\mathrm{mol}}\right]}{R T}\right) P_{H_{2} S} S_{S_{2}}^{0.5} \text { atm }-14 \times 10^{3} \exp \left(\frac{-23.4\left[\frac{\mathrm{kcal}}{\mathrm{mol}}\right]}{R T}\right) P_{H_{2}} P_{S_{2}} \mathrm{~atm}
$$

\subsection{Ammonia Destruction}

Ammonia destruction in the Claus furnace is an important design consideration with respect to the modified Claus process when part of an IGCC plant. This is due to the need to process the ammonia-rich sour water stripper gas. Ammonia is known to deactivate the catalyst in the catalytic stages of the process and cause plugging due to the formation of ammonium salts. Often residence times in the furnace or the oxygen feed rate are increased to ensure the destruction of ammonia $[1,2,10]$; however, it has been found that the primary pathway for ammonia destruction in the furnace is not the combustion reaction (2.6), but rather it is due to the reaction with sulfur dioxide (2.19) and thermal cracking (2.20) [10].

$$
\begin{aligned}
\mathrm{NH}_{3}+\frac{3}{4} \mathrm{SO}_{2} & \rightarrow \frac{3}{2} \mathrm{H}_{2} \mathrm{O}+\frac{3}{8} \mathrm{~S}_{2}+\frac{1}{2} \mathrm{~N}_{2} \\
\mathrm{NH}_{3} & \rightarrow \frac{1}{2} \mathrm{~N}_{2}+\frac{3}{2} \mathrm{H}_{2}
\end{aligned}
$$

It has been shown by Clark et al. [10] that the reactions with ammonia are initiated at $750^{\circ} \mathrm{C}$ and proceed rapidly while the operating temperature of the Claus furnace is typically in the range of $1000-1250^{\circ} \mathrm{C}$.

Rate expressions have been derived for these two reactions and will be discussed in detail later. 


\subsection{Methane Destruction}

Like ammonia, methane destruction is an important consideration when designing the reaction furnace. Methane, like ammonia, has been shown to deactivate and plug the alumina catalyst in the downstream reactors [17]. Methane destruction takes place via the reactions:

$$
\begin{gathered}
\mathrm{CH}_{4}+\mathrm{S}_{2}+\mathrm{H}_{2} \mathrm{O} \rightarrow \mathrm{COS}+\mathrm{H}_{2} \mathrm{~S}+2 \mathrm{H}_{2} \\
\mathrm{CH}_{4}+\mathrm{CO}_{2} \longleftrightarrow 2 \mathrm{CO}+2 \mathrm{H}_{2} \\
\mathrm{CH}_{4}+\mathrm{H}_{2} \mathrm{O} \longleftrightarrow \mathrm{CO}+3 \mathrm{H}_{2}
\end{gathered}
$$

The primary pathway for the destruction of methane in the furnace is not the combustion reaction (2.5) [1], but rather the reaction with sulfur (2.21), carbon dioxide (2.22), and steam methane reforming (2.23) [1,7]. Reaction (2.21) is a combination of two reactions, the first where methane reacts with sulfur to form carbon disulfide and the subsequent one where carbon disulfide reacts with water to form carbonyl sulfide and hydrogen sulfide. Since this model does not consider the formation of carbon disulfide and the second step of this reaction is extremely fast [7], this reaction was simplified as shown above and the overall reaction rate was considered to consist only of the first step.

The following are kinetic expressions for reactions (2.21), (2.22), and (2.23) respectively. Equation (2.21) was obtained from Karan and Behie [11], and (2.22) and (2.23) were obtained from Zhang et al. [5].

$$
r\left[\frac{\mathrm{kmol}}{\mathrm{m}^{3} . \mathrm{s}}\right]=5.53 \times 10^{10} \exp \left(\frac{-38.7\left[\frac{\mathrm{kcal}}{\mathrm{mol}}\right]}{R T}\right) C_{C_{4}} C_{S_{2}}
$$




$$
\begin{aligned}
& r\left[\frac{\mathrm{kmol}}{\mathrm{m}^{3} . \mathrm{s}}\right]=8.06 \times 10^{5} \exp \left(\frac{-4.98\left[\frac{\mathrm{kcal}}{\mathrm{mol}}\right]}{R T}\right) C_{\mathrm{CH}_{4}} C_{\mathrm{CO}_{2}} \\
& r\left[\frac{\mathrm{kmol}}{\mathrm{m}^{3} . \mathrm{s}}\right]=4.56 \times 10^{6} \exp \left(\frac{-5.10\left[\frac{\mathrm{kcal}}{\mathrm{mol}}\right]}{R T}\right) C_{\mathrm{CH}_{4} C_{\mathrm{H}_{2} \mathrm{O}}}
\end{aligned}
$$

\subsection{Carbonyl Sulfide Formation}

Carbonyl sulfide is an undesired product of the reaction furnace that can decrease the overall efficiency of the modified Claus process. Actual production of carbonyl sulfide in the furnace is minimal due to equilibrium constraints; however, upon entering the waste heat boiler, equilibrium is shifted and this is where most of the carbonyl sulfide is formed in the process $[2,6,7]$.

$$
\begin{gathered}
\mathrm{CO}+\frac{1}{2} \mathrm{~S}_{2} \longleftrightarrow \mathrm{COS} \\
\mathrm{CO}+\mathrm{H}_{2} \mathrm{~S} \longleftrightarrow \mathrm{COS}+\mathrm{H}_{2}
\end{gathered}
$$

The major pathway for carbonyl sulfide formation is the reaction of carbon monoxide with sulfur (2.27) and hydrogen sulfide (2.28). The major cause of the formation of carbonyl sulfide is due to the high concentration of carbon monoxide that is produced in the reaction furnace from the water gas shift reaction. It has been shown that decreasing the residence time in the reaction furnace leads to decreased production of the carbonyl sulfide due to the decreased production of carbon monoxide $[1,6]$. 
The following are kinetic expressions for reactions (2.27) and (2.28), respectively. These expressions were obtained from Karan et al. [6].

$$
\begin{aligned}
& r\left[\frac{\mathrm{kmol}}{\mathrm{m}^{3} . \mathrm{s}}\right]=3.18 \times 10^{5} \exp \left(\frac{-13.3\left[\frac{\mathrm{kcal}}{\mathrm{mol}}\right]}{R T}\right)\left(C_{C O} C_{S_{2}}-\exp \left(17.98-\frac{20925 \mathrm{~K}}{T}\right) C_{C O S} C_{S_{2}}^{0.5}\right) \\
& r\left[\frac{\mathrm{kmol}}{\mathrm{m}^{3} . \mathrm{s}}\right]=1.59 \times 10^{5} \exp \left(\frac{-26.5\left[\frac{\mathrm{kcal}}{\mathrm{mol}}\right]}{R T}\right)\left(C_{C O} C_{\mathrm{H}_{2} S}^{0.5}-\exp \left(3.12+\frac{334.47 \mathrm{~K}}{T}\right) \frac{C_{C O S} C_{\mathrm{H}_{2}}}{C_{H_{2} S}^{0.5}}\right)
\end{aligned}
$$

\subsection{Catalytic Reactions}

Unlike the reactions taking place in the reaction furnace, the reactions occurring in the catalytic reactors have been well studied $[17,18]$. The catalytic reactors convert the hydrogen sulfide and sulfur dioxide into sulfur and water via reaction (2.31). In addition, COS formed in the WHB is converted to hydrogen sulfide by hydrolysis, via reaction (2.32).

$$
\begin{gathered}
\mathrm{H}_{2} \mathrm{~S}+\frac{1}{2} \mathrm{SO}_{2} \longleftrightarrow \mathrm{H}_{2} \mathrm{O}+\frac{3}{16} \mathrm{~S}_{8} \\
\mathrm{COS}+\mathrm{H}_{2} \mathrm{O} \longleftrightarrow \mathrm{CO}_{2}+\mathrm{H}_{2} \mathrm{~S}
\end{gathered}
$$

Reaction (2.32), due to its higher activation energy, requires a higher temperature to be initiated than is required to ensure the overall desired sulfur recovery. Because of this, the first reactor is generally run at higher temperatures even though this decreases the conversion of hydrogen sulfide by reaction (2.31) due to equilibrium. The kinetic expressions for reactions (2.31), and (2.32), respectively, follow. Equation (2.33) was obtained from Puchyr et al. [18], and (2.33) was obtained from Tong et al. [17]. 


$$
\begin{aligned}
& r\left[\frac{\mathrm{mol}}{\mathrm{kg.s}}\right]=1.663 \times 10^{-4} \exp \left(\frac{-30.78\left[\frac{\mathrm{kJ}}{\mathrm{mol}}\right]}{R T}\right) \frac{\left(P_{S O_{2}}^{0.5} P_{H_{2}}-9.502 \times 10^{-7} \exp \left(\frac{1.11 \times 10^{4} \mathrm{~K}}{T}\right) P_{H_{2},} P_{S_{s}}^{0.1875}\right)}{\left(1+1.125 \times 10^{-5} \exp \left(\frac{-2.51\left[\frac{\mathrm{kJ}}{\mathrm{mol}}\right]}{R T}\right) P_{H_{2} O}\right)^{2}} \\
& r\left[\frac{\mathrm{mol}}{\mathrm{kg} . \mathrm{s}}\right]=0.6389 \exp \left(\frac{-25.27\left[\frac{\mathrm{kJ}}{\mathrm{mol}}\right]}{R T}\right) \frac{P_{\mathrm{COS}} P_{\mathrm{H}_{2} \mathrm{O}}}{\left.1+1.25 \exp \left(\frac{-83.22\left[\frac{\mathrm{kJ}}{\mathrm{mol}}\right]}{R T}\right) P_{\mathrm{H}_{2} \mathrm{O}}\right)}
\end{aligned}
$$

\subsection{Hydrogenation Reactions}

Inevitably, some sulfur species will not be converted to sulfur in the Claus unit. In order to mitigate sulfur emissions to the atmosphere, it is common to consider a tail-gas treatment unit. In this study, a hydrogenation unit is considered immediately following the Claus plant. The hydrogenation unit's primary function is to convert all remaining sulfur species that exist in the tailgas from the Claus unit to hydrogen sulfide so that it may be recovered in the Selexol unit. No rate expressions or experimental data for the reactions taking place in the hydrogenation unit could be found within the open literature. However, Massie [19] claims that reactions will convert all of the sulfur compounds to hydrogen sulfide. For these reasons, the hydrogenation reactor is considered as an equilibrium reactor consisting of the following reactions.

$$
\begin{gathered}
\mathrm{CO}+\mathrm{H}_{2} \mathrm{O} \longleftrightarrow \mathrm{CO}_{2}+\mathrm{H}_{2} \\
\mathrm{H}_{2} \mathrm{~S} \longleftrightarrow \mathrm{H}_{2}+\frac{1}{2} \mathrm{~S}_{2} \\
\mathrm{H}_{2} \mathrm{~S} \longleftrightarrow \mathrm{H}_{2}+\frac{1}{8} \mathrm{~S}_{8} \\
3 \mathrm{H}_{2}+\mathrm{SO}_{2} \longleftrightarrow \mathrm{H}_{2} \mathrm{~S}+2 \mathrm{H}_{2} \mathrm{O}
\end{gathered}
$$




\section{Chapter 3}

\section{Data Analysis}

For reactions (2.3), (2.13), (2.19), and (2.20), no kinetic expressions could be found in the literature. For reaction (2.3), published data from Hawboldt [2] and Sames and Paskall [13], were used to derive rate expressions. For reactions (2.19) and (2.17), published data from Clark et al. [10] were used to derive rate expressions.

\subsection{Sulfur Dioxide and Ammonia Reaction}

For the reaction:

$$
\mathrm{NH}_{3}+\frac{3}{4} \mathrm{SO}_{2} \rightarrow \frac{1}{2} \mathrm{~N}_{2}+\frac{3}{2} \mathrm{H}_{2} \mathrm{O}+\frac{3}{8} \mathrm{~S}_{2}
$$

it was assumed that the rate of reaction is of the form:

$$
r_{1}=A_{1} \exp \left(\frac{-E_{a_{1}}}{R T}\right) C_{N H_{3}}^{m_{1}} C_{S O_{2}}^{n_{1}}
$$

where $A_{1}$ is the Arrhenius constant, $E_{a_{1}}$ is the activation energy and $C_{\mathrm{NH}_{3}}$ and $\mathrm{C}_{\mathrm{SO}_{2}}$ are the concentrations, in $\mathrm{kmol} / \mathrm{m}^{3}$, of ammonia and sulfur dioxide, respectively. Data from Clark et al. [10] were used to fit rate parameters. The experiments were done in a heated alumina tube with varying temperatures and residence times with product yields given for each experiment. Since this was carried out in a heated tubular reactor, an ideal plug flow reactor was used to model the reactor. To determine the rate constant, $k_{1}$ was found for each datum point using the design equation for a plug flow reactor where $k_{1}=A_{1} \exp \left(\frac{-E_{a_{1}}}{R T}\right)$. 


$$
\frac{d F_{N H_{3}}}{d V}=-r_{N H_{3}}
$$

Assuming isothermal, and isobaric conditions

$$
V=F_{N H_{3}} \int_{0}^{X_{c o n}} \frac{d X}{-r_{N H_{3}}}
$$

At the temperature at which these experiments were run, the dissociation reaction, (2.20), was also taking place. So, the rate of disappearance of ammonia is given by:

$$
-r_{\mathrm{NH}_{3}}=k_{1} C_{\mathrm{NH}_{3}}^{m_{1}} C_{S \mathrm{~S}_{2}}^{n_{1}}+\frac{k_{2} C_{\mathrm{NH}_{3}}^{1.25}}{1+k_{3} C_{\mathrm{H}_{2} \mathrm{O}}}
$$

For simplicity, it is further assumed that the change in the volumetric flowrate in the reactor is negligible due to dilute conditions and because reaction (2.19) is nearly equimolar. With this and the above assumptions and combining reaction rate (3.4) into Equation (3.3) gives:

$$
\frac{R T \tau_{\text {res }}}{P x_{\mathrm{NH}_{3}} i_{i}}=\int_{0}^{X_{c o n}} \frac{d X}{k_{1} C_{N H_{3}}^{m_{1}} C_{\mathrm{SO}_{2}}^{n_{1}}+\frac{k_{2} C_{N H_{3}}^{1.25}}{1+k_{3} C_{\mathrm{H}_{2} \mathrm{O}}}}
$$

With the previous assumptions, the concentrations can be written in terms of conversion as:

$$
\begin{aligned}
& C_{N_{3}}=C_{N H_{3}} \quad 0 \quad 1-X=C_{N H_{3}} \quad 0 \quad 1-X_{1}-X_{2} \\
& C_{S O_{2}}=C_{S O_{2}} \quad 0-\frac{3}{4} C_{N_{3}}{ }_{0} X_{1} \\
& C_{\mathrm{H}_{2} \mathrm{O}}=\frac{3}{2} \mathrm{C}_{\mathrm{NH}_{3}}{ }_{0} \mathrm{X}_{1}
\end{aligned}
$$


where $X_{1}$ and $X_{2}$ are the extent of reaction (2.19) and (2.20), respectively. Combining these equations yields:

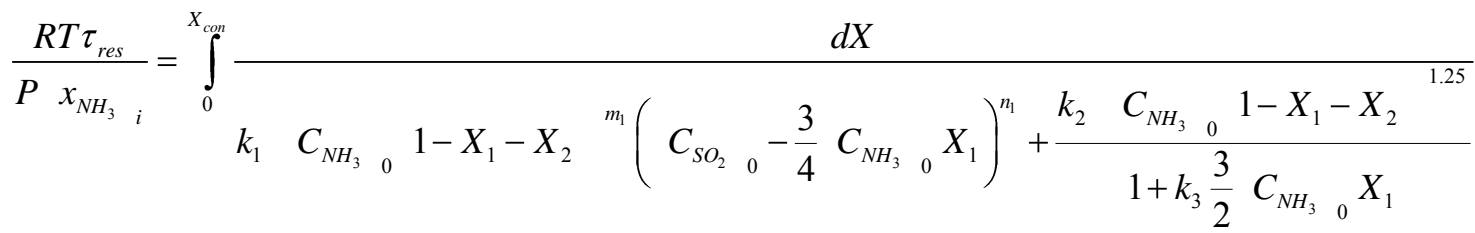

$$
\begin{aligned}
& X=X_{1}+X_{2} \\
& d X=d X_{1}+d X_{2}
\end{aligned}
$$

The extent of reaction (3.1) is known based on the amount of water measured in the output and the overall conversion of ammonia is also known; therefore, the extent of reactions (2.20) and (2.21), $X_{1 \text { total }}$ and $X_{2 t o t a l}$, respectively, are known. The definite integral on the RHS of Eq. (3.9) is difficult to solve by conventional numerical integration techniques. In fact, Equation (3.2) along with other algebraic equations must be solved by a differential algebraic solver. In this work, for simplicity, the following approach was adopted. First, an approximate value of the integral was obtained to get reasonable estimates for $k_{1}$. The integral was approximated by the following expression:

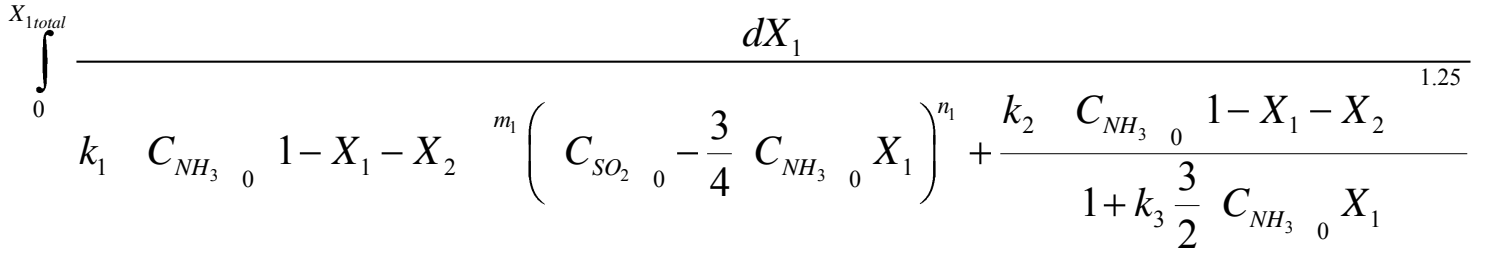

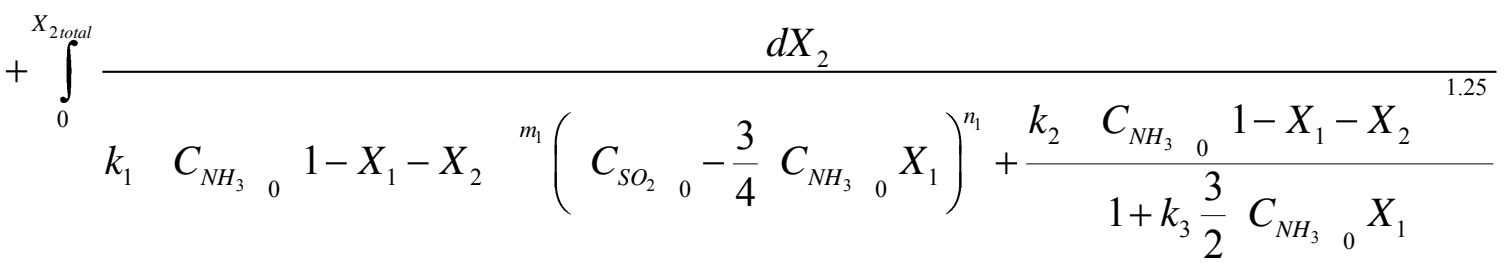


Simpson's 3/8 rule was used to integrate it. Since the LHS of Equation (3.9) is known for each data point, and $k_{2}$ and $k_{3}$ are known, $k_{1}$ was adjusted to minimize the difference between the value of the integral and the LHS of Equation (3.9). After that, an Arrhenius plot was generated with these values of $k_{1}$ as shown in Figure 3.1. To improve the prediction of the rate expression, $m_{1}$ and $n_{1}$ were considered to be tuning parameters. The final values of $m_{1}$ and $n_{1}$ were found to be 0.1 and 1, respectively. As the resulting plot should be linear, the Arrhenius constant and the activation energy were obtained from the linear fit. After this was completed, the Arrhenius constant was found to be $111,600 \mathrm{kmol} \mathrm{m}^{-3} \mathrm{~s}^{-1}$ and the activation energy was found to be $25.0 \mathrm{kcal} \mathrm{mol}^{-1}$. Figure 3.2 shows the fit to the experimental data at varying temperatures, and residence times. Based on the goodness of fit between the data and the model, the assumptions used in the analysis appear to be justified and reasonable. However, these assumptions and approximations will be relaxed in future work.

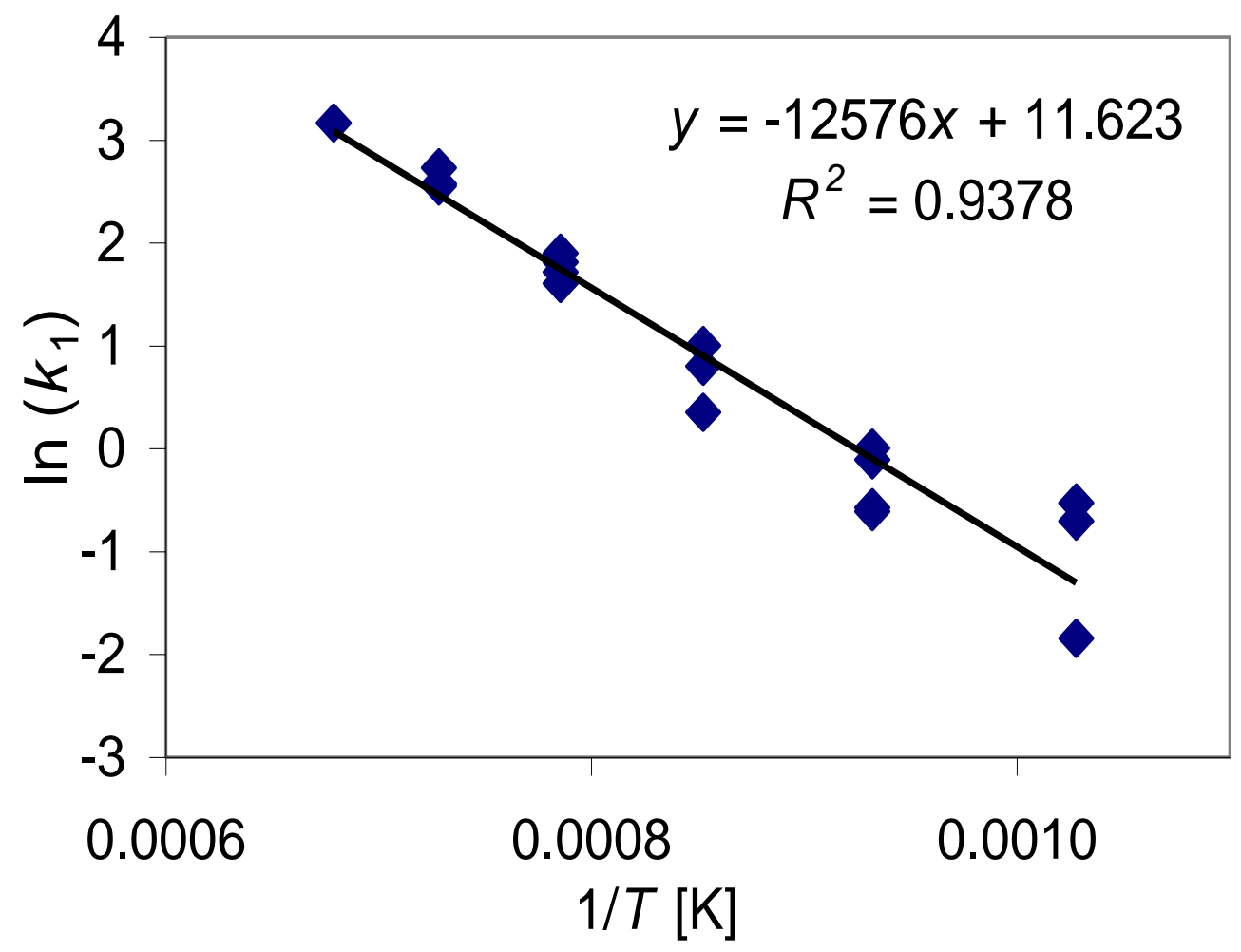

Figure 3.1: Arrhenius plot for ammonia and sulfur dioxide reactions 


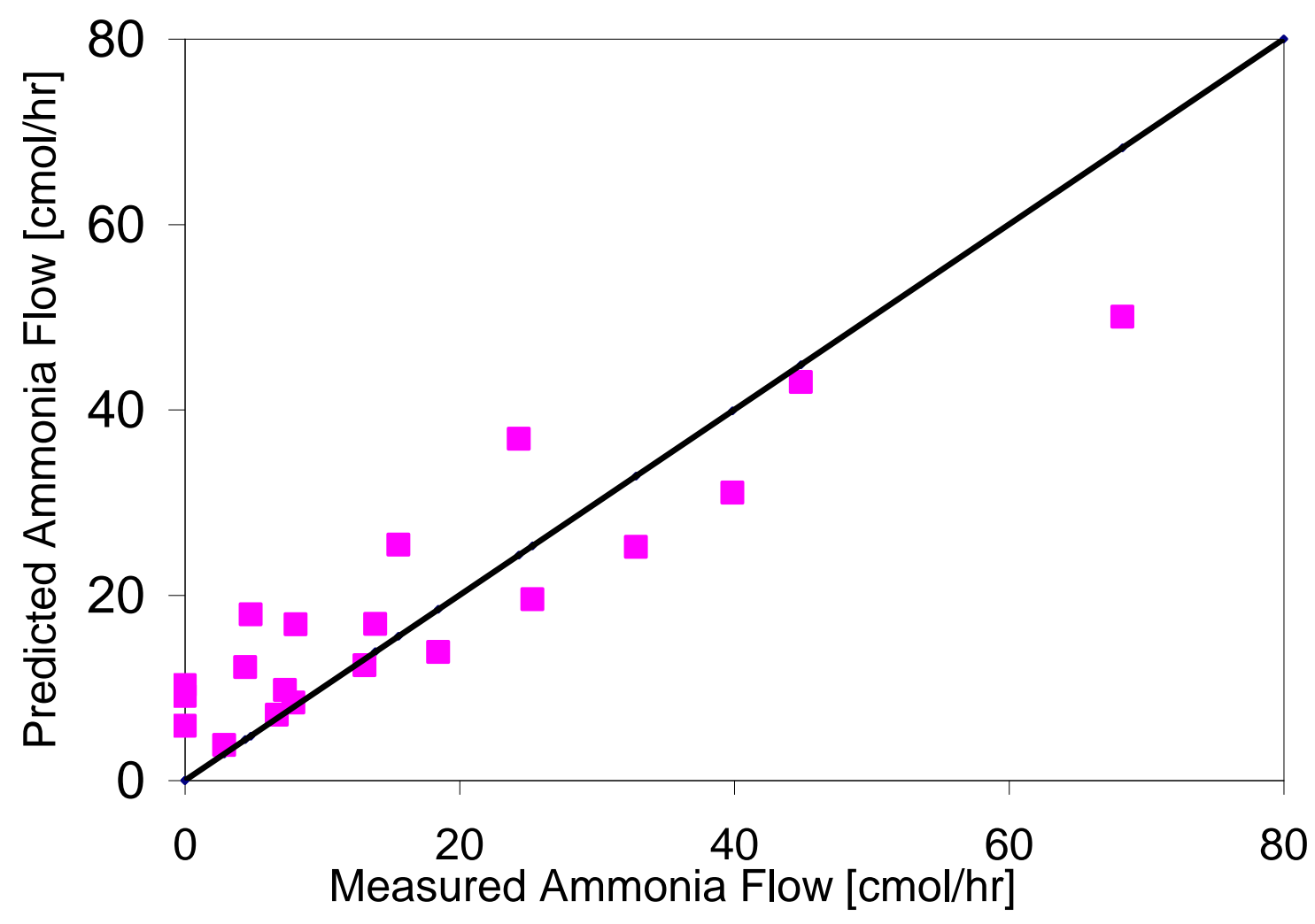

Figure 3.2 Model Predictions vs. Experimental Data

\subsection{Thermal Cracking of Ammonia}

For the reaction:

$$
\mathrm{NH}_{3} \rightarrow \frac{1}{2} \mathrm{~N}_{2}+\frac{3}{2} \mathrm{H}_{2}
$$

It was assumed that the rate of reaction was of the form given by Equation (3.13). This form was assumed due to the work of Monnery et al. [4] which showed that ammonia pyrolysis is of the order 1.25 with respect to ammonia. However, the experiments were performed by Monnery et al. [4] in the absence of water and hydrogen sulfide, which Clark et al. [10] has shown inhibits the reaction. With this information in mind, the following rate expression for the ammonia cracking reaction was assumed: 


$$
r=\frac{A_{2} \exp \left(\frac{-E_{a_{2}}}{R T}\right) C_{N H_{3}}^{1.25}}{1+A_{3} \exp \left(\frac{-E_{a_{3}}}{R T}\right) C_{H_{2} O}+A_{4} \exp \left(\frac{-E_{a_{4}}}{R T}\right) C_{H_{2} S}}
$$

where $A_{2}, A_{3}$, and $A_{4}$ are Arrhenius constants, $E_{a_{2}}, E_{a_{2}}$, and $E_{a_{4}}$ are the activation energies and $\mathrm{C}_{\mathrm{NH}_{3}}, \mathrm{C}_{\mathrm{H}_{2} \mathrm{O}}$, and $\mathrm{C}_{\mathrm{H}_{2} \mathrm{~S}}$ are the concentrations, in $\mathrm{kmol} / \mathrm{m}^{3}$, of ammonia, water, and hydrogen sulfide, respectively. To determine the rate parameters, the values of $k$ were found for each individual datum point using the design equation for a plug flow reactor.

$$
\frac{d F_{N H_{3}}}{d V}=-r_{N H_{3}}
$$

Assuming isothermal and isobaric operation, and that the change in the volumetric flow within the reactor is negligible due to dilute conditions, Equation (3.14) may be written as:

$$
\frac{R T \tau_{\text {res }}}{P x_{A}}=\int_{0}^{X_{\text {con }}} \frac{d x}{-r_{A}}
$$

Substituting expression (3.13) into (3.15) with respect to ammonia yields and with the above assumptions gives:

$$
\begin{aligned}
& \frac{R T \tau_{\text {res }}}{P x_{N_{3}}} i_{i}=\int_{0}^{X_{\text {con }}} \frac{1+k_{3} C_{H_{2} \mathrm{O}}+k_{4} C_{H_{2} S} d X}{k_{2} C_{N H_{3}}^{1.25}} \\
& C_{\mathrm{NH}_{3}}=C_{\mathrm{NH}_{3}}{ }_{0} 1-X
\end{aligned}
$$

Combining these equations yields:

$$
\frac{R T \tau_{r e s}}{P x_{\mathrm{NH}_{3}} \quad{ }}=\int_{0}^{X_{c o n}} \frac{1+k_{3} C_{\mathrm{H}_{2} \mathrm{O}}+k_{4} C_{\mathrm{H}_{2} S} d X}{k_{2} C_{\mathrm{NH}_{3}}{ }_{0}^{1.25} 1-X^{1.25}}
$$


$k_{2}$ was first determined using data on the dissociation of ammonia in the absence of water and hydrogen sulfide. With the values of $k_{2}$, an Arrhenius plot was generated (Figure 3.3).

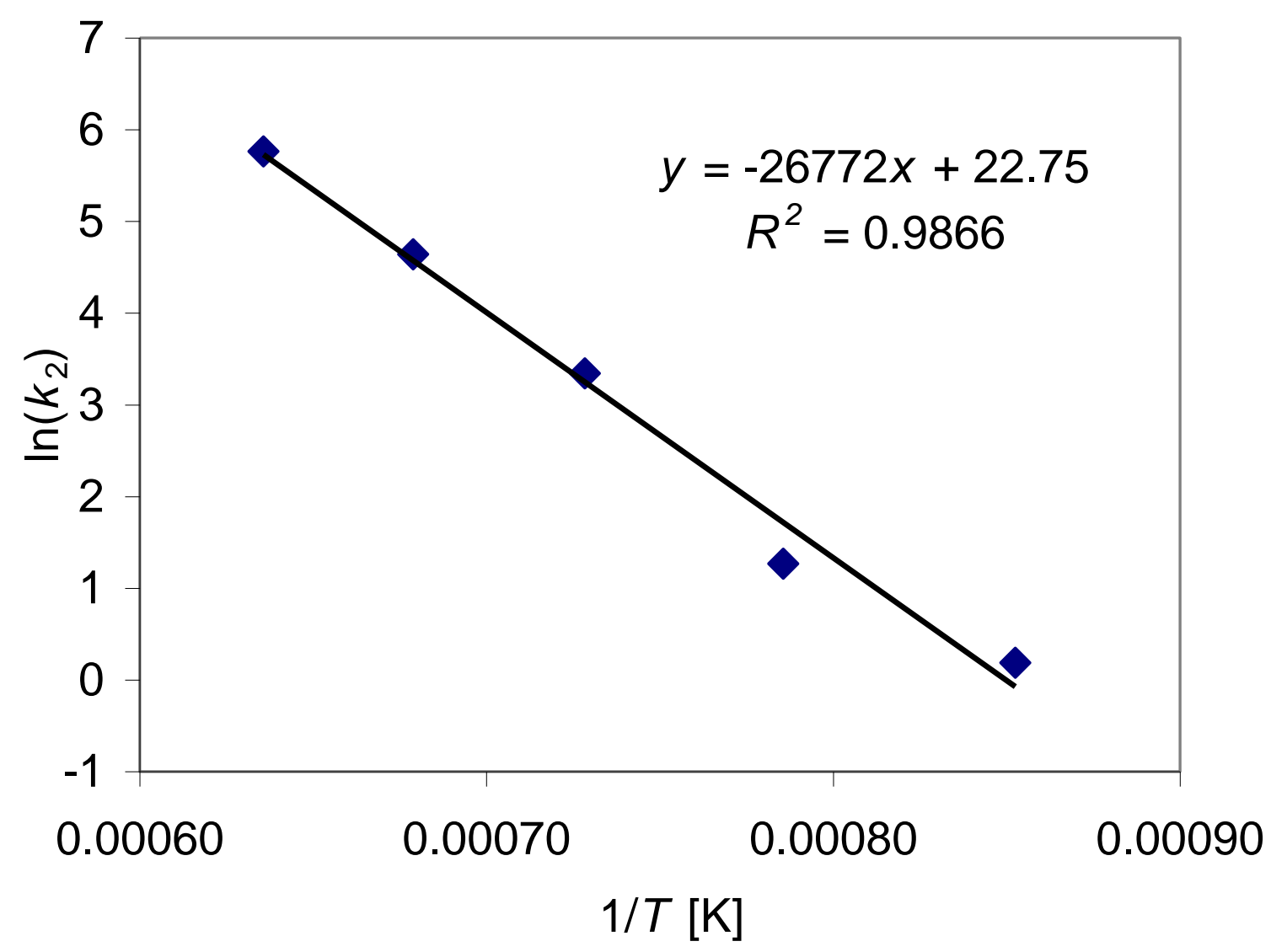

Figure 3.3 Arrhenius plot of thermal cracking of ammonia in the absence of water and hydrogen sulfide

With $k_{2}$ found, $k_{3}$ and $k_{4}$ were determined from data on the thermal cracking of ammonia in the presence of water and hydrogen sulfide. With the values of $k_{3}$ and $k_{4}$, Arrhenius plots were generated (Figures 3.4 and 3.5). 


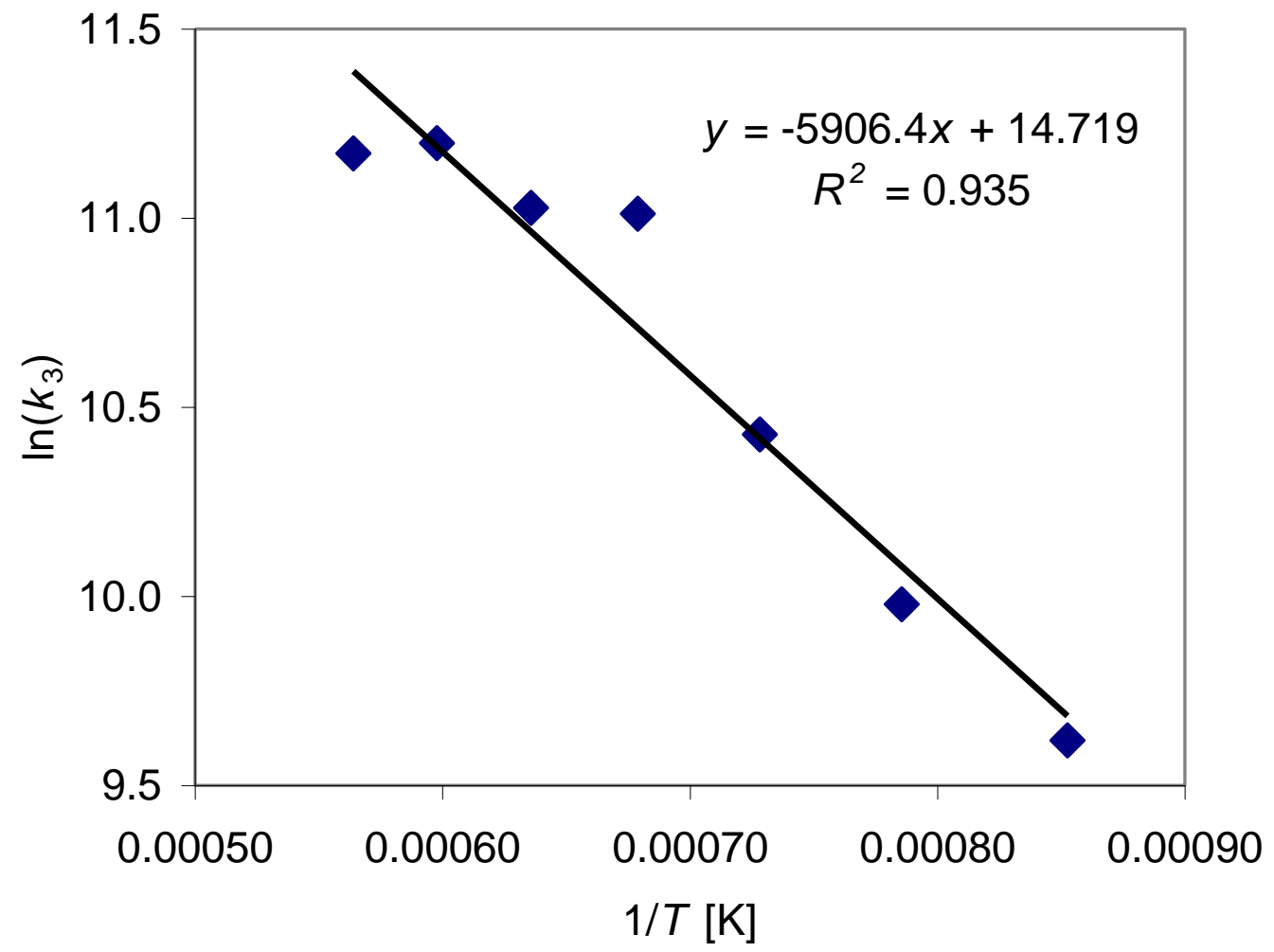

Figure 3.4 Arrhenius Plot of $k_{3}$

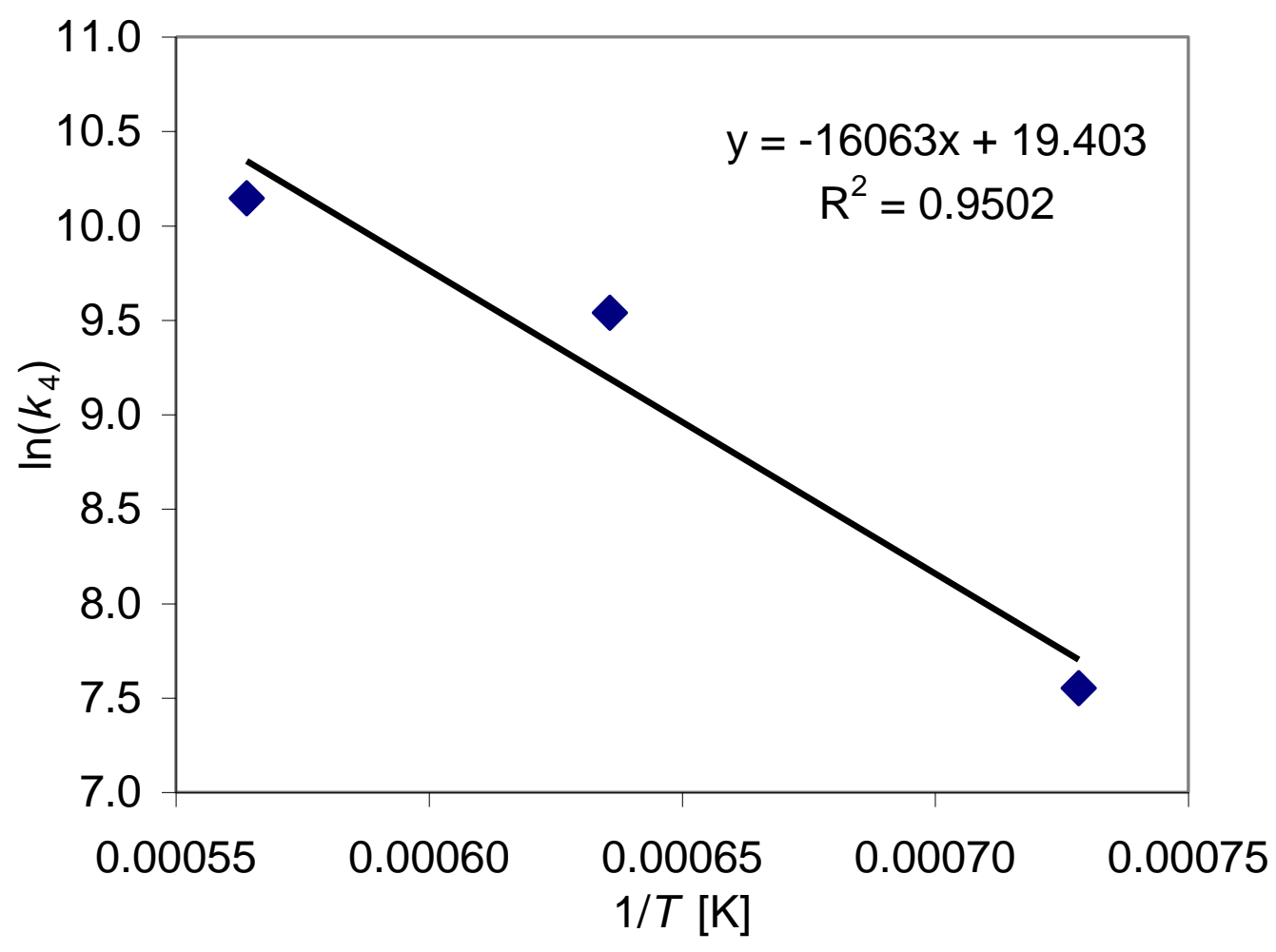

Figure 3.5 Arrhenius Plot of $k_{4}$ 
Using the rate constants found from the Arrhenius plots, the following results were generated at varying temperatures and residence times.

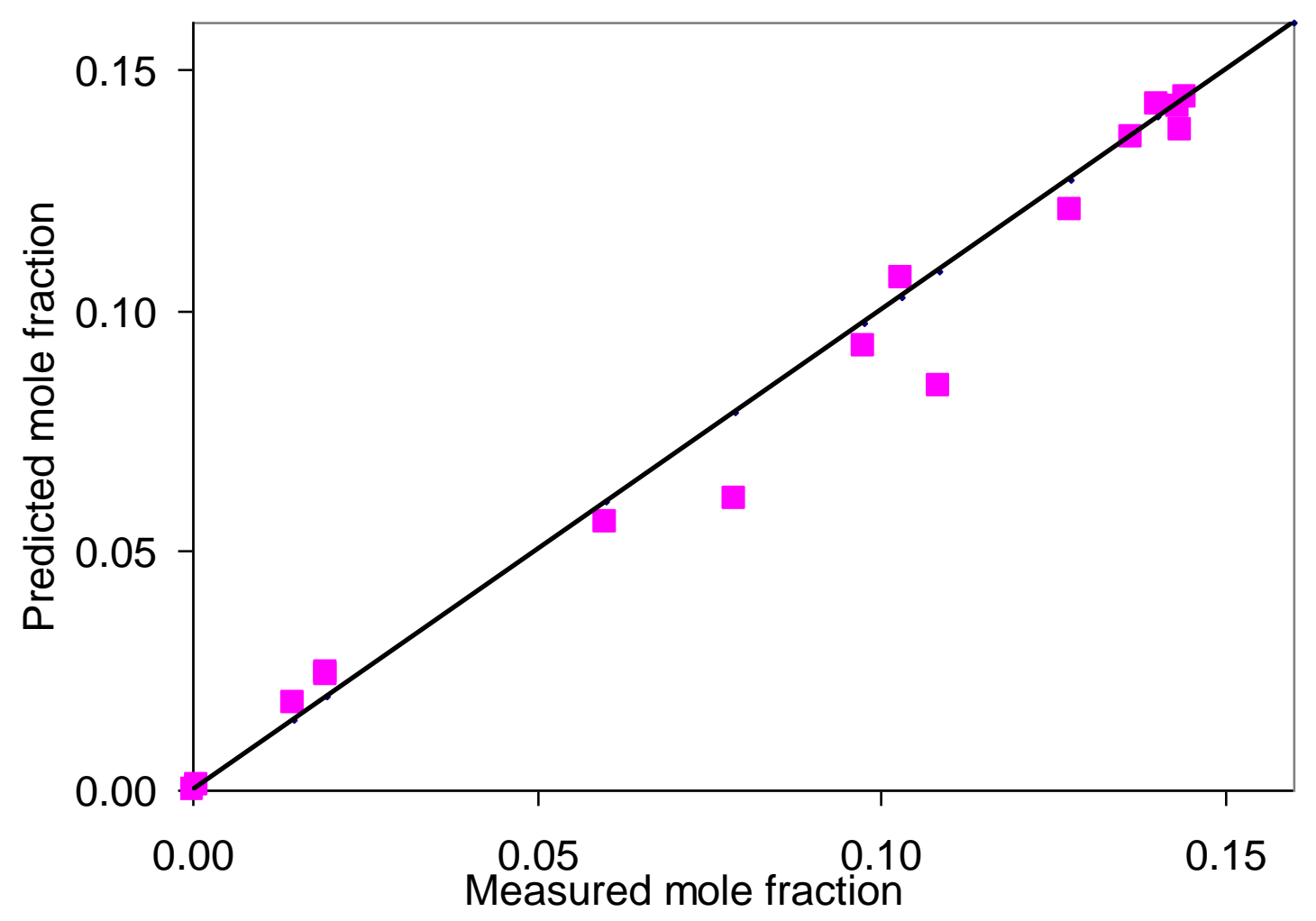

Figure 3.6 Model Predictions vs. Experimental Data

Figure 3.6 shows that there is a good agreement between the measured ammonia outlet and the predicted ammonia outlet.

\subsection{Combustion of hydrogen sulfide}

For the reaction:

$$
\mathrm{H}_{2} \mathrm{~S}+\frac{1}{2} \mathrm{O}_{2} \rightarrow \frac{1}{2} \mathrm{~S}_{2}+\mathrm{H}_{2} \mathrm{O}
$$

it was assumed that the reaction rate was of the form: 


$$
r=A_{6} \exp \left(\frac{-E_{6}}{R T}\right) P_{H_{2} S}^{m_{6}} P_{O_{2}}^{n_{6}}
$$

where $A_{6}$ is the Arrhenius constant, $E_{6}$ is the activation energy and $P_{\mathrm{H}_{2} \mathrm{~S}}$ and $P_{\mathrm{O}_{2}}$ are the partial pressures of hydrogen sulfide and oxygen, respectively. To determine the unknown parameters for the rate expression (3.18), an optimization were done using industrial data for the anoxic region of the furnace as given by Sames and Paskall [13]. The anoxic region was included because the industrial data was sampled from the anoxic region of the furnace and not the flame region. This optimization was performed using Aspen Plus's data fit toolbox. With all reactions in the model active, $A_{6}, E_{6}, m_{6}$, and $n_{6}$ were considered as decision variables to minimize the squared error between the predicted output and the measured output. Initial guesses were generated by using the published data and the known rate parameter for the oxidation of hydrogen sulfide to sulfur dioxide given by Hawboldt [2]. The reactions considered for the oxidation of hydrogen sulfide are:

$$
\begin{gathered}
H_{2} S+\frac{3}{2} O 2 \rightarrow S O_{2}+H_{2} O \\
r_{5}=A_{5} \exp \left(\frac{-E_{5}}{R T}\right) P_{H_{2} S}^{m_{5}} P_{O_{2}}^{n_{5}} \\
H_{2} S+\frac{1}{2} O 2 \rightarrow \frac{1}{2} S_{2}+H_{2} O \\
r_{6}=A_{6} \exp \left(\frac{-E_{6}}{R T}\right) P_{H_{2} S}^{m_{6}} P_{O_{2}}^{n_{6}} \\
\frac{r_{5}}{r_{6}}=\frac{A_{5}}{A_{6}} \exp \left(\frac{E_{6}-E_{5}}{R T}\right) P_{H_{2} S}^{m_{5}-m_{6}} P_{O_{2}}^{n_{5}-n_{6}} \\
\ln \left(\frac{r_{5}}{r_{6}}\right)=\ln \left(\frac{A_{5}}{A_{6}}\right)+E_{6}-E_{5} \frac{1}{R T}+m_{5}-m_{6} \ln P_{H_{2} S}+n_{5}-n_{6} \ln P_{O_{2}}
\end{gathered}
$$


The experimental data gave the initial temperature, initial partial pressure of hydrogen sulfide, hydrogen sulfide to oxygen ratio and the amount of sulfur dioxide generated. To generate the initial guess for the parameters $A_{6}, E_{6}, m_{6}$, and $n_{6}$ for the Aspen Plus's data fit toolbox, the following approach was taken. Since the extent of each reaction, $\xi_{i}$, could be determined from the data, it was assumed that $\frac{\xi_{1}}{\xi_{2}} \approx \frac{r_{1}}{r_{2}}$. Therefore, for each datum point the LHS of the equation was known as were the initial temperature and partial pressures. The relative parameters (i.e., $E_{6}-E_{5}, m_{5}-m_{6}$, etc.) were adjusted to minimize the sum of squares difference between the LHS with the RHS of the equation. This resulted in the following relative parameters: $\ln \left(\frac{A_{5}}{A_{6}}\right)=11.91, \frac{E_{6}-E_{5}}{R}=-3986, m_{5}-m_{6}=-0.42$, $n_{5}-n_{6}=1.26$

The calculated values of $A_{6}, E_{6}, m_{6}$, and $n_{6}$ from the equations above were used as initial guesses for the optimization based on the published plant data [13]. Using the known, published, rate expressions for all the reactions, an optimization of the combustion parameters for reaction (1.4) was performed so as to match the product distribution within the anoxic zone. The parameters were found to be $A_{2}=10.7 \mathrm{~mol}$ $\mathrm{cm}^{-3} \mathrm{~s}^{-1} \mathrm{~atm}^{-1}, E_{2}=12 \mathrm{kcal} \mathrm{mol}^{-1}, m_{2}=1$, and $n_{2}=1.6 \times 10^{-5}$. 


\section{Chapter 4}

\section{Model Methodology}

\subsection{Zone Analysis}

The approach taken in modeling the furnace was to use a zoned analysis. Figure 4.1 illustrates the zones and the differences in these zones. The flame zone is considered as an adiabatic, plug-flow reactor consisting of only combustion reactions. The anoxic zone is considered as an adiabatic plug flow reactor with all of the remaining reactions active. The waste heat boiler (WHB) was considered as a multi-tube, plug-flow reactor with heat exchange against a coolant of constant temperature. The number and size of tubes for the WHB were chosen to match with typical reported industrial configurations [14]. The heat transfer coefficient of the WHB was calculated rigorously using Aspen HTFS+ and was found to be 80 $\mathrm{W} \mathrm{m} \mathrm{m}^{-2} \mathrm{~K}^{-1}$. 


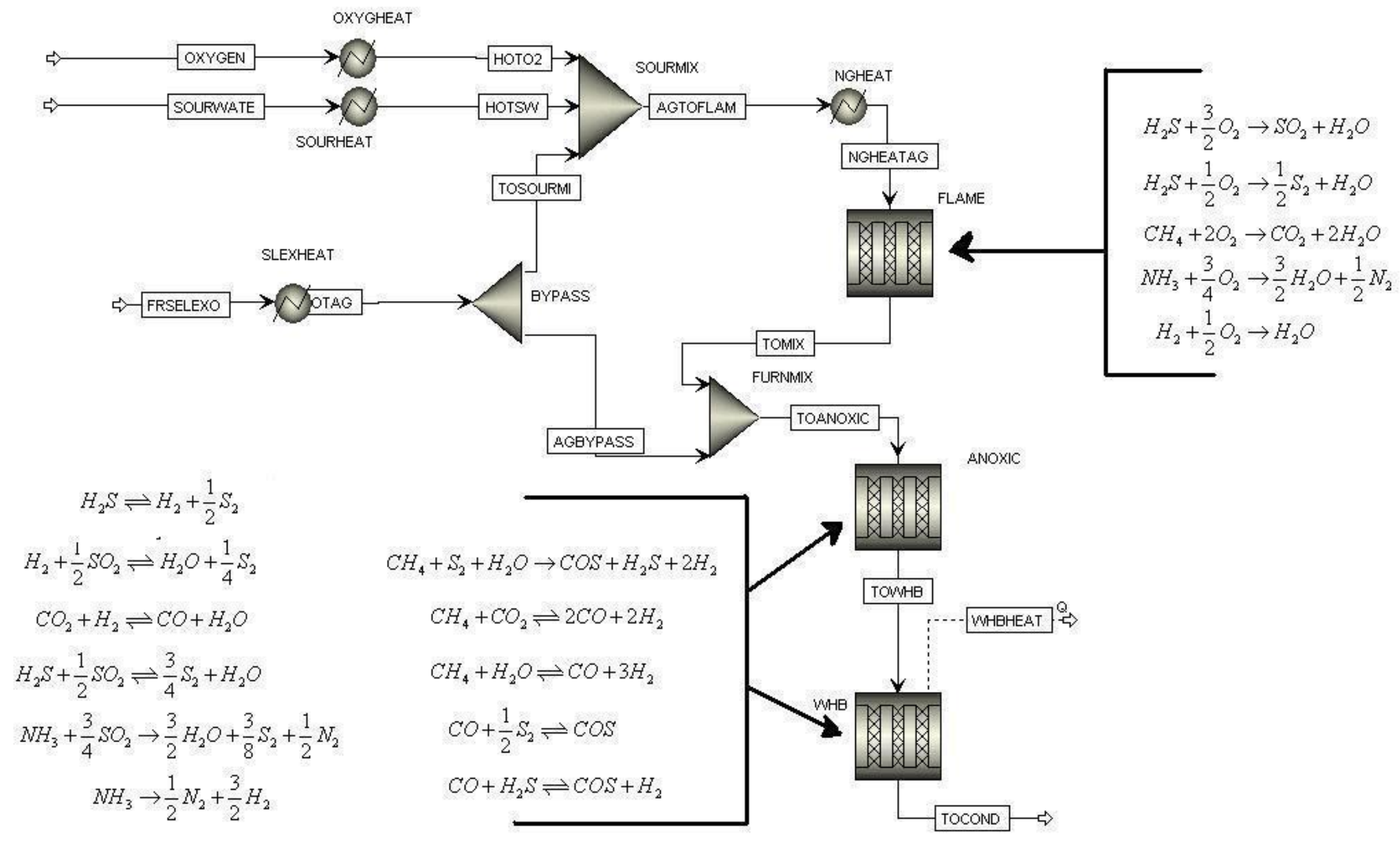

Figure 4.1 Zone analysis of the Claus reaction furnace 
Catalytic reactors are considered as plug-flow reactors with a space velocity of $1000 \mathrm{hr}^{-1}$ [17] and a voidage of 0.9 [18]. The hydrogenation reactor is considered as an equilibrium reactor. A simplified flowsheet of the modeled Claus process is given as Figure (4.2).

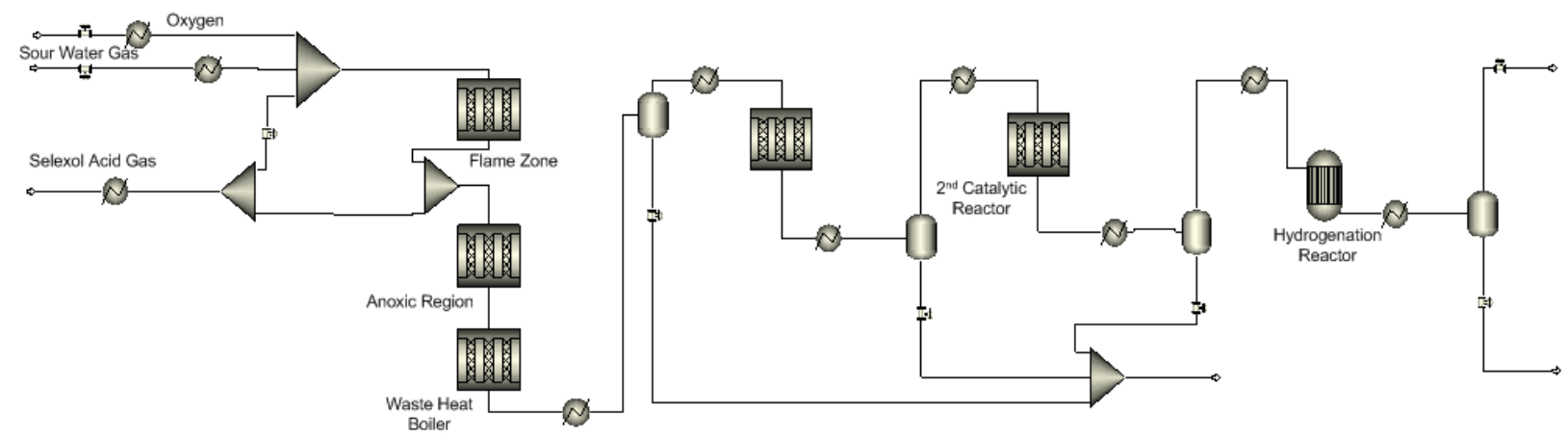

Figure 4.2. Simplified Flowsheet of 2-Stage Claus Process

\subsection{Parametric Optimization}

Using the published rate expressions resulted in model predictions with equilibrium conversion; however, this is contrary to what the plant data show, shown in Table 4.1. Therefore, an optimization of the pre-exponentials and activation energies of the four reactions, (2.12), (2.13), (2.14), and (2.15), was carried out. These reactions where chosen since they involve the major species of the Claus process and, in addition, no data could be found for reaction (2.13). 
Table 4.1. Comparison of measured plant data to that of equilibrium predictions[13]

\begin{tabular}{|c|c|c|c|c|}
\hline & \multicolumn{2}{|c|}{ Plant data at $2428^{\circ} \mathrm{F}$} & \multicolumn{2}{c|}{ Plant data at $2791^{\circ} \mathrm{F}$} \\
\hline$\left[\mathrm{kmol} \mathrm{hr}^{-1}\right]$ & Equilibrium & Measured & Equilibrium & Measured \\
\hline $\mathrm{H}_{2}$ & 9.69 & 3.69 & 5.60 & 2.85 \\
\hline $\mathrm{CO}$ & 2.89 & 1.37 & 1.59 & 0.90 \\
\hline $\mathrm{H}_{2} \mathrm{~S}$ & 11.21 & 11.12 & 8.45 & 6.66 \\
\hline $\mathrm{SO}_{2}$ & 6.97 & 4.59 & 5.22 & 2.45 \\
\hline $\mathrm{S}_{\text {vap }}$ & 26.91 & 27.69 & 19.01 & 21.01 \\
\hline
\end{tabular}

This optimization was done using Aspen Plus's data-fit tool. The data-fit tool works by minimizing the following sum of squares objective function:

$$
\sum_{i=1}^{N_{\text {datureat }}} W_{i}\left(\sum_{j=1}^{J_{\text {resulsts }}}\left(\frac{\left(X_{m j}-X_{j}\right)}{\sigma_{j}}\right)^{2}\right)
$$

where, $W_{i}$ is a weighting parameter, $X_{m j}$ is the measured result, and $X_{j}$ is the predicted result. The parameter, $\sigma_{j}$, was used as a scaling factor so that all values are within the same order of magnitude.

To obtain an acceptable fit, the plant data were broken into different data sets. Sulfur-containing species were considered as one set of data points, and all others species were considered as another set. In addition, data were divided between higher temperature and lower temperature data sets. Finally, data for both the furnace output as well as the WHB output were provided for each datum point and considered as a different data set. This resulted in eight different data sets. The weighting factor for each data set was considered as another variable for 
manipulation, to improve the quality of the solutions that were found. Several different weight factors were used, and results from each weight matrix were compared to determine optimal weight parameters. As an example of what was done, the predictions of hydrogen sulfide and sulfur dioxide were deemed to be more important than the predictions for other compounds; therefore, more weight was given to them. Likewise, predictions for the output of the WHB were deemed to be more important than the predictions for the anoxic zone, so more weight was given to the WHB data sets. In addition, it was important not to sacrifice the accuracy of some predictions for others, therefore anytime it was felt that this occurred, weight parameters were adjusted. With an optimal set of weight parameters determined, different initial guesses were used to find different solutions and an optimal solution was chosen from the different resulting parameters. The choice of different initial guesses significantly affected the quality of the solution attained. Tables 4.2 and 4.3 give the flows of each plant data set. The results of the parameter optimization are given in Figures 4.3-4.7 and the resulting parameters are given in Table 4.4. The change to reaction (2.12) parameters was negligible, so these values were not changed.

Table 4.2. Summary of feed Conditions

\begin{tabular}{|c|c|c|c|c|}
\hline Set Number & $\begin{array}{c}\text { Acid Gas Flow } \\
{\left[\mathrm{kmol} \mathrm{hr}^{-1}\right]}\end{array}$ & $\begin{array}{c}\text { Sour Water Flow } \\
{\left[\mathrm{kmol} \mathrm{hr}^{-1}\right]}\end{array}$ & $\begin{array}{c}\text { Oxygen Flow } \\
{\left[\mathrm{kmol} \mathrm{hr}^{-1}\right]}\end{array}$ & $\begin{array}{c}\text { Air Flow } \\
{\left[\mathrm{kmol} \mathrm{hr}^{-1}\right]}\end{array}$ \\
\hline 1 & 81.44 & 35.26 & 9.86 & 168.89 \\
\hline 2 & 68.71 & 31.52 & 0.00 & 189.37 \\
\hline 3 & 59.77 & 0.00 & 0.00 & 112.06 \\
\hline 4 & 83.32 & 0.00 & 6.96 & 123.59 \\
\hline 5 & 92.94 & 51.39 & 25.66 & 139.14 \\
\hline
\end{tabular}


Table 4.3. Summary of feed compositions (mole percent, dry basis) Acid Gas

Sour Water

$\begin{array}{crrrr}\text { Set Number } & 1,2 & 3,4,5 & 1,2 & 3,4,5 \\ \mathrm{~N}_{2} & 0.479 & 0.165 & 0.581 & 0.277 \\ \mathrm{CH}_{4} & 0.033 & 0.019 & 0.000 & 0.023 \\ \mathrm{CO}_{2} & 10.567 & 10.554 & 2.310 & 1.759 \\ \mathrm{C}_{2} \mathrm{H}_{4} & 0.030 & 0.026 & 0.023 & 0.019 \\ \mathrm{C}_{2} \mathrm{H}_{6} & 0.035 & 0.027 & 0.034 & 0.015 \\ \mathrm{H}_{2} \mathrm{~S} & 88.799 & 89.161 & 58.708 & 54.477 \\ \mathrm{C}_{3} \mathrm{H}_{8} & 0.057 & 0.048 & 0.064 & 0.040 \\ \mathrm{C}_{4+} & 0.000 & 0.000 & 0.313 & 0.169 \\ \mathrm{NH}_{3} & 0.000 & 0.000 & 37.967 & 43.221\end{array}$

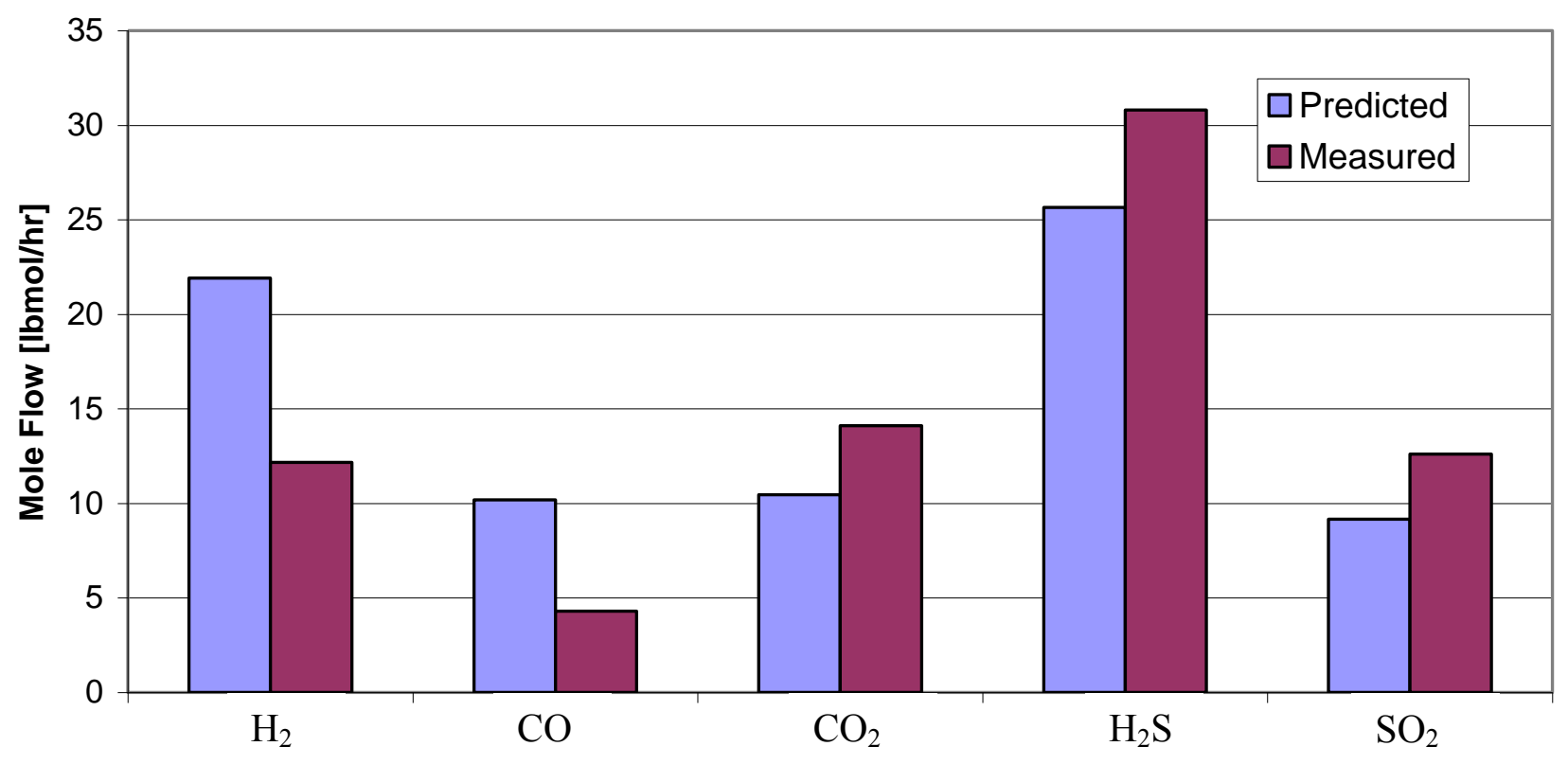

Figure 4.3. Comparision of Model Predictions with Plant Data Set 1 


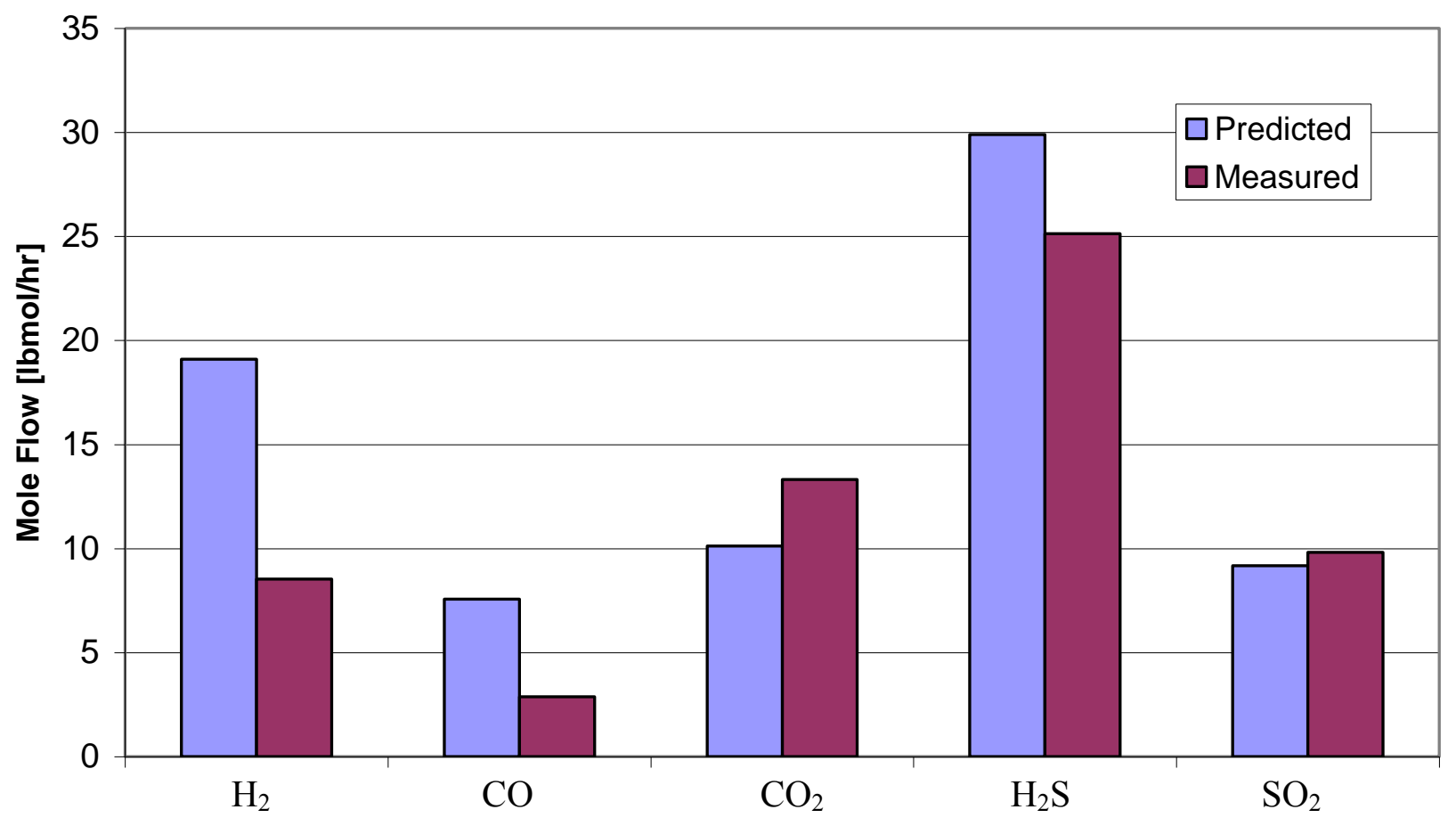

Figure 4.4. Comparision of Model Predictions with Plant Data Set 2

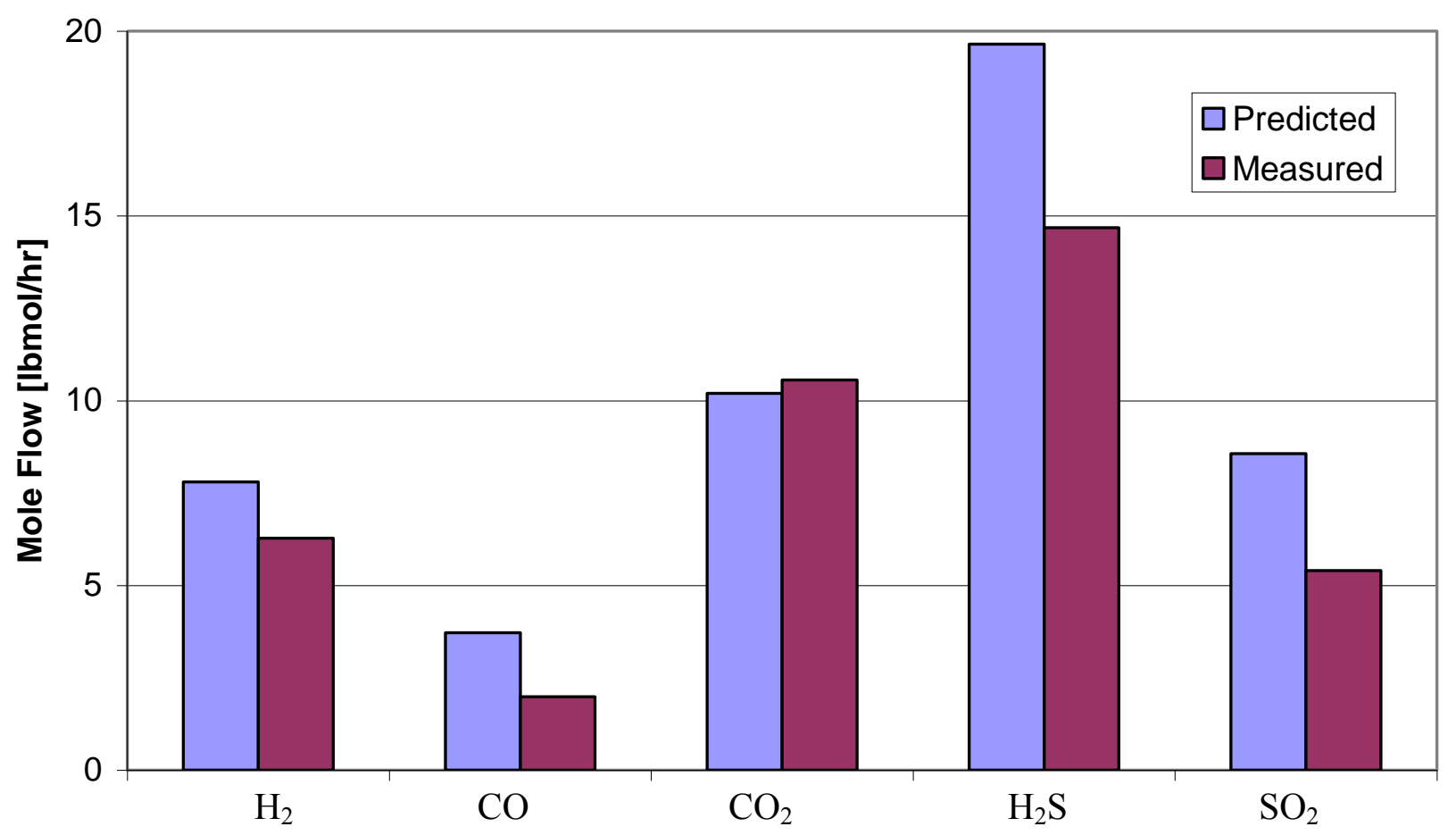

Figure 4.5. Comparsion of Model Predictions with Plant Data Set 3 


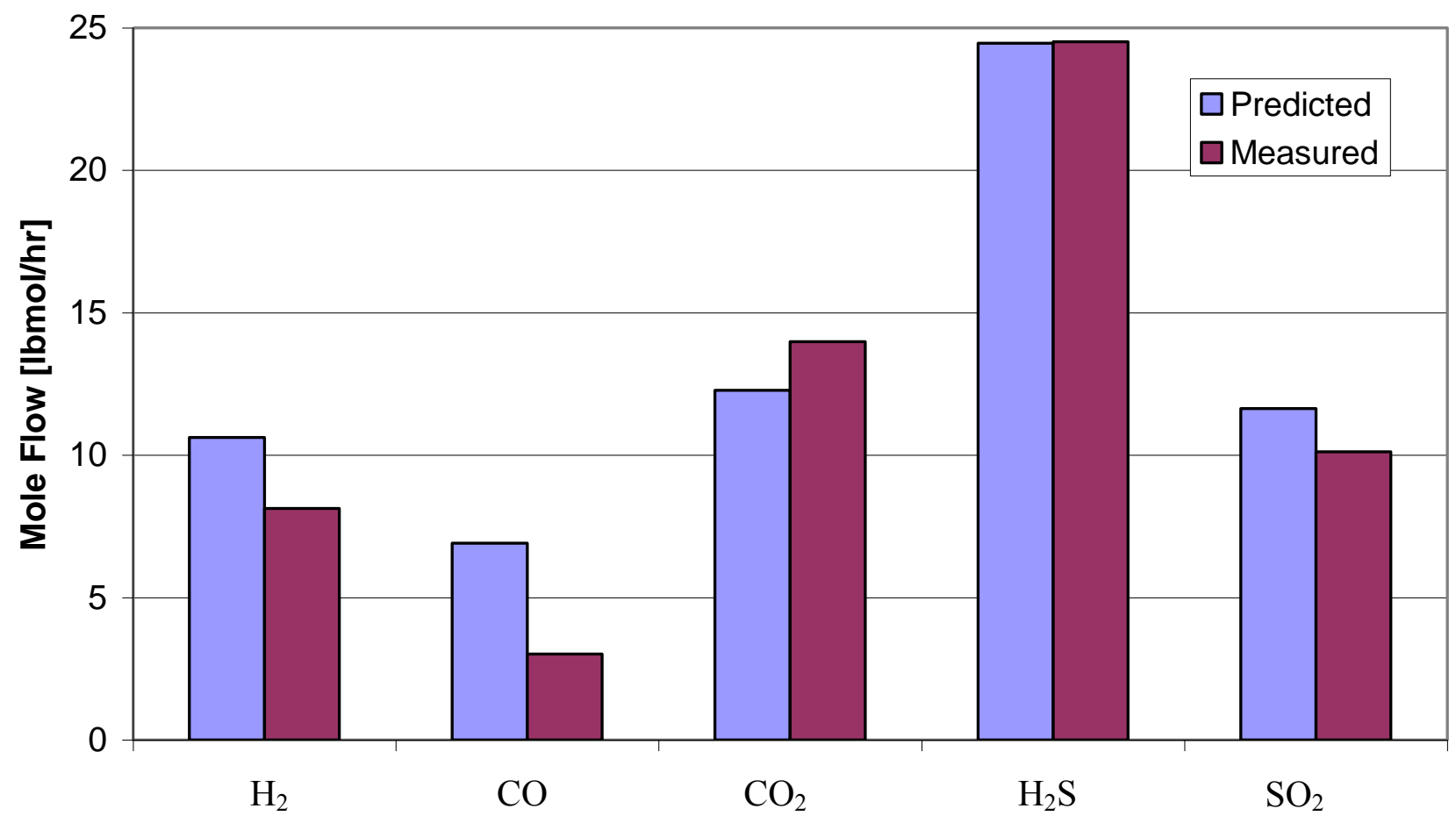

Figure 4.6. Comparsion of Model Predictions with Plant Data Set 4

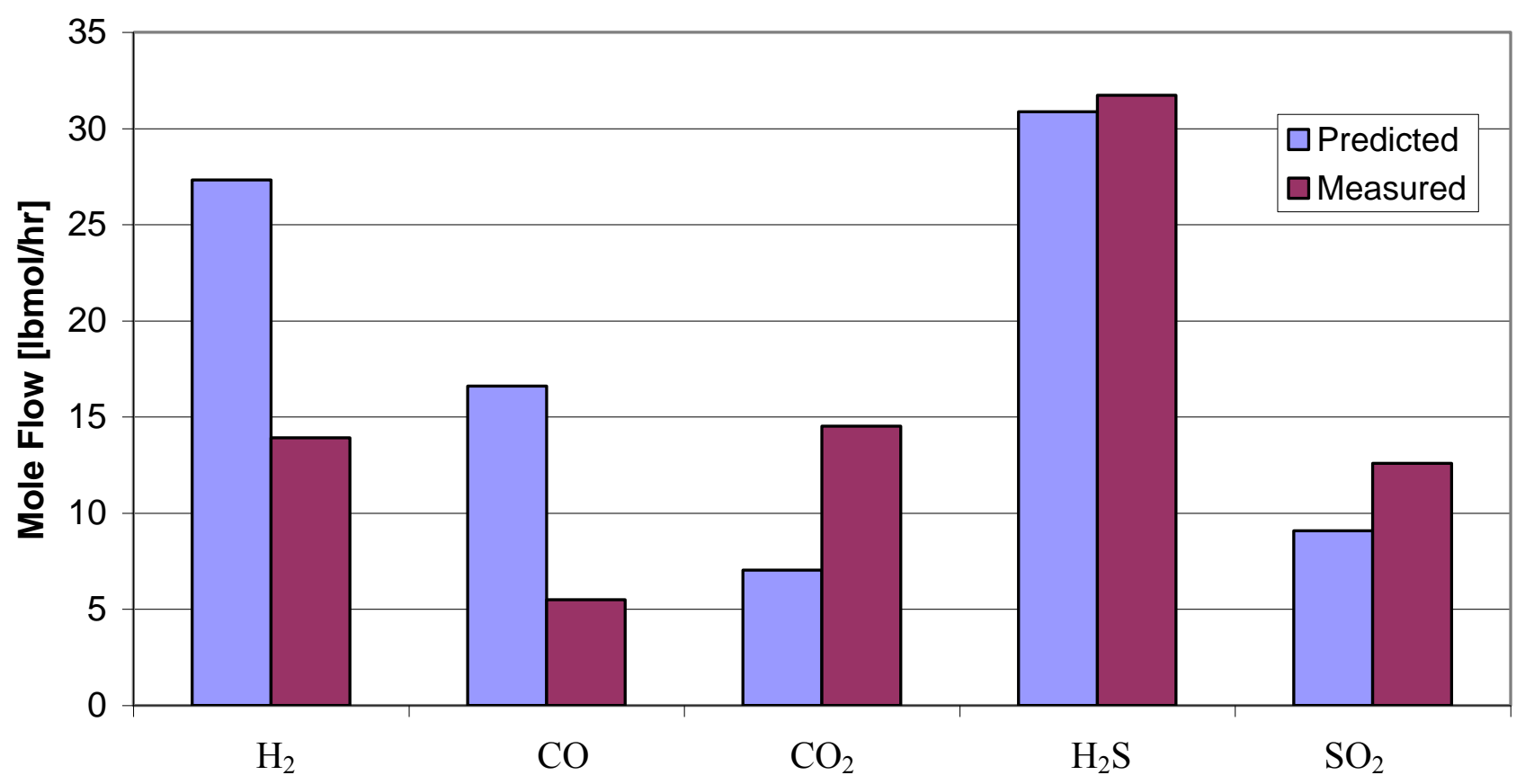

Figure 4.7. Comparsion of Model Predictions with Plant Data Set 5 
Table 4.4. Comparison between published rate parameters and adjusted rate parameters

\begin{tabular}{|c|c||c||l|l|}
\hline Reaction & $\begin{array}{l}\text { Adjusted } \\
\text { Pre- } \\
\text { exponential } \\
{\left[\mathbf{m o l ~ c m}^{-3} \mathbf{~ s}^{-1}\right.} \\
\left.\mathbf{a t m}^{-1}\right]\end{array}$ & $\begin{array}{l}\text { Published } \\
\text { Pre-exponential } \\
{\left[\mathbf{m o l ~ c m}^{-3} \mathbf{~ s}^{-1} \mathbf{~ a t m}^{-1}\right]}\end{array}$ & $\begin{array}{l}\text { Adjusted } \\
\text { Activation } \\
\text { Energy } \\
{\left[\mathbf{k c a l ~ m o l ~}^{-1}\right]}\end{array}$ & $\begin{array}{l}\text { Published } \\
\text { Activation } \\
\text { Energy } \\
{\left[\mathbf{k c a l ~ m o l ~}^{-1}\right]}\end{array}$ \\
\hline $\mathrm{H}_{2} \mathrm{~S} \longleftrightarrow \mathrm{H}_{2}+\frac{1}{2} S_{2}$ & 0.0157 & $5,260 \pm 260$ & 44.8 & $45.0 \pm 0.3$ \\
\hline $\mathrm{H}_{2} \mathrm{~S}+\frac{1}{2} \mathrm{SO}_{2} \longleftrightarrow \frac{3}{4} \mathrm{~S}_{2}+\mathrm{H}_{2} \mathrm{O}$ & 7,700 & $15,762 \pm 1,200$ & 49.9 & $49.9 \pm 0.3$ \\
\hline $\mathrm{H}_{2}+\frac{1}{2} \mathrm{SO}_{2} \longleftrightarrow \mathrm{H}_{2} \mathrm{O}+\frac{1}{4} \mathrm{~S}_{2}$ & 184 & $\mathrm{~N} / \mathrm{A}$ & 27.5 & N/A \\
\hline
\end{tabular}

Using these adjusted rate parameters, a comparison was made between the predictions of this model, TSweet ${ }^{\circledR}$ and the Western Research correlation presented in Figure 4.3-4.7. TSweet ${ }^{\circledR}$ is a commercial software program used to model sulfur recovery and uses restricted equilibrium to predict Claus furnace outputs. The results used here are taken from a series of case studies provided in the DOE EPA case studies [15]. Within the document for these case studies it states that the TSweet ${ }^{\circledR}$ program was used to calculate the compositions leaving the Claus furnace. Feed conditions for these cases are shown in Table 4.5. The results of this comparison are presented in Figures 4.8-4.12. Figure 4.13 shows the comparison of all species across the five model comparisons. 
Table 4.5. Feed conditions of cases

Case Number

Acid Gas Flow [kmol hr ${ }^{-1}$ ]

Sour Water Flow $\left[\mathrm{kmol} \mathrm{hr}^{-1}\right]$

Acid Gas Bypass [\%]

Acid Gas Composition [mol\%]

$\mathrm{H}_{2} \mathrm{~S}$
$\mathrm{CO}_{2}$

$\mathrm{NH}_{3}$

Sour Water Composition [mol\%]

$\mathrm{H}_{2} \mathrm{~S}$

$\mathrm{CO}_{2}$

$\mathrm{NH}_{3}$

$\begin{array}{lll}1 & 2 & 3\end{array}$

$\begin{array}{lll}398 & 547 \quad 367\end{array}$

$186 \quad 104 \quad 146$

$15 \quad 29$

37.7

36.7

2.7

17.2

0.8

14.9
29.4

70.3

0.0

9.5

14.2

59.7
46

3

4

39.6

43.4

3.7

4

375
119

388

87

13

$30 \quad 13$

$28.7 \quad 41.0$

$41.1 \quad 44.8$

$0.0 \quad 2.0$

44.8
2.0




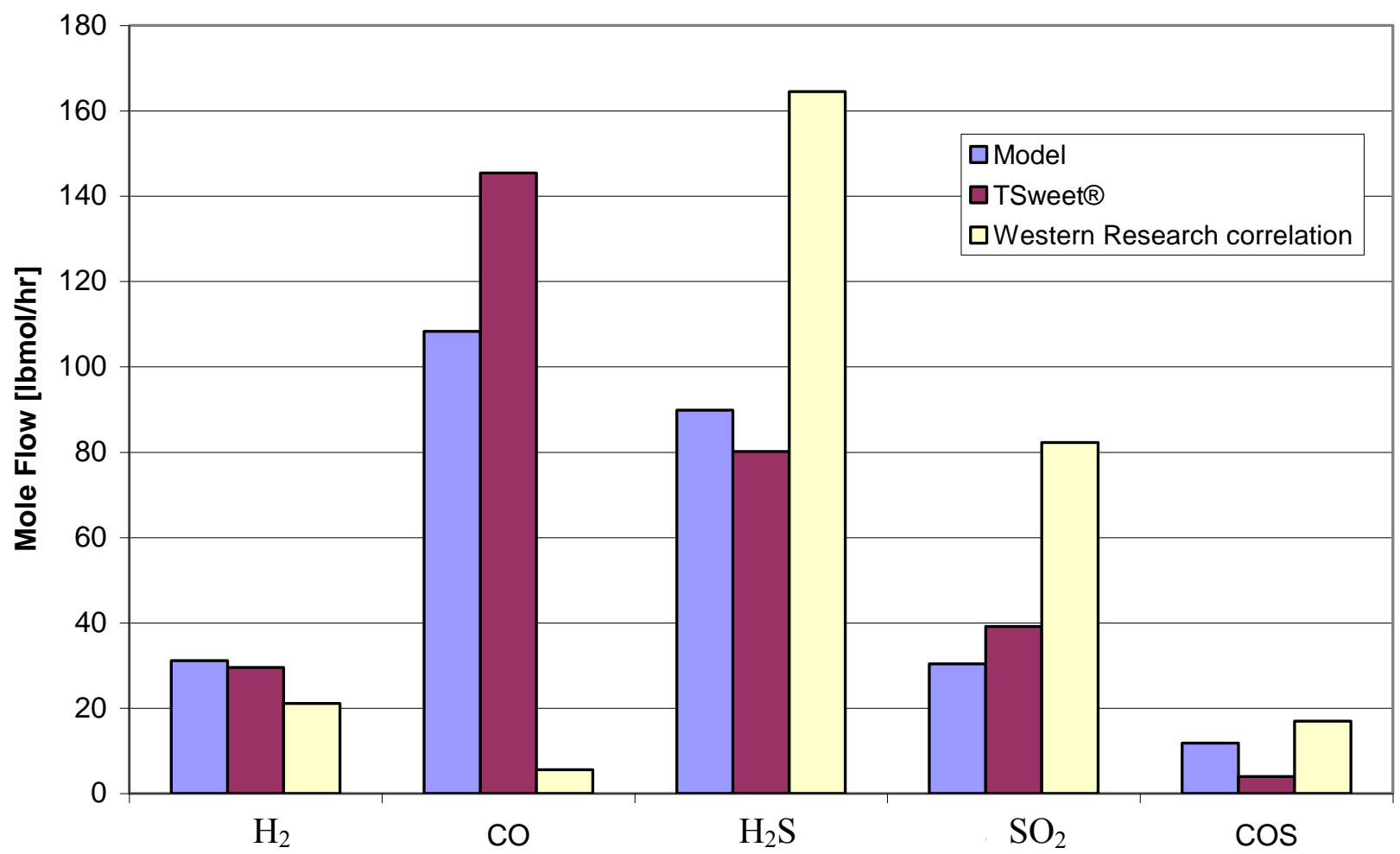

Figure 4.9 Model Comparsions Case 2

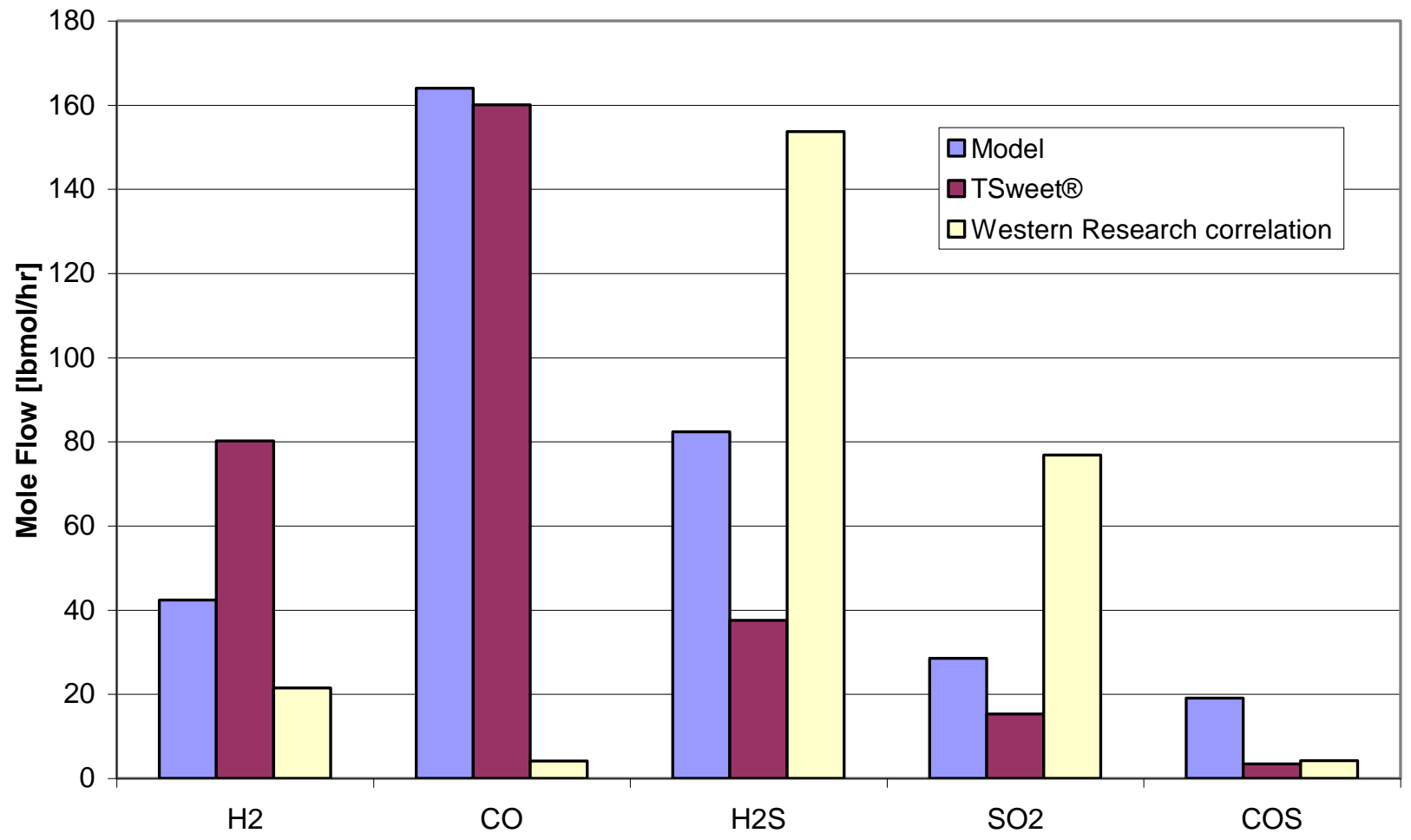

Figure 4.10 Model Comparsions Case 3 


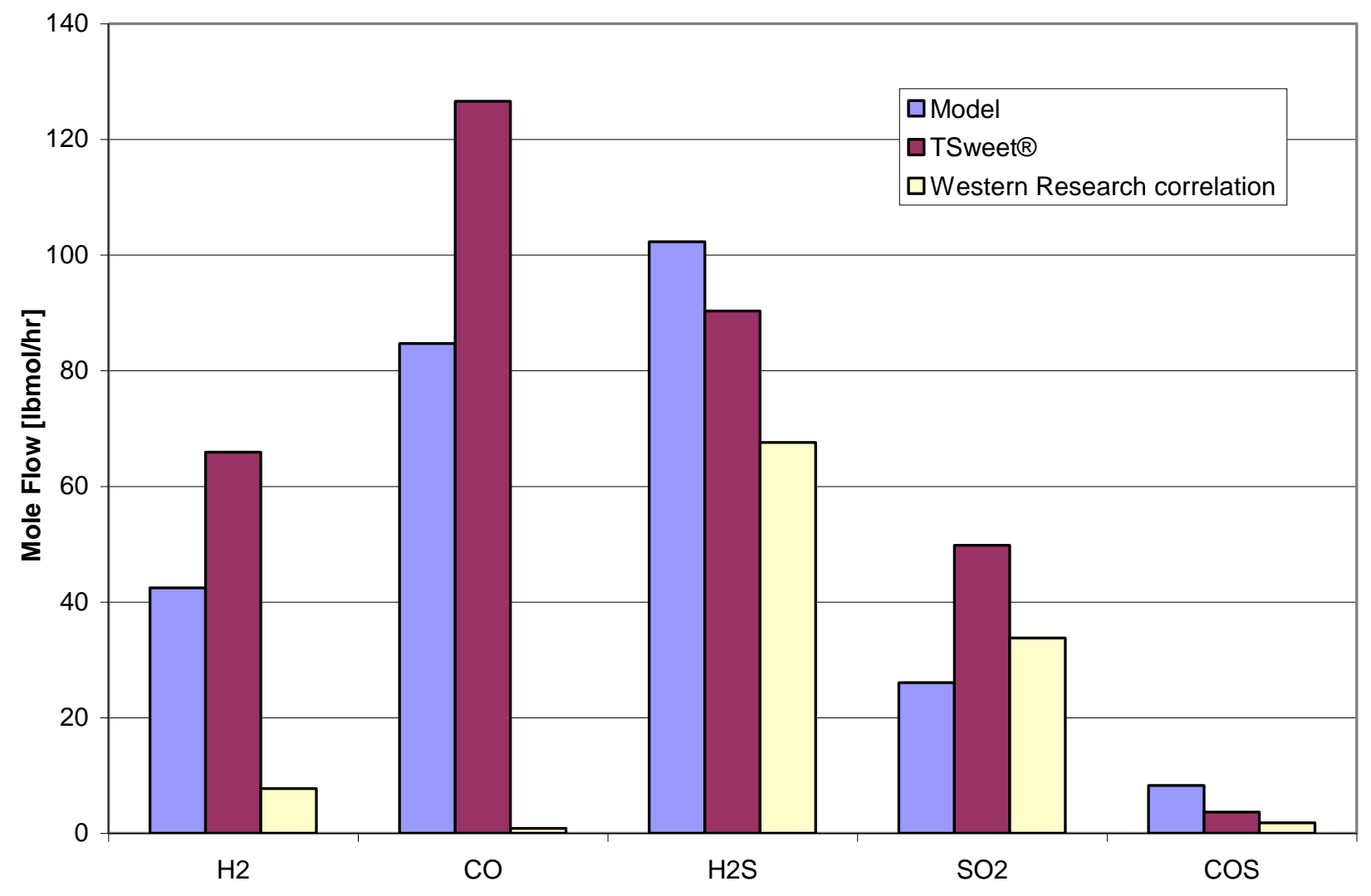

Figure 4.11 Model Comparsions Case 4

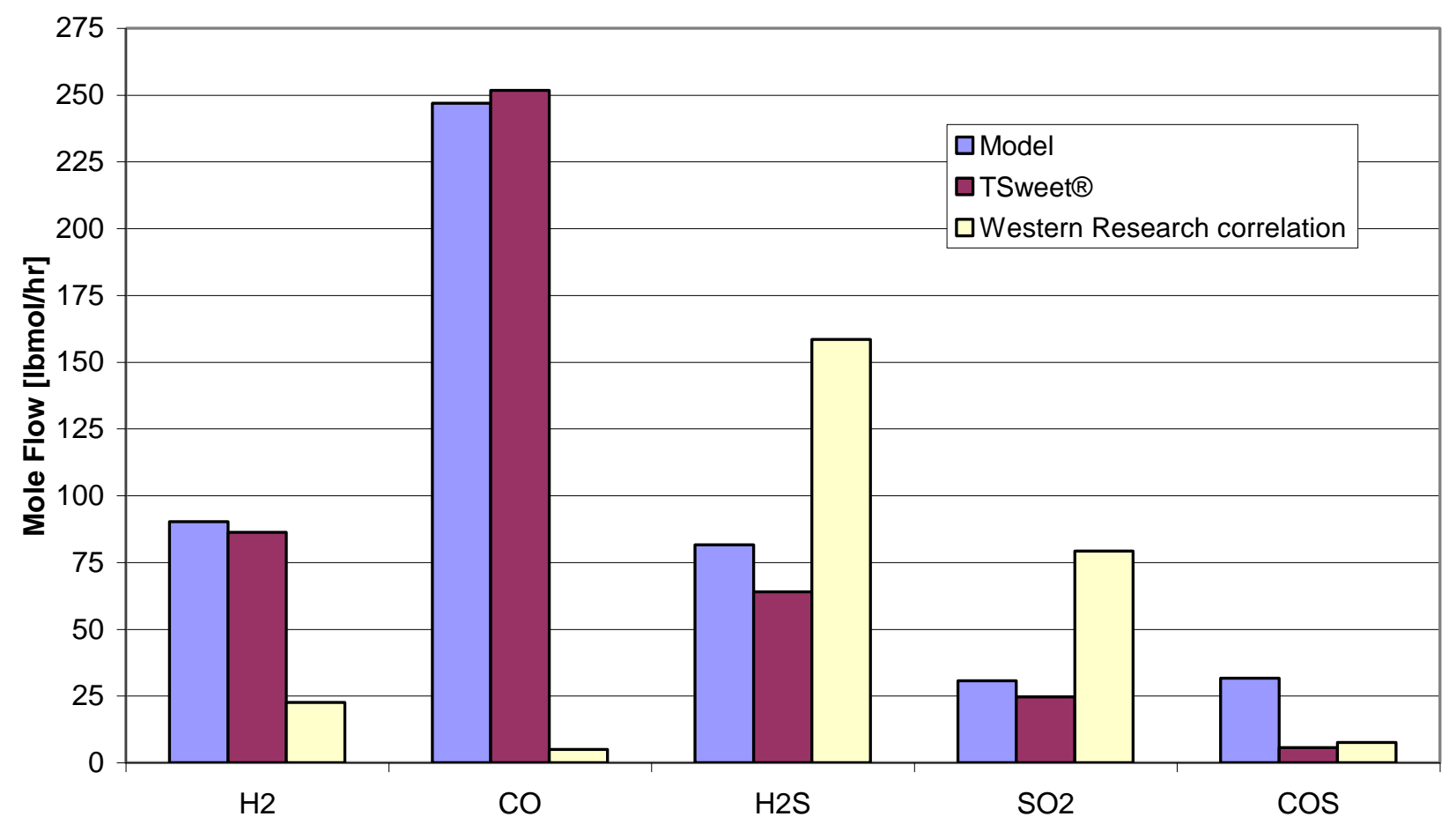

Figure 4.12 Model Comparsions Case 5 


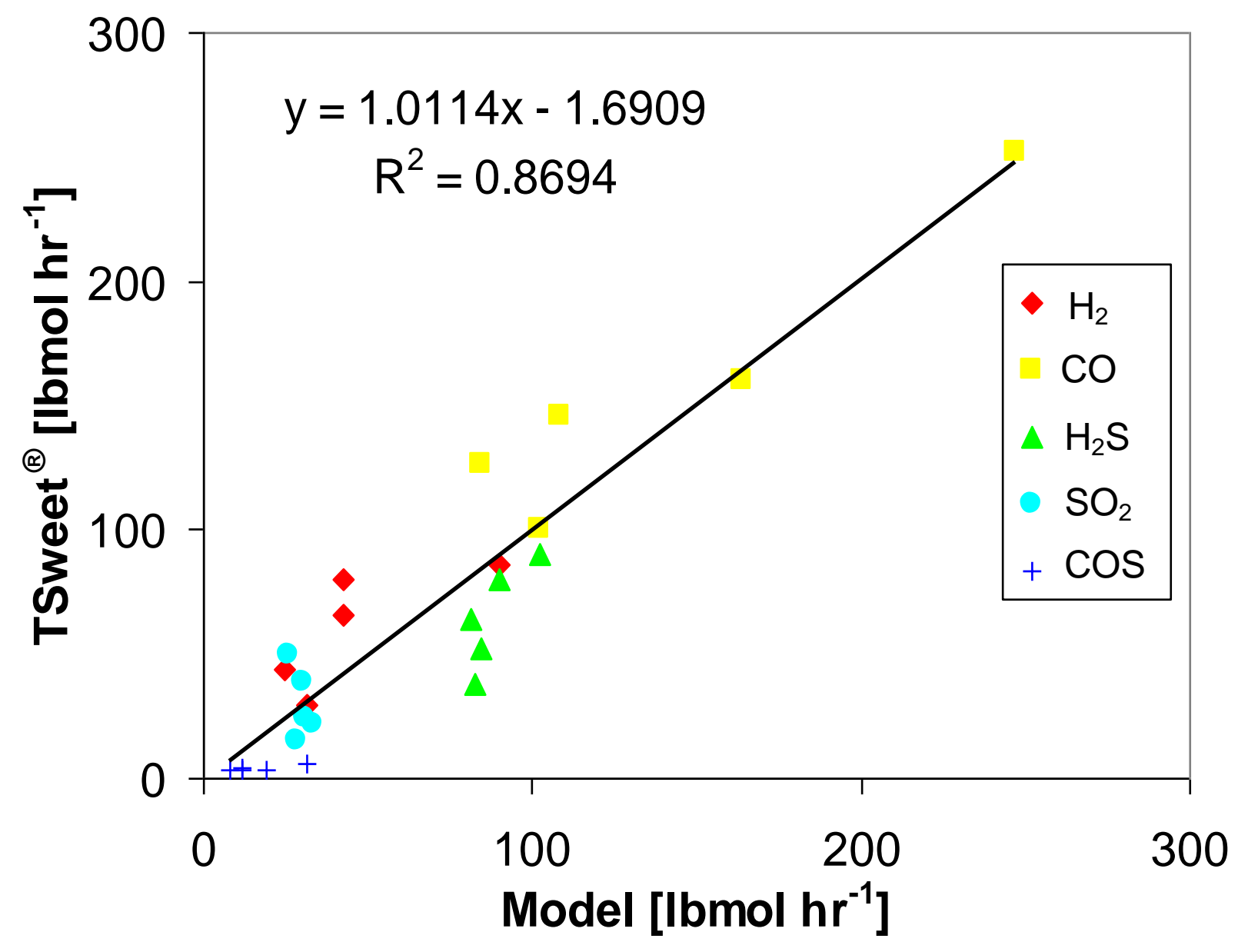

Figure 4.13 Comparison of the Model with TSweet ${ }^{\circledR}$

As shown in Figures (4.8) - (4.13), results of the model compare favorably with the TSweet ${ }^{\circledR}$ software. 


\section{Chapter 5}

\section{Steady State Optimization}

\subsection{Problem Description}

An optimization was done on the Modified Claus Process using the Aspen Plus optimization tool. The Aspen Plus optimization block seeks to minimize or maximize a user-defined objective function by manipulating user specified variables subject to specified constraints. The objective function used for this optimization is a function that describes the equivalent power production of the Modified Claus Process, given as Equation (5.1). The goal of this optimization was to maximize the objective function.

$$
\begin{aligned}
& -15.71 \cdot \dot{n}_{O_{2}}\left[\frac{\mathrm{kmol}}{\mathrm{hr}}\right]-W_{\text {tailcomp }} h p+W_{\text {steamturb }} h p \\
& +63.81 \cdot \dot{n}_{\mathrm{H}_{2}}\left[\frac{\mathrm{kmol}}{\mathrm{hr}}\right]-24.12 \cdot A \cdot \dot{n}_{\mathrm{H}_{2} S}\left[\frac{\mathrm{kmol}}{\mathrm{hr}}\right]
\end{aligned}
$$

The first term of the objective function is the associated power requirement to produce the $95 \%$-pure oxygen that is used as the oxidant. This power requirement was derived based on the power requirements of the air separation unit's main air compressors and oxygen compressors per lbmol of oxygen produced in the base case [20]. The second term is the associated power requirement for the tailgas compressors. The number of stages, intercooled temperature, and isentropic efficiencies are based on the base case values [21] and are $4,100^{\circ} \mathrm{F}$, and $84 \%$, respectively. The third term represents the power production possible by using the steam generated in the waste heat boiler to power the steam turbines. Steam production was estimated by summing the heat streams of the WHB and heaters and using that heat stream to generate saturated steam from saturated water at 150 atm. As the tail gas is recycled to the Selexol unit, the hydrogen content of the tail gas is utilized for power production in the syngas expander, gas turbine, and steam 
turbines in an IGCC plant. Considering this effect, the fourth term is associated with the power production possible from the hydrogen that is recycled to the Selexol unit through the tail gas. The assumed power production per pound of hydrogen is based on the base case power production from the syngas expander, gas turbine, and steam turbines [21]. The unconverted sulfur species from the Claus unit is recycled to the Selexol unit via the tail gas stream. The additional power requirement of the Selexol unit is captured by the fifth term. The assumed power cost of the recycled hydrogen sulfide is based upon a fraction, $A$, of the base case power requirement of the Selexol unit associated with the recovery of hydrogen sulfide from the syngas and the recycled tailgas [21]. The power requirement in the Selexol unit per $1 \mathrm{bmol} /$ hour of $\mathrm{H}_{2} \mathrm{~S}$ at its inlet is calculated considering the power consumption in the stripped gas compressor, the lean Selexol pump, refrigeration duty in the solvent cooler, and the stripper reboiler duty [21]. This is a conservative estimate for power requirement per $1 \mathrm{bmol} / \mathrm{hr}$ of the tail gas for two reasons. First, the concentration of $\mathrm{H}_{2} \mathrm{~S}$ in the syngas is much lower than that in the tail gas. Second, the lean Selexol from the stripper first goes to the $\mathrm{CO}_{2}$ absorber and captures a considerable amount of $\mathrm{CO}_{2}$ there. Since the concentration of $\mathrm{CO}_{2}$ and $\mathrm{H}_{2} \mathrm{~S}$ in the tail gas is more than the syngas, comparably lower increments in the lean Selexol flowrate would be expected. For a rigorous optimization, the Selexol unit should also be considered as part of this optimization study. For simplicity, the parameter $A$ is used in this study to capture the uncertainty in the value of the power requirement in the Selexol unit per $1 \mathrm{bmol} / \mathrm{hr}$ of hydrogen sulfide in tail gas. In addition, the flow of the acid gas from the Selexol unit is changed based on the base-case flow and the base-case hydrogen sulfide flow to the Selexol unit by a design specification based on Equation (5.2). This equation is derived assuming that the amount of $\mathrm{H}_{2} \mathrm{~S}$ remains unchanged in 
the clean syngas from the Selexol unit. It is also assumed that the composition of the Selexol off-gas to the Claus unit remains unchanged at the base case condition.

$$
\dot{m}_{\text {Selexol }}\left[\frac{l b}{h r}\right]=30531.14+2.649 \cdot \dot{m}_{\mathrm{H}_{2} \mathrm{~S} \text {, Tailgas }}\left[\frac{l b}{h r}\right]
$$

\subsection{Results}

A sensitivity study was done to determine the effect of the oxygen flow on the terms present within the objective function, Equation (5.1). Figure 5.1 shows the effect of oxygen flow on hydrogen and hydrogen sulfide flow in the tailgas. Figure 5.2 shows the effect of oxygen flow on $W_{\text {steam }}-W_{\text {tail }}$ and its effect on the value of the power production from the Claus unit when the parameter $A$ is chosen to be $50 \%$. These figures show that there exist an optimal oxygen flow to maximize the power production of the IGCC as you want to both minimize hydrogen sulfide flow in the tailgas and to maximize the hydrogen flow in the tailgas.

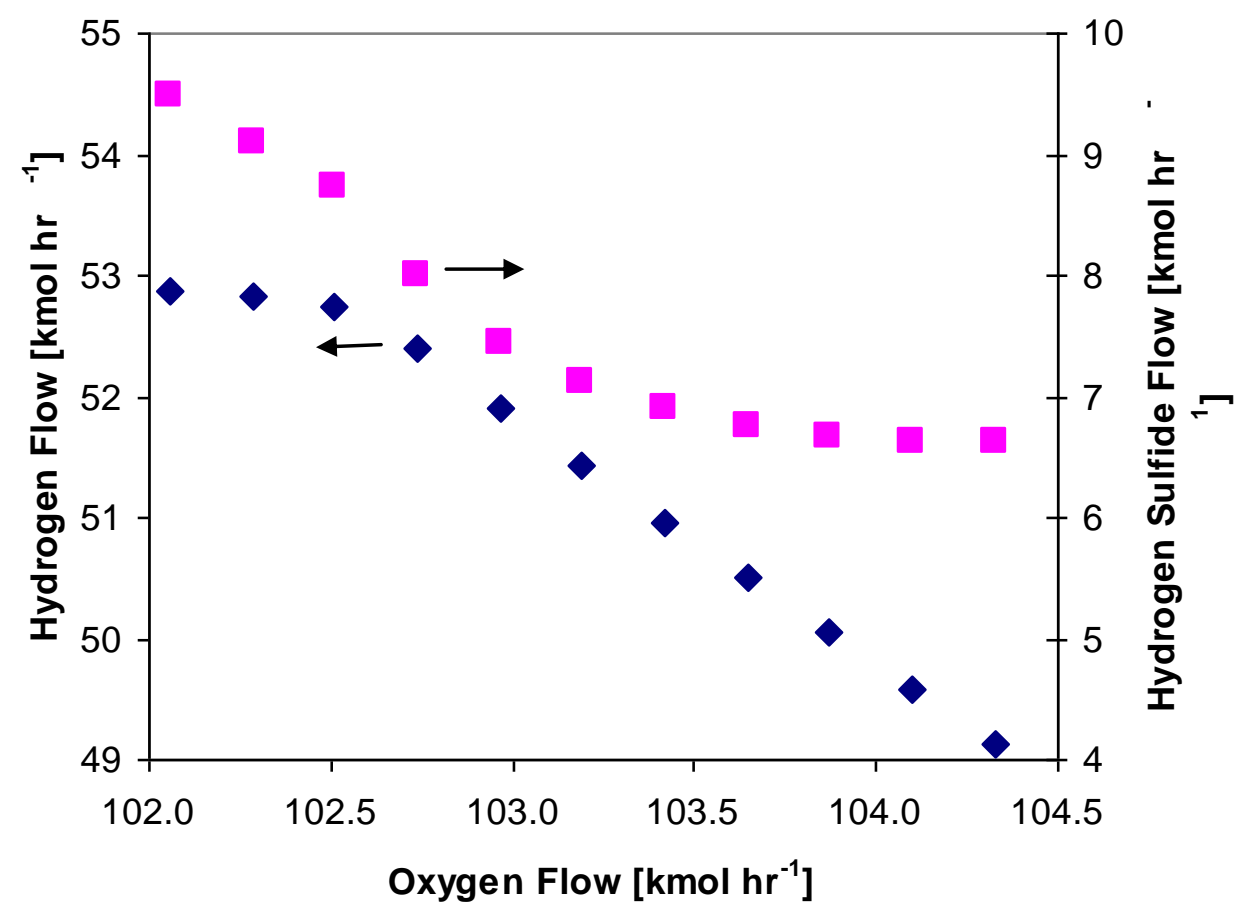

Figure 5.1 Effect of oxygen flow on hydrogen and hydrogen sulfide flow in tailgas 


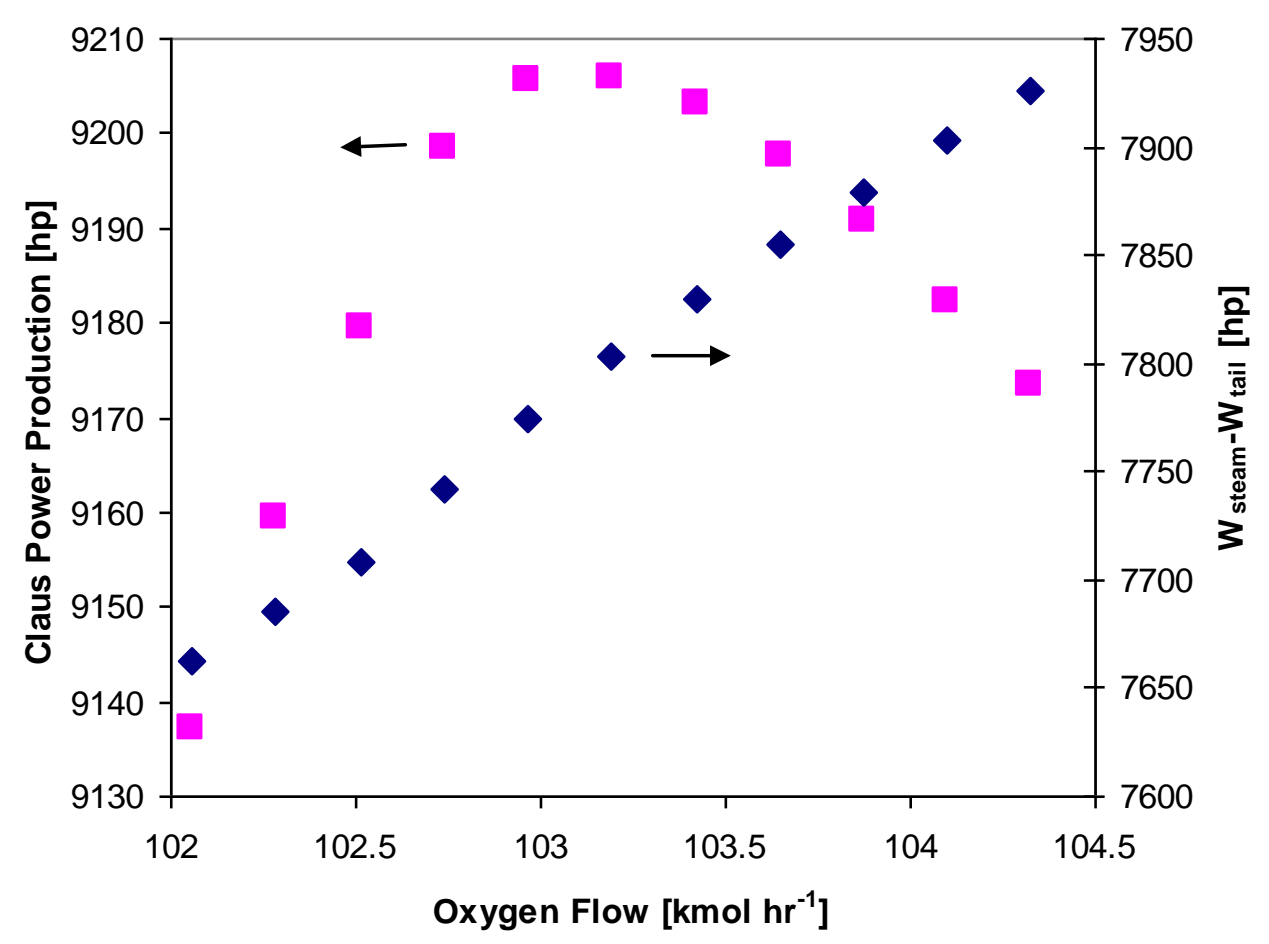

Figure 5.2 Effect of oxygen flow on Claus power production and power produced by steam turbines minus power requirement of tailgas compressors

Figures 5.1-5.3 show the results of this optimization for varying values of the parameter $A$. It should be mentioned that each of the data points in Figures 5.1- 5.3 are optima for each particular value of $A, A$ representing the power required to recover hydrogen sulfide in the tailgas. It is felt that the most likely value of $A$ is approximately $70 \%$, marked on Figures 5.1-5.3, based upon the partial pressure of $\mathrm{CO}_{2}$ in the tailgas as compared to the syngas, for the base case. 


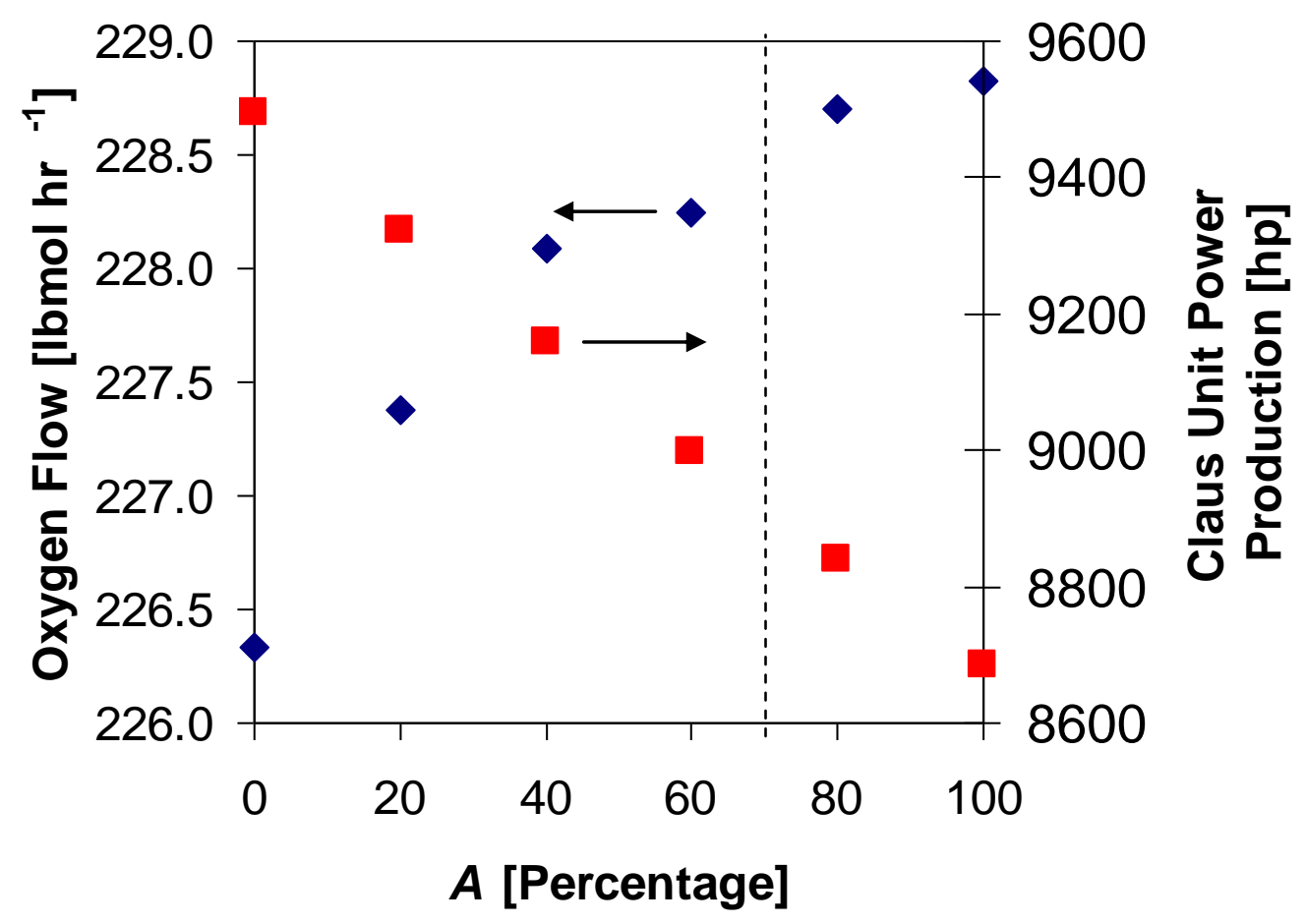

Figure 5.3 Effect of Selexol power requirement on optimal oxygen flow and objective function value

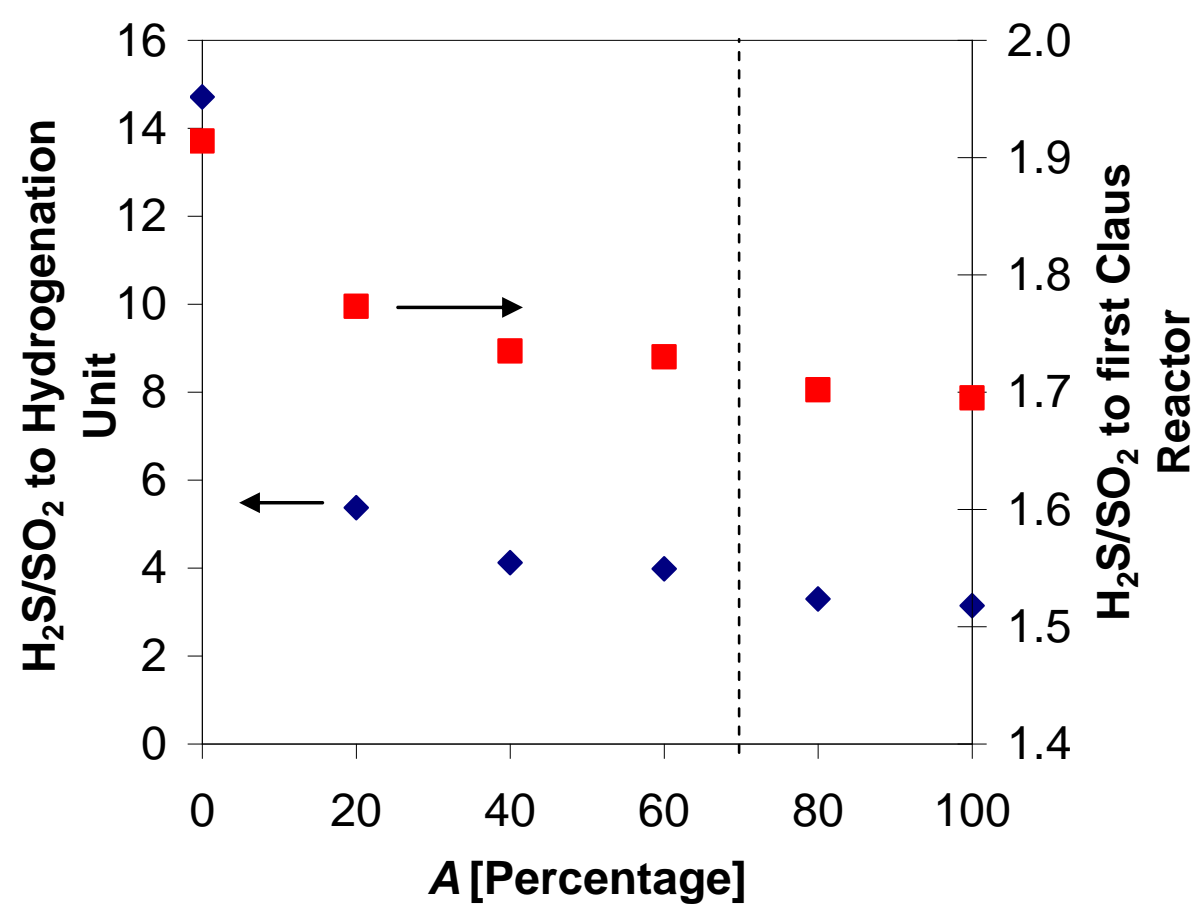

Figure 5.4 Effect of Selexol power requirement on optimal $\mathrm{H}_{2} \mathrm{~S} / \mathrm{SO}_{2}$ ratio at the inlet of the hydrogenation unit and $1^{\text {st }}$ Claus Reactor 


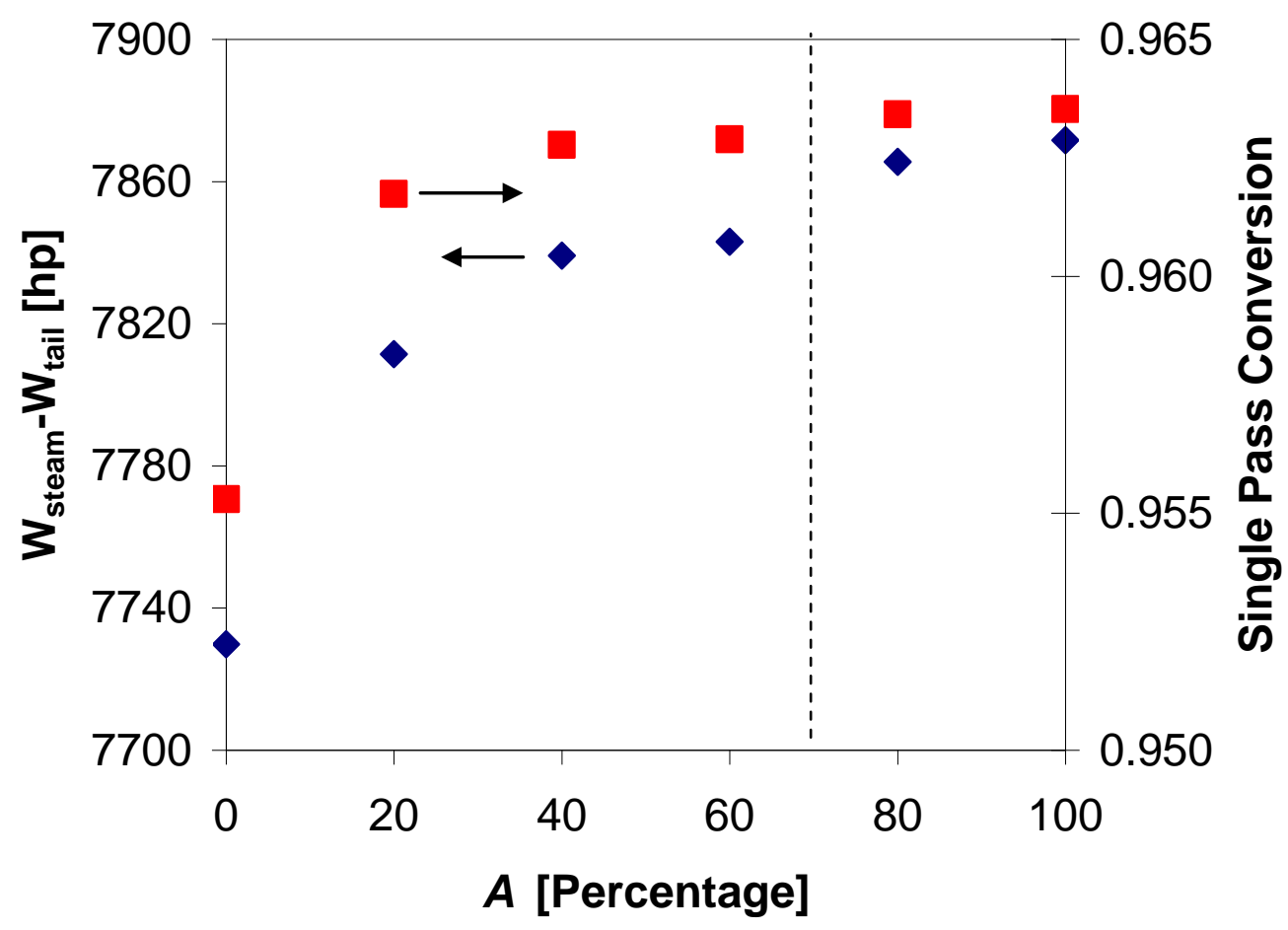

Figure 5.5 Effect of Selexol power requirement on optimal power generation of steam turbine and requirement of tailgas compressor and single pass conversion

As shown in Figure 5.2, for a low cost of hydrogen sulfide recovery, i.e. low values of $A$, optimal $\mathrm{H}_{2} \mathrm{~S} / \mathrm{SO}_{2}$ in the tailgas is higher than two, which is the stoichiometric ratio of the Claus reaction, reaction (2.31). This decreases the single-pass conversion, as shown in Figure 5.3 and results in an increase in the power required in the tailgas compressors and decreases power generated from the steam turbines, as shown in Figure 5.3. There are two factors that move the optimum in this direction: 1) a decrease in oxygen required for overall conversion, as shown in Figure 5.1 and 2) an increased hydrogen yield from the process. The second is the larger effect, as it is assumed that all hydrogen produced in the process is sent with the cleaned syngas for power production in the gas turbine, etc. Additionally, as shown in Figure 5.1, net power production is maximized when $A$ is a minimum. However, as the cost of hydrogen sulfide recovery in the Selexol unit is increased, i.e. increased values of $A$, as one would expect, optimal $\mathrm{H}_{2} \mathrm{~S} / \mathrm{SO}_{2}$ 
ratio nears the stoichiometric ratio (2.0) of reaction (2.31) and single-pass conversion increases. This increased conversion decreases the power requirement of the tailgas compressors and increases the power production in the steam turbines due to increased combustion of hydrogen sulfide. However, until a model of the hydrogen sulfide recovery section of the Selexol unit is added to this model, it is unclear how the cost in the Selexol unit will change with changes in tailgas flow and composition or how the composition and flow of the off gas from the Selexol unit sent to the Claus unit with change. These factors may play a large part in the optimal operation of the Claus unit. 


\section{Chapter 6}

\section{Control Studies}

\subsection{Simplifying Assumptions and Development of a Dynamic Model}

When exporting the steady state model into the Aspen Plus Dynamics

environment, some simplifying assumptions needed to be made to ensure stable dynamic runs.

1) The flame zone is converted to a CSTR.

2) All methane is assumed to be destroyed via hydrolysis in a conversion reactor.

3) All ammonia destruction is done via a conversion reactor.

4) No carbonyl sulfide hydrolysis takes place in the catalytic reactors. These assumptions were made in order to decrease the number of corresponding equations in the dynamic simulation. Since oxygen, methane, ammonia, and carbonyl sulfide flows approach zero in some blocks within the simulation, discretization of the reactors in which this occurs must be significantly higher than normal to prevent negative mass flows. The increased discretizations present several problems in the Aspen Plus Dynamics environment such as increasing the number of equations to be solved and requiring higher pressure drops in the blocks that require more discretizations due to a minimum pressure drop requirement for each discretization. These problems can significantly increase the time required for convergence or cause convergence failures. Additionally, reactions (2.5)-(2.7) were turned off due to their low extent of reaction in comparison to reactions (2.1) and (2.3). Finally, the pre-exponential term of reaction (2.3) was changed to match the output of the plug flow reactor model.

For the sake of this study, heaters are considered to have very fast (instantaneous) dynamics with heat being supplied by condensing steam. Coolers are considered 
to have very fast (instantaneous) dynamics with cooling being provided by cooling water. As mentioned previously, sizing of the reactors is based upon standards available within the literature $[17,18]$. Sizing of flash vessels is based upon heuristics from Turton et al. [25].

\subsection{Regulatory Controls}

A simplified flowsheet of the Modified Claus Process with controls is shown in Figure 6.1. 


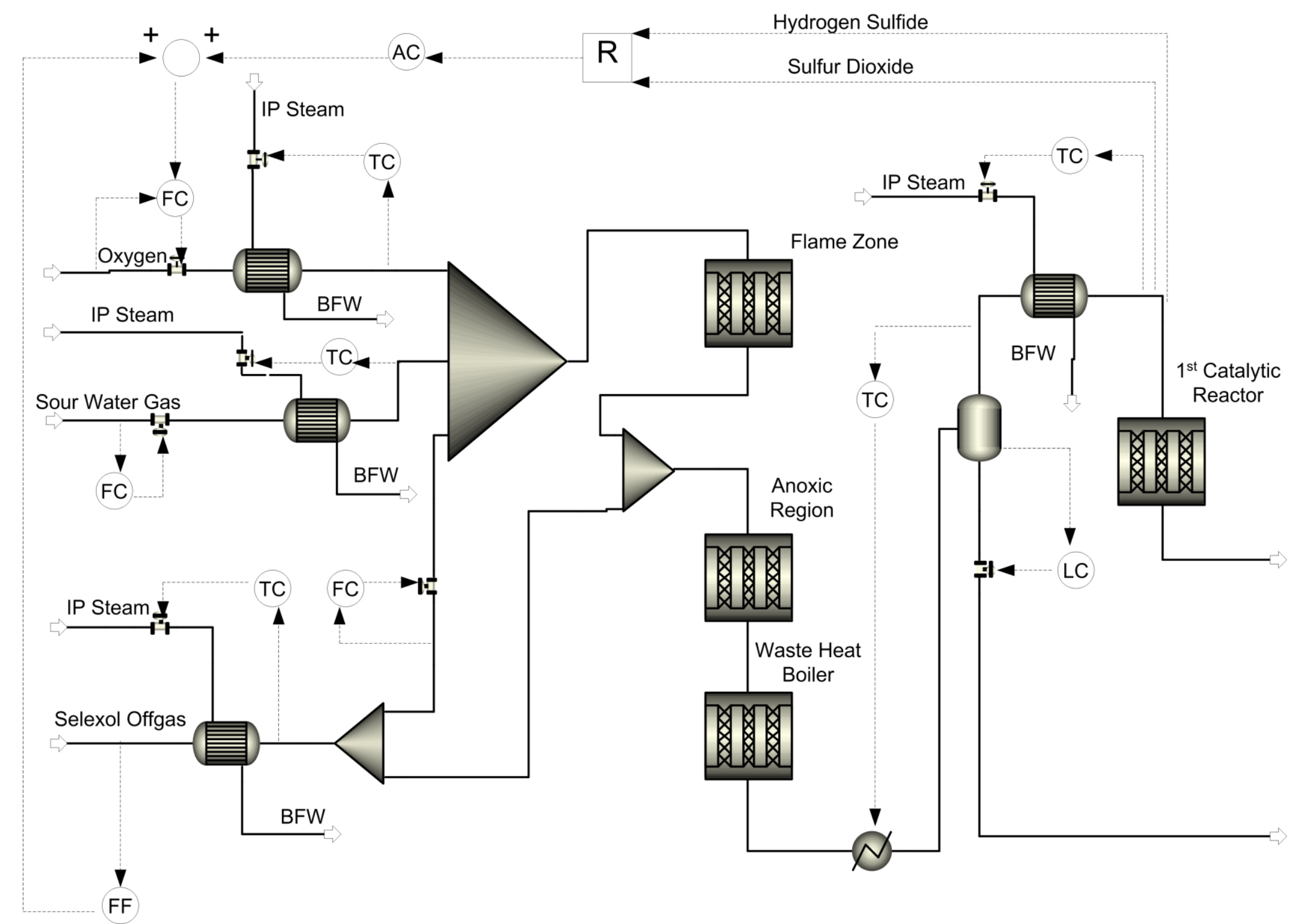

Figure 6.1: Simplified Flowsheet of Modified Claus Process with Controls 
It has been shown by Taggart [16] that the preferred control variable of the Claus Process is the $\mathrm{H}_{2} \mathrm{~S} / \mathrm{SO}_{2}$ ratio and that the manipulated variable is the air flow (or in this case oxygen flow). The regulatory controls, i.e., pressure, temperature, etc., were added and tuned using the Aspen Plus Dynamics tuning toolbox. The Aspen Plus Dynamics tuning toolbox, when using the open loop tuning method, gives a user a specified step change to the manipulated variable and fits the system response to a first-order process model with time delay, as given by Equation (6.1):

$$
g s=K \frac{e^{-\alpha s}}{\tau s+1}
$$

With the fitted, first-order model parameters, it calculates controller constants for either a P, PI, or PID controller using either Ziegler-Nichols, Equation (6.2) [26], Cohen-Coon, Equation (6.3) [26], IMC (Internal Model Control), Equation (6.4) [26], or parameters based on minimizing one of the time-integral criteria, either IAE (Integral Absolute Error), ISE (Integral Squared Error), and ITAE (Integral Time-Weighted Absolute Error), Equation (6.5) [26], shown as Equations (6.6)(6.8). For completeness, the ITSE (Integral Time-Weighted Squared Error) criterion is also shown as Equation (6.9) as it will be used later to analyze performance. The ISE criterion penalizes large errors at anytime; the ITAE criterion penalizes errors at long times; the ITSE criterion penalizes large errors at long times.

$$
\begin{aligned}
K_{C} & =\frac{0.9}{K}\left(\frac{\tau}{\alpha}\right) \\
\tau_{I} & =3.33 \alpha
\end{aligned}
$$




$$
\begin{aligned}
& K_{C}=\frac{1}{K}\left(\frac{\tau}{\alpha}\right)\left[0.9+\frac{1}{12}\left(\frac{\alpha}{\tau}\right)\right] \\
& \tau_{I}=\alpha\left[\frac{30+3\left(\frac{\alpha}{\tau}\right)}{9+20\left(\frac{\alpha}{\tau}\right)}\right] \\
& K_{C}=\frac{2 \tau+\alpha}{2 \lambda K} \\
& \tau_{I}=\tau+\frac{\alpha}{2} \\
& \text { w/ } \lambda>1.7 \alpha \\
& K_{C}=\frac{0.859}{K}\left(\frac{\tau}{\alpha}\right)^{0.977} \\
& \tau_{I}=\frac{\tau}{0.674}\left(\frac{\alpha}{\tau}\right)^{0.680} \\
& \mathrm{IAE}=\int_{0}^{\infty}|\varepsilon t| \partial t \\
& \mathrm{ISE}=\int_{0}^{\infty} \varepsilon^{2} t \partial t \\
& \mathrm{ITAE}=\int_{0}^{\infty} t|\varepsilon t| \partial t \\
& \text { ITSE }=\int_{0}^{\infty} t \varepsilon^{2} t \partial t
\end{aligned}
$$




\subsection{Control Strategies}

Two control strategies were considered for maintaining $\mathrm{H}_{2} \mathrm{~S} / \mathrm{SO}_{2}$ ratio: a feedback controller and a feedforward-augmented feedback scheme. Feedforward control was considered as a measure for ensuring that operation is maintained within a certain range so as not to violate operating constraints, i.e. maintaining adiabatic flame temperature as not to damage refractory lining and to prevent possible flame blowouts. As shown in Figure 6.1, the oxygen controller is cascaded with the feedback and, if applicable, feedforward controllers. Feedback control is based on the $\mathrm{H}_{2} \mathrm{~S} / \mathrm{SO}_{2}$ ratio at the outlet of the first flash vessel and the inlet to the $1^{\text {st }}$ reheater. All controllers in these studies are considered as PI controllers. The derivative action was not considered for the following reasons, as given by Luyben [27]: 1) Three tuning constants must be specified. 2) Signal noise is amplified. 3) Derivative action is more useful for processes with large deadtimes. For the feedback-only control scheme, a first approximation for control parameters were derived using the Aspen Plus Dynamics tuning toolbox, as described previously. However, these parameters gave poor performance and manual tuning was used to minimize overshoot, settling time, and oscillation. Parameters used for the feedback controller are 0.6 for the gain constant and $0.15 \mathrm{~min}$ for the integral time constant.

A block flow diagram of a feedforward-augmented feedback control scheme is shown in Figure 6.2. 


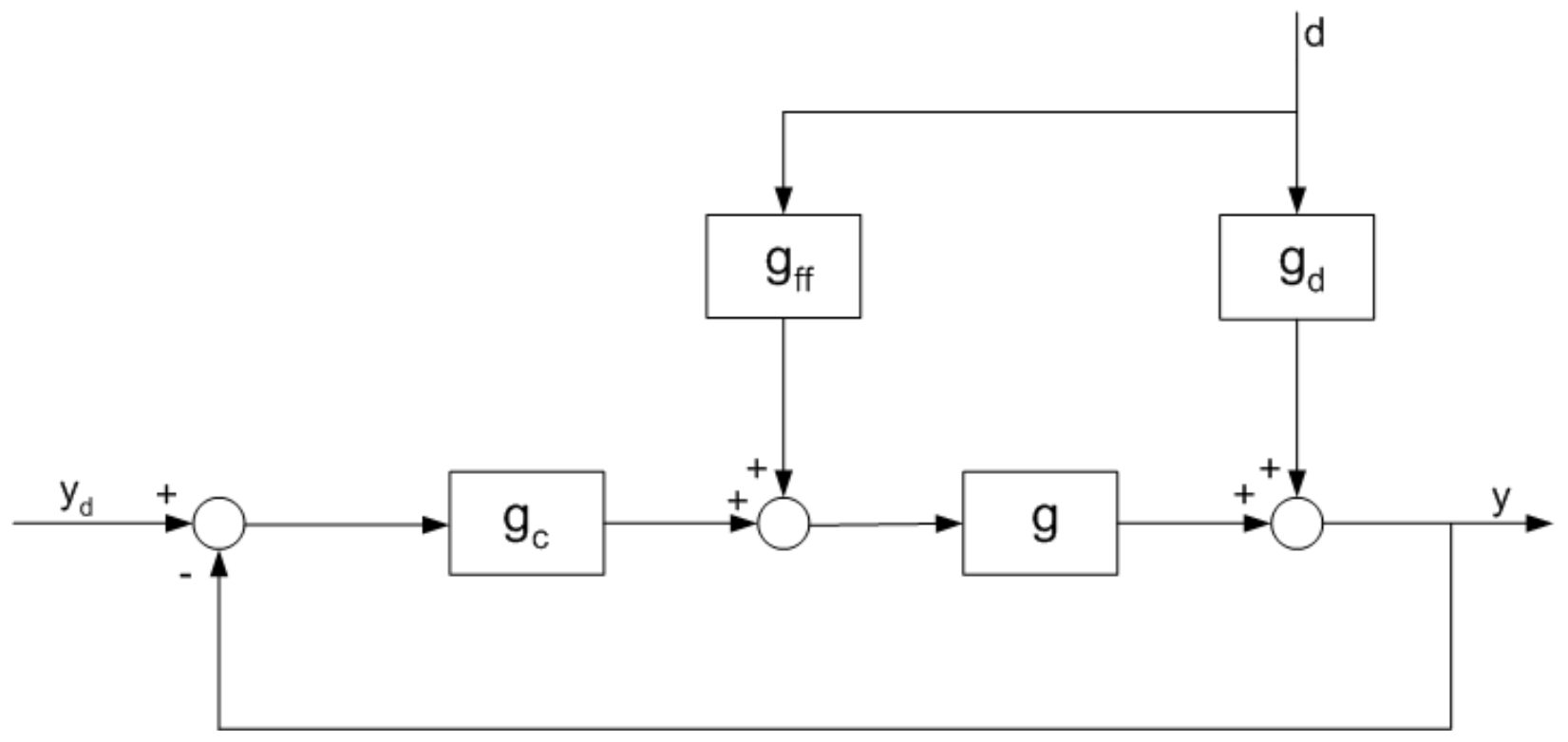

Figure 6.2: Block flow diagram of a feedforward-augmented feedback control scheme

Feedforward parameters, for the case of disturbance rejection, are derived based on Equation (6.10), where $g(s)$ is the process model and $g_{d}(s)$ is the disturbance model.

$$
g_{f f}=-\frac{g_{d} s}{g s}
$$

A fitted first-order model of the process was determined by giving a 13\% step down to oxygen flow. The fitted transfer function is given as Equation (6.11) and the data and fitted model are shown in Figure 6.3.

$$
g s=\frac{0.145}{0.0053 s\left[\mathrm{~min}^{-1}\right]+1}
$$




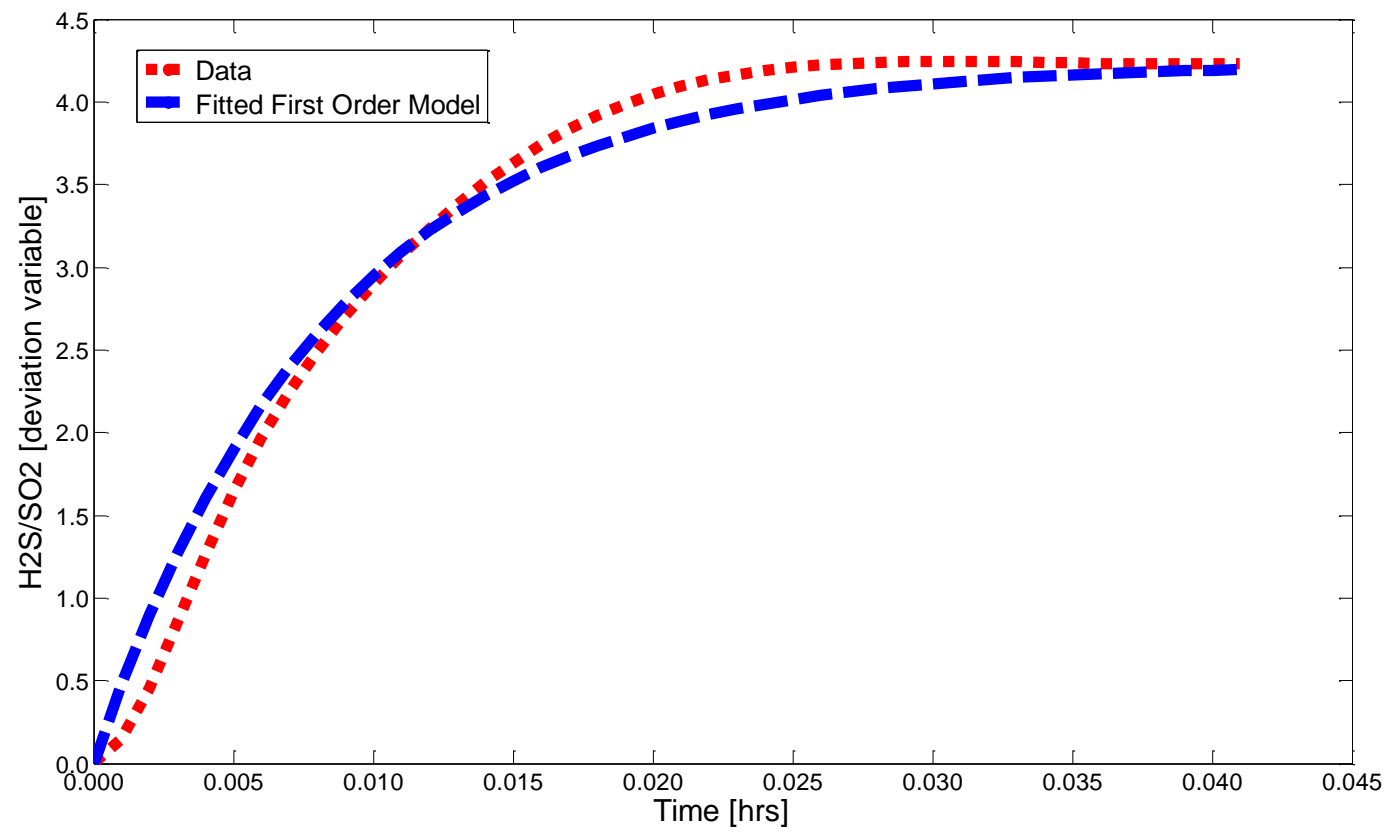

Figure 6.3: Process response and fitted model to a $13 \%$ step decrease in oxygen flow

Since the time constant of the system is significantly larger than the dead time, the dead time was neglected. A fitted first-order model of the disturbance was determined by giving a $27 \%$ step down to hydrogen sulfide concentration in the Selexol acid gas. The fitted transfer function is given as Equation (6.12) and the data and fitted model are shown in Figure 6.4.

$$
g_{d} s=\frac{18.8}{0.0083 s\left[\mathrm{~min}^{-1}\right]+1}
$$




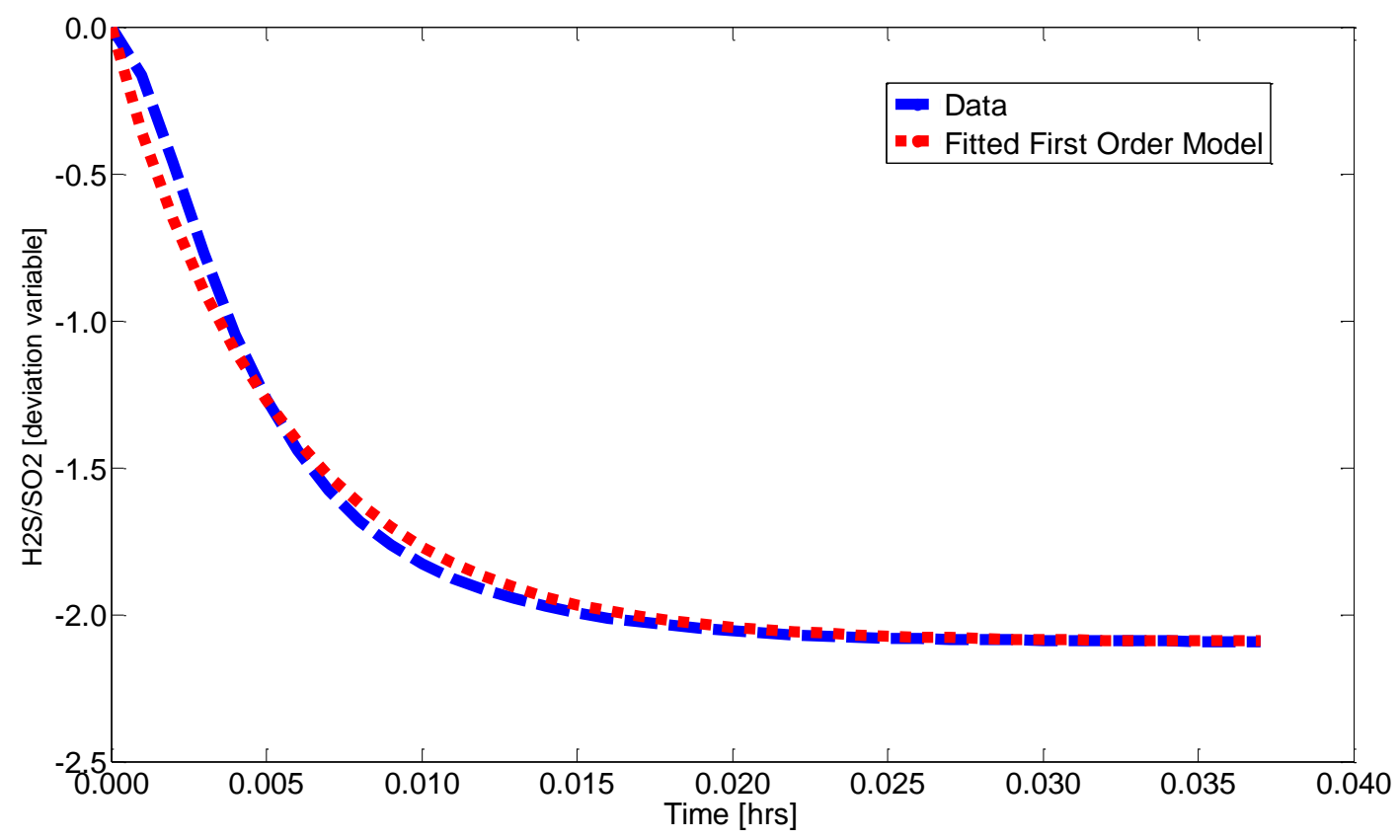

Figure 6.4: Process response and fitted model to a $27 \%$ step decrease in hydrogen sulfide concentration in Selexol acid gas

As with the fitting of the process curve, dead time was neglected. With the fitted models, parameters for the feedforward control were calculated using Equation (6.10). The feedforward control transfer function is given as Equation (6.13) and feedback control parameters are 0.8 for the gain constant and 0.15 min for the integral time constant.

$$
g_{f f}=129.5 \frac{0.0053 s+1}{0.0083 s+1}
$$

A comparison of the feedforward-augmented feedback and feedback strategies was made by giving a $27 \%$ step decrease in hydrogen sulfide concentration of the Selexol offgas sent to the Claus unit at $\mathrm{t}=0$. Results of feedforward-augmented feedback and feedback control strategies are shown in Figures 6.5. 

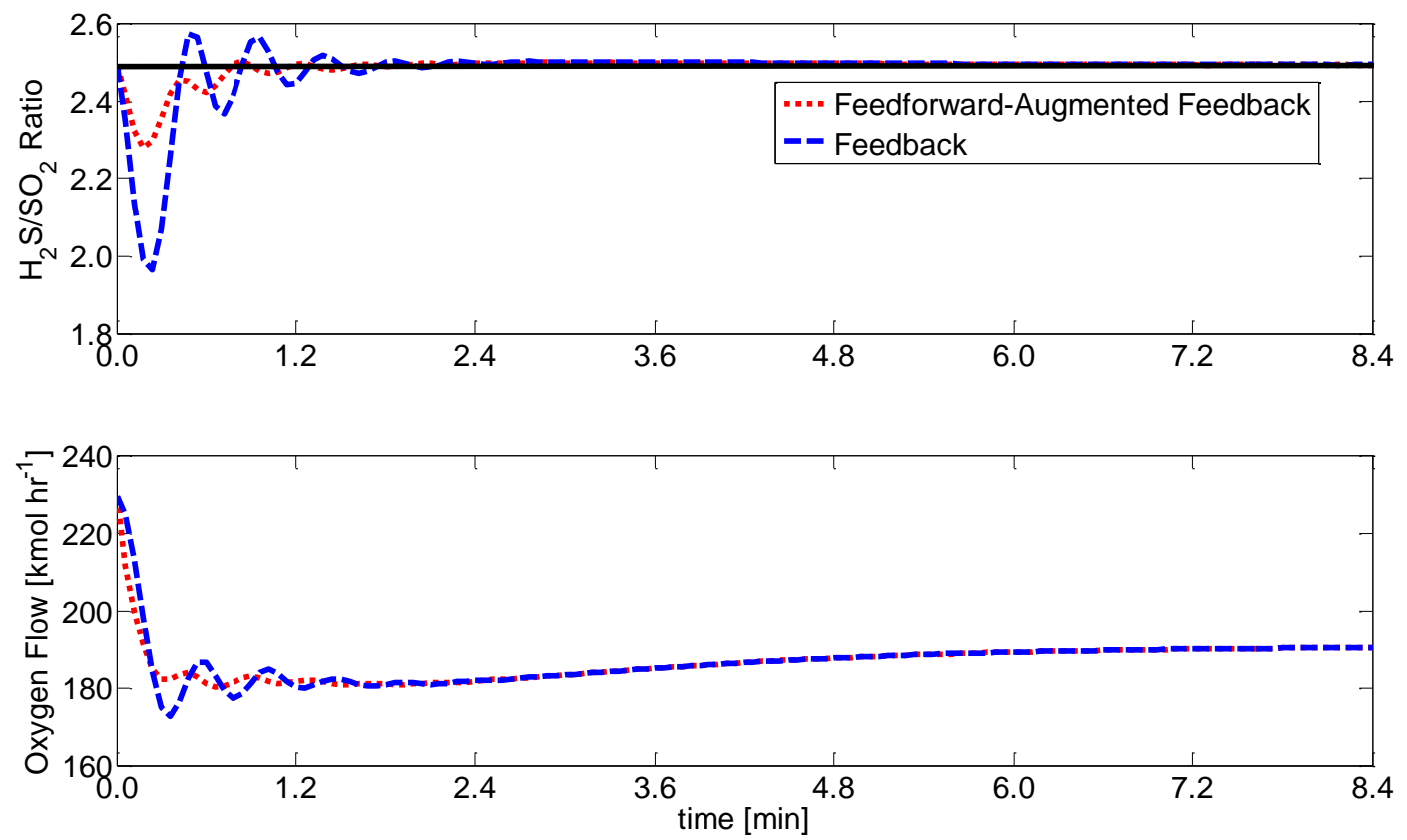

Figure 6.5: $\mathrm{H}_{2} \mathrm{~S} / \mathrm{SO}_{2}$ ratio and oxygen flow for feedforward-augmented feedback and feedback control for a $27 \%$ step decrease in $\mathrm{H}_{2} \mathrm{~S}$ concentration in Selexol gas

Table 6.1 shows the time-integral performance criteria of both strategies. Equations (6.6)-(6.9) define each criteria.

Table 6.1: Time-integral performance criteria

\begin{tabular}{|c|c|c|}
\hline & Feedforward-Augmented Feedback & Feedback \\
\hline IAE & $1.619 \times 10^{-3}$ & $3.595 \times 10^{-3}$ \\
\hline ISE & $1.605 \times 10^{-4}$ & $9.794 \times 10^{-4}$ \\
\hline ITAE & $3.200 \times 10^{-5}$ & $5.460 \times 10^{-5}$ \\
\hline ITSE & $7.434 \times 10^{-7}$ & $4.461 \times 10^{-6}$ \\
\hline
\end{tabular}

As can be seen in Table 6.2, the feedforward-augmented feedback control strategy performs better than the feedback strategy based on all criteria. This means that the feedforward-augmented feedback control has less error (IAE), smaller errors (ISE), faster settling time (ITAE), and smaller errors at long times (ITSE) than the feedback only controller. 


\section{Chapter 7}

\section{Conclusions}

After completing an extensive literature survey of the Claus unit, rate expressions, experimental data, and industrial data were collected to develop a kinetic model of a Modified Claus process and hydrogenation unit. Kinetic expressions that could not be found within the open literature were derived from available experimental data or used as a fitting parameter for matching with industrial data. The rate parameters of reactions $(2.12)-(2.15)$ were considered as decision variables so as to minimize the difference between the model predictions and available industrial data. The rate parameters calculated from this data fitting were found to provide superior predictions as compared to the published rate expressions.

This model was then used to optimize the operation of the Claus plant. The objective of this optimization was the decrease in the equivalent power requirement of the Claus unit and associated unit operations of an IGCC plant with $\mathrm{CO}_{2}$ capture. It was found that when the cost of hydrogen sulfide recovery from the tailgas of the Claus unit is low, optimal single-pass conversion is less than the maximum possible. This is due to the increased hydrogen production from the unit at lower oxygen flows to the furnace which results in an $\mathrm{H}_{2} \mathrm{~S} / \mathrm{SO}_{2}$ ratio greater than 2 thus resulting in lower single pass conversion due to a larger difference between the $\mathrm{H}_{2} \mathrm{~S} / \mathrm{SO}_{2}$ ratio and the stoichiometric ratio of reaction (2.31). These effects result in a higher net power production from the Claus unit when the cost of hydrogen sulfide recovery from the tailgas is low.

The developed steady-state model was then used as the basis of a dynamic pressure-driven simulation in the Aspen Plus Dynamic environment where several control studies were carried out. For a Claus unit as part of an IGCC power plant 
with $\mathrm{CO}_{2}$ capture, several disturbances can occur due to changes in sulfur content of gasifier feed materials. The control objective for the Claus unit is maintaining the $\mathrm{H}_{2} \mathrm{~S} / \mathrm{SO}_{2}$ ratio at a desired value by rejecting these disturbances. For the purpose of satisfying this control objective, first-order models were identified between the disturbance $\left(\mathrm{H}_{2} \mathrm{~S}\right.$ concentration in the Selexol offgas) and the input (oxygen flow to the furnace) to the output $\left(\mathrm{H}_{2} \mathrm{~S} / \mathrm{SO}_{2}\right.$ ratio). Using these identified models, a feedforward controller was developed for satisfying this control objective. The feedforward controller was found to provide superior performance as compared to the standard PI controller for this given perturbation. 


\section{Chapter 8}

\section{Suggestions for Future Work}

It is suggested that the simplifying assumptions made in the development of the rate expression for reactions (2.19) and (2.20) be relaxed. This includes the inclusion of the volume change of the gas as it undergoes the chemical reaction, and solving Equation (3.9) without simplifying assumptions.

The inclusion of a model of the hydrogen sulfide recovery section of the Selexol unit would allow for a more rigorous determination of optimal steady state operation of the Claus plant than what is currently possible.

Relaxing some of the simplifying assumptions made in the development of the dynamic model would provide more accurate and representative data of an actual Claus unit. This may include having the destruction of methane and ammonia as kinetic reactions and including carbonyl sulfide hydrolysis in the catalytic reaction. Additionally, tuning of the controls based on Ziegler-Nichols stability margin controller tuning parameters may provide better system response than the method currently used. This is due to the limited range that the controller tuning rules (Equations $6.2-6.4$ ) available in Aspen Plus Dynamics ; namely $0.1 \leq \frac{\alpha}{\tau} \leq 1.0$ [26].

Other disturbances to the Claus unit as part of an IGCC plant such as change in the $\mathrm{NH}_{3}$ concentration, change in the flowrate of the acid gas from the Selexol unit should also be considered and the performance of the feedforward-augmented feedback control strategy should be evaluated. To make the control study more applicable to the "real-world," a multiple-input-multiple-output (MIMO) system could be considered. In the control studies of a Claus unit, several constraints should also be considered. For example, the Claus furnace temperature cannot exceed certain temperature in view of material constraints. It cannot be lower than 
a certain temperature to avoid burner blow out and/or incomplete $\mathrm{NH}_{3}$ conversion in the furnace. For handling such constraints as part of a control system design, a model predictive control (MPC) strategy should be considered. 


\section{Notation}

A

$\Delta H_{R}$

$E_{a}$

F

k

$m, n$

P

$r$

$T$

$t$

$U$

\section{Greek letters}

$\tau$

$\xi$

$\sigma$

Subscripts

$i$

j
Arrhenius Constant and parameter in Equations (1.1-1.5)

Heat of Reaction

Activation Energy

Molar Flowrate

Reaction Rate Constant

Reaction Order

Pressure

Reaction Rate

Temperature

Time

Overall Heat Transfer Coefficient

Residence Time

Extent of Reaction

Standard Deviation

Species

Data Set 


\section{$\underline{\text { References }}$}

1. Clark, P, „Chemistry of the Claus Furnace', Sulfur (2003) 285, 24-26

2. Hawboldt, K.A., 'Kinetic Modelling of Key Reactions in the Modified Claus Plant Front End Furnace', Ph.D. Thesis, Department of Chemical and Petroleum Engineering, University of Calgary, Canada, 1998.

3. Lindberg, J.; Hermansson, R., ,Modification of Reaction Rate Parameters for Combustion of Methane Based on Experimental Investigation at Furnace-like Conditions', Energy \& Fuels (2004) 18, 1482-1484

4. Monnery, W.D., Hawboldt, K.A., Pollock, A.E., Svrcek, W.Y., „Ammonia Pyrolysis and Oxidation in the Claus Furnace', Ind. Eng. Chem. Res. (2001), 40 144-151

5. Molnar, M., Marek, C.J., ,Simplified Two-Time Step Method for Calculating Combustion Rates and Nitrogen Oxide Emissions for Hydrogen/Air and Hydrogen/Oxygen' (2005)

6. Karan, K., Mehrotra, A.K., Behie, L.A., „A high-temperature experimental and modeling study of homogeneous gas-phase COS reactions applied to Claus plants', Chemical Engineering Science (1999) 54, 2999-3006

7. Clark, P.D., Dowling, N.I., Huang, M., Svrcek, W.Y., Monnery, W.D., „Mechanisms of CO and COS Formation in the Claus Furnace', Ind. Eng. Chem. Res. (2001) 40, 497-508

8. Monnery, W.D., Hawboldt, K.A., Pollock, A., Svrcek, W.Y., ,New experimental data and kinetic rate expression for the Claus Reaction', Chemical Engineering Science (2000) 55, 5141-5148

9. Hawboldt, K.A., Monnery, W.D., Svrcek, W.Y., „New experimental data and kinetic rate expression for $\mathrm{H}_{2} \mathrm{~S}$ pyrolysis and re-association', Chemical Engineering Science (2000) 55, 957-966

10.Clark, P.D., Dowling, N.I., Huang, M., „Mechanisms of Ammonia Destruction in the Claus Furnace', (2001) 
11.Karan, K.; Behie, L. A. , $\mathrm{CS}_{2}$ Formation in the Claus Reaction Furnace: A Kinetic Study of Methane-Sulfur and Methane-Hydrogen Sulfide Reactions.' Ind. Eng. Chem. Res. (2004) 43, 3304-3313

12.Zhang Jia-yuan.; Zhou Jie-min; Yan Hong-jie, ,Kinetic model on coke oven gas with steam reforming.' J. Cent. South Univ. Technol (2008) 15, 127-131

13.Sames, J.A.; Paskall, H.G., ,Field Measurements of Hydrogen Production in an Oxygen-enriched Claus Furnace.' Western Research. (1990)

14.Linda V. Nasto.; Kunal Karan; Anil K. Mehrotra; Leo A. Behie, ,Modeling reaction quench times in the waste heat boiler of a Claus plant.' Ind. Eng. Chem. Res. (1994) 33, 4-13

15.John Haslbeck; Pamela Capicotto; Michael Matuszewski, ,Model Documentation: IGCC with GE Energy Gasifier and $\mathrm{CO}_{2}$ Capture.'

16. G.W. Taggart „Optimize Claus Control’ Hydrocarbon Processing (1980), 133138

17. Shimin Tong, Ivo G. Dalla Lana, Karl T. Chuang, ,Effect of Catalyst Shape on the Hydrolysis of COS and $\mathrm{CS}_{2}$ in a Simulated Claus Converter' Ind. Eng. Chem. Res. (1997) 36, 4087-4093

18. David M. J. Puchyr, Anil K. Mehrotra, Leo A. Behie, Nicolas Kalogerakis „Hydrodynamics and kinetic modeling of circulating fluidized bed reactors applied to a modified Claus Plant' Chemical Engineering Science (1996) 51, $5251-5262$

19. Stephen N. Massie, „Less Fuel - Less Fire - Less Pollution Using Low Temperature Tail Gas Catalyst and Catalytic Incineration in Sulfur Plants' Gas Processors Association Europe Spring Conference (2006)

20. Cost and performance baseline for fossil energy power plants study, Volume 1: Bituminous coal and natural gas to electricity. National Energy Technology Laboratory, http://www.netl.doe.gov, DOE/NETL-2007/1281, August 2007

21. Bhattacharyya, D.; Turton, R.; Zitney, S. Steady-state simulation and optimization of an integrated gasification combined cycle (IGCC) power plant with $\mathrm{CO}_{2}$ capture. Submitted to Ind. Eng. Chem Res (2010) 
22. Bhattacharyya, D.; Turton, R.; Zitney, S. Plant-wide Dynamic Simulation of an IGCC Plant with $\mathrm{CO}_{2}$ Capture. Proc. of the $26^{\text {th }}$ Annual International Pittsburgh Coal Conference, September 21-24, Pittsburgh, PA (2009)

23. Encyclopedia of Energy Engineering and technology, Vol 2-3, Ed. B. L. Capehart, CRC Press, Boca Raton, FL, (2007)

24. Arthur L. Kohl; Richard Nielson, „Gas Purification, Fifth Edition’ Gulf Professional Publishing (1997)

25. Richard Turton; Richard C. Bailie; Wallace B. Whiting; Joseph A. Shaeiwitz, „Analysis, Synthesis and Design of Chemical Processes ( $3^{\text {rd }}$ Edition)' Prentice Hall (2009)

26. Babatunde A. Ogunnaike; W. Harmon Ray, ,Process Dynamics, Modeling, and Control' Oxford University Press (1994)

27. William L. Luyben, ,Plantwide Dynamic Simulators in Chemical Processing and Control' CRC Press (2002) 
Appendix A:

Optimal design and integration of an Air Separation Unit (ASU) for an Integrated Gasification Combined Cycle (IGCC) Power Plant with $\mathrm{CO}_{2}$ Capture

Dustin Jones ${ }^{1}$, Debangsu Bhattacharyya ${ }^{1}$, Richard Turton ${ }^{1}$, and Stephen E. $\underline{\text { Zitney }}^{2}$

${ }^{1}$ Department of Chemical Engineering, West Virginia University, Morgantown, WV 26506

${ }^{2}$ U.S. Department of Energy, National Energy Technology Laboratory, Morgantown, WV 26507

Submitted to Fuel Processing Technology (2010) 


\section{ABSTRACT}

The air separation unit (ASU) plays a key role in improving the efficiency, availability, and operability of an oxygen-fed integrated gasification combined cycle (IGCC) power plant. An optimal integration between the ASU and the balance of the plant, especially the gasifier and the gas turbine (GT), has significant potential for enhancing the overall plant efficiency. Considering the higher operating pressure of the GT, an elevated-pressure air separation unit (EPASU) is usually favored instead of the conventional low-pressure air separation units (LP-ASU). In addition, a pumped liquid oxygen (PLOX) cycle is usually chosen if the operating pressure of the gasifier is high. A PLOX cycle helps to improve plant safety and availability and to decrease the capital cost by reducing the size of the oxygen compressor or by eliminating it completely. However, the refrigeration lost in withdrawn liquid oxygen must be efficiently recovered. This paper considers five different configurations of an ASU with PLOX cycle and compares their power consumptions with an EP-ASU with a traditional gaseous oxygen (GOX) cycle. The study shows that an optimally designed EP-ASU with a PLOX cycle can have similar power consumption to that of an EP-ASU with GOX cycle in the case of $100 \%$ nitrogen integration. In the case of an IGCC with precombustion $\mathrm{CO}_{2}$ capture, the lower heating value (LHV) of the shifted syngas, both on a mass and volumetric basis, is in between the LHV of the unshifted syngas from an IGCC plant and the LHV of natural gas, for which the GTs are generally designed. The optimal air integration in the case of a shifted syngas was found to be much lower than that of an unshifted syngas. This paper concurs with the existing literature that the optimal integration occurs when air extracted from the GT can be replaced with the nitrogen from the ASU without exceeding mass/volumetric flow limitations of the GT. Considering nitrogen and air integration between the ASU and the GT, this paper compares the power savings in an LP-ASU with a PLOX cycle to the power savings in an EP-ASU with GOX cycle and EP-ASU with PLOX cycle. The results show that an LP-ASU with a PLOX cycle has less power consumption if the nitrogen integration levels are less than $50-60 \%$. In addition, a study was carried out by varying the concentration of nitrogen and steam in the fuel diluents to the GT while the NOx level was maintained constant. The study shows that when the nitrogen injection rate exceeds $50 \%$, an EP-ASU with a PLOX cycle is a better option than an LP-ASU with a PLOX cycle. This paper shows that an optimal design and integration of an ASU with the balance of the plant can help to increase the net power generation from an IGCC plant with $\mathrm{CO}_{2}$ capture.

Keywords: Elevated-Pressure, ASU, IGCC, pumped liquid oxygen (PLOX), optimization, integration 


\section{Introduction}

Integrated gasification combined cycle (IGCC) is a promising technology for generating clean, affordable, and secure power. However, a coal-fed IGCC power plant has lower net plant efficiency compared to a conventional natural gas combined cycle (NGCC) power plant. A recent NETL study shows that the net plant efficiency of a coal-fed IGCC plant with a General Electric Energy (GEE)type gasifier is $38.2 \%$ compared to $50.8 \%$ efficiency for NGCC plants [1]. The net plant efficiency of the IGCC plant further decreases to $32.5 \%$ when the $\mathrm{CO}_{2}$ capture option is considered. In order to make IGCC technology more competitive, efforts should be exerted to improve its efficiency. Recently, an optimization study has been carried out for improving the efficiency of IGCC plants with $\mathrm{CO}_{2}$ capture [2]. The plant layout is shown in Figure 1. The study considered a GEE-type entrained flow gasifier mainly because of its high carbon conversion rates and environmental advantages [2,3]. In high temperature gasifiers, such as the GEEtype, the gasifier efficiency increases and the size of downstream equipment is reduced when oxygen, instead of air, is used in the gasifier [4]. Figure 1 shows that the shifted syngas from the gasifier goes to a SELEXOL ${ }^{\mathrm{TM}}$ solvent unit for acid gas removal. Use of oxygen in the gasifier increases the partial pressure of the acid gases at the inlet to the acid gas removal (AGR) unit. This, in turn, decreases the auxiliary energy consumption in the AGR unit because of a reduced circulation rate of the solvent (for a solvent-based AGR technology) and a decrease in the refrigeration duty, if refrigeration is considered. Even though the use of oxygen has a number of advantages, the NETL study shows that the air separation unit (ASU) in an GEE-gasifier-based IGCC plant with $\mathrm{CO}_{2}$ capture, consumes about $64 \%$ of the total auxiliary power and about $16 \%$ of the gross power when the power consumptions in the main air compressor (MAC), oxygen compressor, and nitrogen compressor are included [1]. 
Three product streams from an ASU are of interest for an IGCC plant as shown in Figure 1. The oxygen stream is mainly used in the gasifier while a small portion of it goes to the Claus unit for combusting hydrogen sulfide. It has been found that an oxygen purity of $95 \mathrm{~mol} \%$ is optimal for a cryogenic ASU $[4,5]$. A low-pressure nitrogen stream, produced from the low-pressure (LP) column of the ASU, is used as a fuel diluent for NOx reduction and power augmentation in the gas turbine (GT) so long as the oxygen concentration is less than $2 \mathrm{~mol} \%$ to prevent flashback [10]. Furthermore, a high purity nitrogen $\left(<50 \mathrm{ppm}_{2}\right)$ is also produced from the top of the high-pressure (HP) column for use in purges, pads, and sootblowing in the fuel transfer system and gasification plant [10].

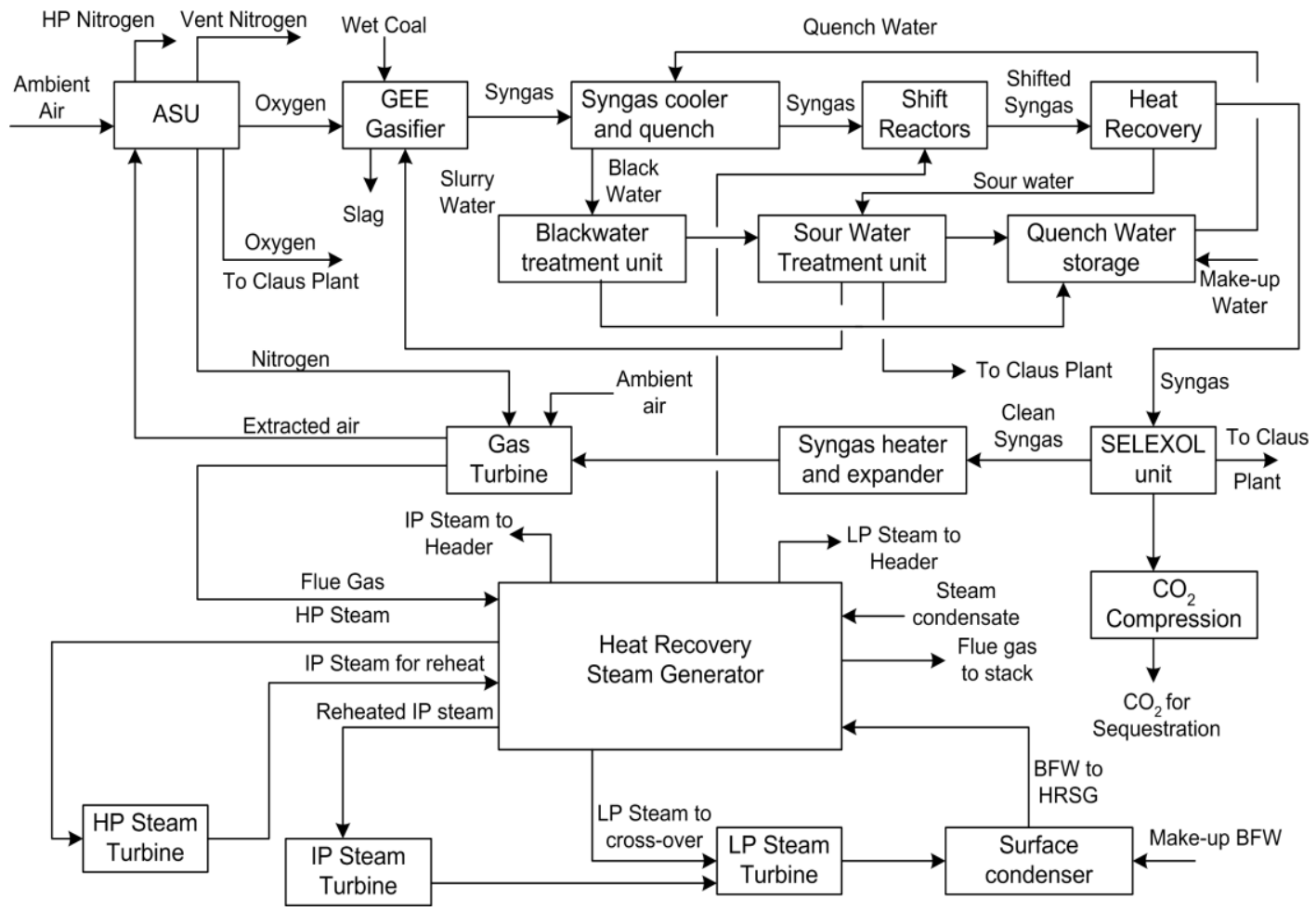

Figure 1. Block Flow Diagram of IGCC Power Plant with Carbon Capture

In the design of an ASU as part of an IGCC plant, the main design decisions are: operating pressure of the ASU and the phase of the products, mainly $\mathrm{O}_{2}$, withdrawn from the columns. Based on the operating pressure of the ASUs, they can be classified as low-pressure (LP) ASU or elevated-pressure (EP) ASU. The 
operating pressure of the HP column in an LP ASU is usually 4-7 atm compared to 10-14 atm in an EP-ASU. In addition, $\mathrm{O}_{2}$ can be withdrawn from the bottom of the LP column in gas phase, known as gaseous oxygen (GOX) cycle or in liquid phase known as liquid oxygen (LOX) cycle.

The ASU is generally operated at elevated pressures for IGCC plants since both the oxygen and nitrogen are required at high pressures for the gasifier and the GT, respectively. Even though the power consumptions in the oxygen and nitrogen compressors decrease in an elevated-pressure (EP) ASU, the power consumption in the MAC increases to compensate. In addition, the higher operating pressure in an EP-ASU also decreases the relative volatility of oxygen and nitrogen, causing significant separation challenges [8, 19, 21]. However, an optimal integration between the ASU and GT can significantly improve the power production in an IGCC plant as well as its operability. For air integration between the GT and MAC, a part of the ASU air is extracted from the GT. If a considerable portion of the ASU air is extracted from the GT, it is generally desirable to have the operating pressure of the ASU close to that of the gas turbine in order to maximize the savings in the oxygen and nitrogen compression $[6,7,8,10,21,31]$.

For a traditional standalone ASU, a gaseous oxygen (GOX) cycle is typically chosen. This cycle takes only gaseous products from the distillation columns and is less power intensive when products are desired at near atmospheric pressures [16]. However, a pumped liquid oxygen (PLOX) cycle, where liquid oxygen is withdrawn from the sump of the LP column, is generally chosen when the gasifier is operated at high pressures to increase IGCC efficiency and to decrease the size of equipment [27]. It is generally accepted that the operating pressure of a wet feed gasifier is limited by the delivery pressure of the oxygen [27]. There are safety related problems in compressing oxygen to high pressure [20]. In addition, the efficiency of the oxygen compressors is usually low [20]. 
When the liquid oxygen is removed from the system, one must efficiently recover the refrigeration contained in the liquid oxygen $[12,21]$. This can be achieved by condensing a high-pressure air or nitrogen stream by exchanging heat with the vaporizing oxygen stream in a cryogenic exchanger $[12,21]$. Pumping the oxygen to an intermediate or the final pressure provides the opportunity to reduce the size of the oxygen compressor or to eliminate it completely. In addition, with GOX cycles, hydrocarbons can accumulate in the sump of the LP column [26]. To avoid this safety hazard, a slip stream of liquid oxygen must be removed from the bottom of the LP column in a GOX cycle. A PLOX cycle eliminates this problem. A PLOX cycle provides additional degrees of freedom for optimization by choosing the pressure of the PLOX cycle, considering various sources of the high-pressure streams, and distributing the liquefied high-pressure stream optimally between the HP and the LP column in an ASU.

The discussions above shows that there are degrees of freedom available that can be utilized for developing an optimal design of the ASU and for optimizing the heat and power integration between different sections of an IGCC plant including the ASU. That is the focus of this paper. In particular, the following studies have been presented in this paper:

1. The first study is focused on an optimal design of an ASU with PLOX cycle. As mentioned previously, the refrigeration lost due to the withdrawal of liquid oxygen in a PLOX cycle can be recovered with high-pressure air and/or nitrogen. If high-pressure air is used for recovering the refrigeration, the compression ratio required is much less compared to nitrogen since a part of the MAC discharge air is compressed, stream 3 in Figure 2. In addition, the highpressure air stream does not cause any additional mass flow to the ASU system. However, a larger flow of the liquefied air to the system results in a lower flow of the vapor feed to the HP column. This results in a decrease in the reboiler 
duty of the LP column. A larger flow of the liquefied air directly to the LP column significantly affects the final product quality since it bypasses the HP column. Therefore, it becomes difficult to achieve the desired product quality as the amount of liquefied air increases. On the other hand, if a part of the LP product nitrogen is compressed and recycled to the system as a high-pressure stream, stream 4 in Figure 2, a penalty in the operating efficiency occurs because of the higher compression ratio and the additional mass flow [12]. However, a significant portion of this recycle nitrogen, if not all, can bypass the HP column and can be sent directly to the LP column as top reflux. This additional reflux helps to increase the operating pressure of the ASU without sacrificing the product qualities. In this paper, we have explored the possibility of using an optimal combination of both the high-pressure streams in order to further decrease the auxiliary power consumption. In addition, a sidedraw, stream 9 in Figure 2, withdrawn from an intermediate stage of the HP column and recycled to an intermediate stage in the LP column, has been considered to further optimize the ASU design for a PLOX cycle.

2. The second study focuses on optimal degree of air integration for the shifted syngas as applicable to an IGCC with pre-combustion $\mathrm{CO}_{2}$ capture. Most gas turbines are designed to be operated with natural gas, with an LHV of $48 \mathrm{MJ}$ $\mathrm{kg}^{-1}[7,9,13,17]$. When a lower energy fuel is used, such as syngas, with an LHV of 8-9 $\mathrm{MJ} \mathrm{kg}^{-1}$, more fuel (approximately 4-5 times the volumetric flow and 5-6 times the mass flow as compared to natural gas) [7] must be supplied, which may prevent a lot of the compressed air from being sent to the turbine due to volumetric/mass flow limitations. This extracted air can be used as an air feed to the ASU. Integration of the ASU with the GT presents the possibility of increasing the efficiency of an IGCC power plant by extracting air from the GT $[1,5-12,19]$ to use as a feed to the ASU. Several papers have 
been published on the integration of the ASU and GT [5-11, 19, 21, 28-30]. Most of these papers agree that the optimal degree of integration occurs when all nitrogen available from the ASU is sent to the GT and air that can not be sent through the GT, due to mass/volumetric flow limitations, is extracted for use as feed to the ASU. This level of air extraction is typically found to be around $25-50 \%$ for a syngas, which has a low heating value (LHV) of $8-9$ $\mathrm{MJ} \mathrm{kg}^{-1}$ [7]. For pre-combustion carbon capture in an IGCC plant, the syngas is shifted and cleaned before being sent to the GT $[7,8]$. The shifted hydrogenrich syngas has a much higher LHV of $43 \mathrm{MJ} \mathrm{kg}^{-1}$, close to that of natural gas, which is $48 \mathrm{MJ} \mathrm{kg}^{-1}$.

3. It has been suggested that in order to maximize the benefit of the high-pressure air available through air extraction an EP-ASU should be used so as to increase the savings from the decreased load on the MAC [6-11]. No quantitative study has been found within the open literature showing whether equivalent savings are possible from an LP-ASU using a PLOX cycle at varying degrees of air integration. Smith et al. [8] suggest that at degrees of integration below approximately $40 \%$, an LP-ASU with a PLOX cycle is comparable to that of an EP-ASU. In this paper, a study has been carried out for an IGCC plant with $\mathrm{CO}_{2}$ capture by comparing the net power production from an LP-ASU with a PLOX cycle with that of an optimal EP-ASU at varying levels of air integration.

4. Optimal operating pressure for the ASU is thought to depend upon the operating pressure of the GT, the degree of air integration, and the fraction of nitrogen injection [5-11, 19]. It is also thought that operating the ASU at a pressure near the operating pressure of the GT in the case of a high degree of air integration will maximize system efficiency, albeit accompanied by a challenge in system operability due to the varying pressure of the extracted air [8]. Frey 
and Zhu [6] found that when syngas humidification is used to reduce $\mathrm{NO}_{\mathrm{X}}$ formation, in combination with nitrogen injection, an LP-ASU is more efficient than an EP-ASU up until approximately $60 \%$ of the available nitrogen is injected. A study has been done on a steam injected GT with topping steam turbine [14] that also shows that at lower degrees of nitrogen injection, an LPASU is more efficient. In this paper, we have studied the effects of the degree of air integration on the optimal ASU operating pressure in an IGCC plant with $\mathrm{CO}_{2}$ capture when a combination of syngas humidification and nitrogen injection is performed to reduce $\mathrm{NO}_{\mathrm{X}}$ formation.

\section{Modeling of the ASU}

A simplified flowsheet of the ASU discussed in this paper is shown in Figure 2. Figure 2 shows the six configurations examined in this paper. However depending on the exact configuration, not all streams shown may be considered. Table 1 shows which streams are relevant for each configuration. Unnumbered streams are considered in all configurations. Table 1 also shows the final operating conditions for each configuration. 


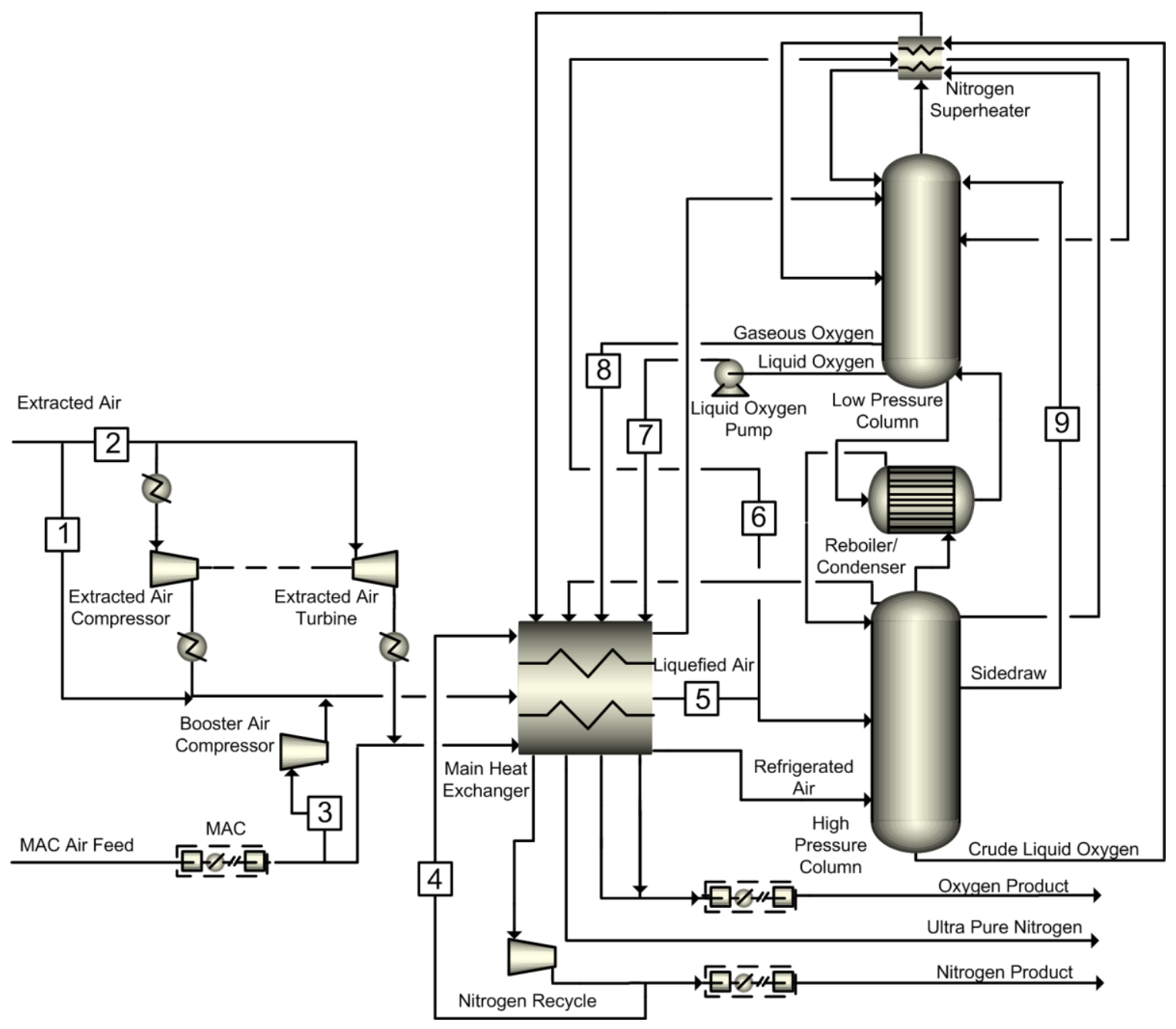

Figure 2: Simplified flowsheet of cryogenic air separation unit 
Table 1: Configuration of Streams for Different ASU Cycles

\begin{tabular}{|c|c|c|c|c|c|c|}
\hline Cycle & $\begin{array}{c}\text { Configuration } \\
\text { Number }\end{array}$ & $\begin{array}{c}\text { Active } \\
\text { Streams }\end{array}$ & $\begin{array}{c}\text { HP } \\
\text { Column } \\
\text { Pressure } \\
\text { [atm] }\end{array}$ & $\begin{array}{c}\text { LP } \\
\text { Column } \\
\text { Pressure } \\
\text { [atm] }\end{array}$ & $\begin{array}{c}\text { Nitrogen } \\
\text { Recycle } \\
\text { Flowrate } \\
{[\mathrm{kmol}} \\
\left.\mathrm{hr}^{-1}\right]\end{array}$ & $\begin{array}{c}\text { Liquid } \\
\text { Air } \\
\text { Flowrate } \\
{[\mathrm{kmol}} \\
\left.\mathrm{hr}^{-1}\right]\end{array}$ \\
\hline $\begin{array}{c}\text { LP with } \\
\text { PLOX }\end{array}$ & 1 & $3,5,6,7$ & 6.80 & 1.70 & - & 7150 \\
\hline $\begin{array}{c}\text { EP with } \\
\text { GOX }\end{array}$ & 2 & $3,5,8$ & 12.93 & 4.15 & - & 370 \\
\hline $\begin{array}{c}\text { EP with } \\
\text { PLOX } \\
\text { and } \\
\text { liquid } \\
\text { air }\end{array}$ & 3 & $3,5,6,7$ & 11.23 & 3.42 & - & 7150 \\
\hline $\begin{array}{c}\text { EP with } \\
\text { PLOX } \\
\text { and } \\
\text { nitrogen } \\
\text { recycle }\end{array}$ & 4 & 4,7 & 13.47 & 4.32 & 5750 & - \\
\hline $\begin{array}{c}\text { EP with } \\
\text { PLOX } \\
\text { and } \\
\text { liquid } \\
\text { air and } \\
\text { nitrogen } \\
\text { recycle }\end{array}$ & 5 & $3,4,5,7$ & 12.93 & 4.15 & 2320 & 3750 \\
\hline $\begin{array}{c}\text { EP with } \\
\text { PLOX, } \\
\text { liquid } \\
\text { air, } \\
\text { nitrogen } \\
\text { recycle, } \\
\text { and side } \\
\text { draw }\end{array}$ & 6 & $3,4,5,7,9$ & 12.93 & 4.15 & 1570 & 4870 \\
\hline
\end{tabular}

The ASU consists of a multi-stream heat exchanger (main heat exchanger) that recovers refrigeration from the product streams and cools the incoming streams. Products leave the main heat exchanger at near ambient temperatures 
after refrigerating one air stream and, if applicable, liquefying another air stream and the nitrogen reflux [21]. For Configurations 1, 3, 5, and 6 the refrigerated air stream leaves the main heat exchanger as a saturated vapor. For Configurations 1 and 3, refrigerated air flow represents approximately $70 \%$ of total air flow whereas in Configurations 5 and 6, refrigerated air flow represents approximately 85\% of the total air flow. For all configurations where nitrogen recycle is considered (Configurations 4, 5, and 6), it leaves the main heat exchanger as a saturated liquid. The liquefied air stream leaves the main heat exchanger as a saturated liquid. For both Configurations 2 and 4, refrigerated air leaving the main heat exchanger is superheated by approximately $10^{\circ} \mathrm{C}$. For Configuration 2 , the liquefied air stream, approximately $1 \%$ of total air flow, leaves the main heat exchanger as a saturated liquid. The air provided to the ASU, for cases when $100 \%$ integration with the GT is not chosen, comes from the MAC. The refrigerated air stream is then sent to the bottom of the high-pressure column. The refrigerated air stream provides the boilup for the HP column and the LP column via the coupled reboiler/condenser. The liquefied air stream is split with a portion being sent to the nitrogen superheater for subcooling and the remainder being sent to an intermediate stage of the HP column. The HP column, for studies considered here, operates at a pressure of $6.8 \mathrm{~atm}$ for the LP-ASU configuration and pressures between 11 and $13.5 \mathrm{~atm}$ for the EP-ASU configurations. The HP column consists of 50 valve trays with a total pressure drop of $41 \mathrm{kPa}$. The HP column yields a crude liquid oxygen product $\left[\sim 33 \mathrm{~mol} \% \mathrm{O}_{2}\right]$ from the bottom and an ultra-pure, high-pressure gaseous nitrogen product $\left[<50 \mathrm{ppm} \mathrm{O}_{2}\right.$ ] from the top [15].

The crude oxygen from the bottom and liquid nitrogen from the top of the HP column are subcooled in a multi-stream heat exchanger (nitrogen superheater) against the nitrogen vapor from the top of the LP column. The subcooled streams are sent to the LP column. The LP column, for the studies considered in this paper, 
operates at a pressure of $1.7 \mathrm{~atm}$ for the LP-ASU configurations and a pressure range of 3.4 to $4.3 \mathrm{~atm}$ for the EP-ASU configurations. The LP column is modeled as a packed column with an HETP of $0.35 \mathrm{~m}$ [18], 25 equivalent stages, and a total pressure drop of $6 \mathrm{kPa}$. Packing is generally chosen for this column because nitrogen product is desired at the highest possible pressure while still maintaining a $2.8^{\circ} \mathrm{C}$ temperature approach in the reboiler/condenser. The low-pressure nitrogen is sent to the nitrogen compressors, consisting of four intercooled compressors with an assumed isentropic efficiency of $89 \%$, where it is discharged at 31.6 atm. The oxygen product is sent to the oxygen compressors, consisting of four intercooled compressors with an assumed isentropic efficiency of $89 \%$, where it is discharged at $66.7 \mathrm{~atm}$. All product specifications for the ASU are given in Table 2. This study considers $100 \%$ nitrogen integration where the entire LP nitrogen stream produced by the ASU is sent to the GT as diluent.

Table 2: Product Specifications

\begin{tabular}{|l|c|l|}
\hline & Flowrate $\left[\mathrm{kmol} \mathrm{hr}^{-1}\right]$ & Purity \\
\hline $\mathrm{O}_{2}$ & 5970 & $95 \% \mathrm{O}_{2}$ \\
\hline Low-Pressure $\mathrm{N}_{2}$ & 22490 & $2 \% \mathrm{O}_{2}$ \\
\hline High-Pressure $\mathrm{N}_{2}$ & 680 & $50 \mathrm{ppm} \mathrm{O}_{2}$ \\
\hline
\end{tabular}

This process model was developed in the steady-state simulator, Aspen Plus, using the Peng-Robinson equation of state. Design specifications were used to control the following process variables:

1) The HP column reflux was manipulated to maintain high-pressure nitrogen purity.

2) The heating duty of the reboiler/condenser was manipulated to maintain a specified high-pressure nitrogen flow.

3) The liquid air flow split fraction between the HP and LP columns was manipulated to maintain low-pressure nitrogen purity for Configuration 3. 
4) The nitrogen reflux was manipulated to maintain low-pressure nitrogen purity for Configurations 4 and 5.

5) The refrigerated air temperature was manipulated to maintain low-pressure nitrogen purity for Configuration 2 .

6) The total liquefied air flow was manipulated to control oxygen purity for Configurations 2, 3, and 5 .

7) The refrigerated air temperature was manipulated to maintain oxygen purity for Configurations 1 and 4.

8) LP column pressure was manipulated to maintain a specified temperature approach within the reboiler/condenser.

\section{Modeling of the HRSG and GT with a topping steam turbine}

Fuel produced by this IGCC with $\mathrm{CO}_{2}$ capture system is a shifted, nonhumidified, hydrogen-rich syngas. For the studies discussed in this paper, fuel flow and properties are held constant and their values are shown in Table 3. The shifted syngas is fed to a power production GT, considered, for these case studies, to be similar to a GE 7FB $[7,8,9,15]$. As shown in Figure 3, the hot exhaust gas is used to generate high-pressure (HP), intermediate-pressure (IP), and lowpressure (LP) steam streams in a heat recovery steam generation unit (HRSG). The steam produced in the HRSG is then used to drive additional power-generating steam turbines. In addition to the combined cycle configuration, a steam injected GT with a topping steam turbine configuration has also been investigated [14]. In this configuration, steam generated in the HRSG is first used to drive high-pressure steam turbines and then is returned to the GT as a fuel diluent for inhibiting $\mathrm{NO}_{\mathrm{X}}$ formation. Figure 3 shows a simplified diagram of the HRSG and GT with a topping steam turbine. 
Table 3: Fuel Properties

\begin{tabular}{|c|c|}
\hline Flowrate [kmol hr-1] & 17383 \\
\hline Pressure [atm] & 31.3 \\
\hline Temperature $\left[{ }^{\circ} \mathrm{C}\right]$ & 193 \\
\hline Composition $[\mathrm{mol} \%]$ & \\
\hline Hydrogen & 91.1 \\
\hline Carbon Dioxide & 4.5 \\
\hline Carbon Monoxide & 1.9 \\
\hline Nitrogen & 1.3 \\
\hline Argon & 1.1 \\
\hline Water & 0.1 \\
\hline
\end{tabular}

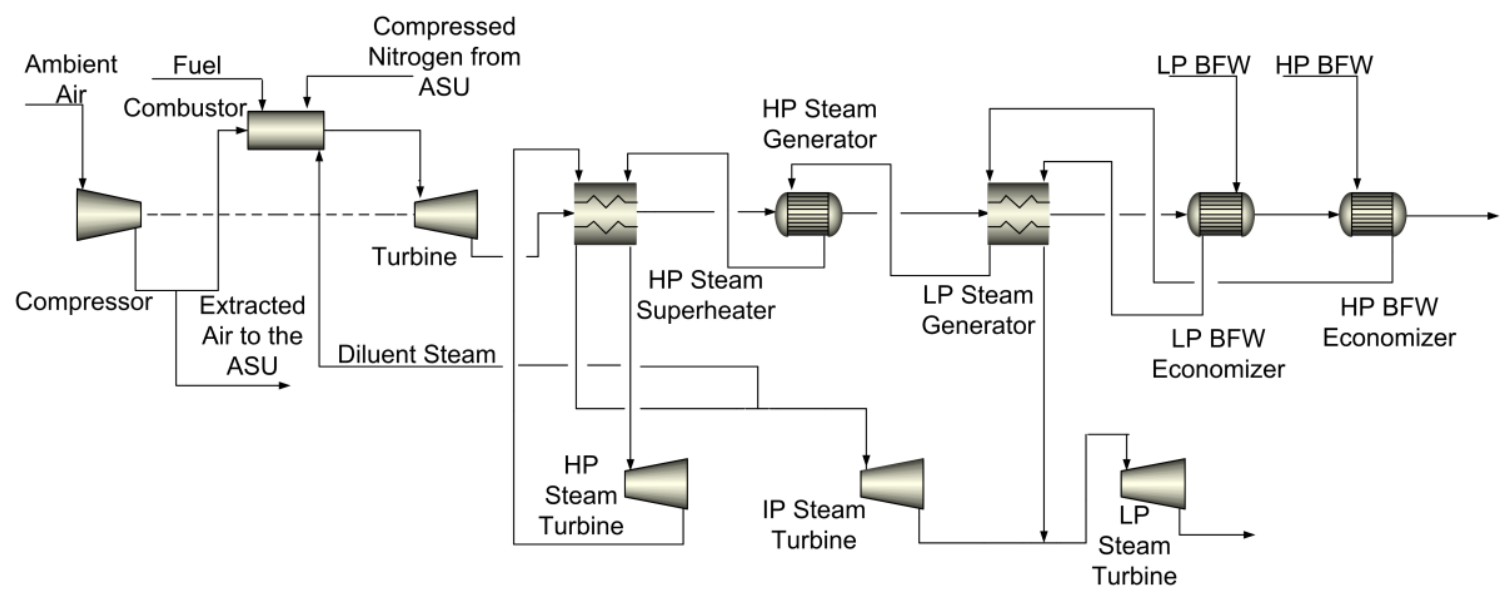

Figure 3. A simplified schematic of the HRSG and GT with a topping steam turbine

Increasingly stringent gas turbine emission control regulations may require single digit $\mathrm{NO}_{\mathrm{X}}$ concentrations [32]. To inhibit $\mathrm{NO}_{\mathrm{X}}$ formation in the GT, nitrogen and steam dilution is considered. To determine $\mathrm{NO}_{\mathrm{X}}$ concentration in the flue gas from the gas turbine, an empirical relation was developed based on data presented by $\mathrm{GE}$ on $\mathrm{NO}_{\mathrm{X}}$ formation with a hydrogen-rich fuel with steam dilution and syngas with nitrogen dilution $[13,25]$. Equations $1 \mathrm{a}$ and $1 \mathrm{~b}$ and Figure 4 are the correlations used to predict $\mathrm{NO}_{\mathrm{X}}$ concentration based on the LHV of the fuel with nitrogen dilution and fit against published GE data. Equations $2 \mathrm{a}$ and $2 \mathrm{~b}$ and 
Figure 5 are the correlations used to predict $\mathrm{NO}_{\mathrm{X}}$ concentration based on the LHV of the fuel with steam dilution and are fit against published GE data.

$$
\begin{gathered}
\text { For } \mathrm{LHV} \leq 6.71 \frac{\mathrm{MJ}}{\mathrm{m}^{3}} ; \mathrm{NO}_{\mathrm{x}} \quad \text { ppmvd }=1.918 \exp \left(9.032 \times 10^{-4} \mathrm{LHV}\left[\frac{\mathrm{MJ}}{\mathrm{m}^{3}}\right]\right) \\
\text { For LHV }>6.71 \frac{\mathrm{MJ}}{\mathrm{m}^{3}} ; \mathrm{NO}_{\mathrm{x}} \quad \text { ppmvd }=10.33 \exp \left(5.63 \times 10^{-4} \mathrm{LHV}\left[\frac{\mathrm{MJ}}{\mathrm{m}^{3}}\right]\right)
\end{gathered}
$$

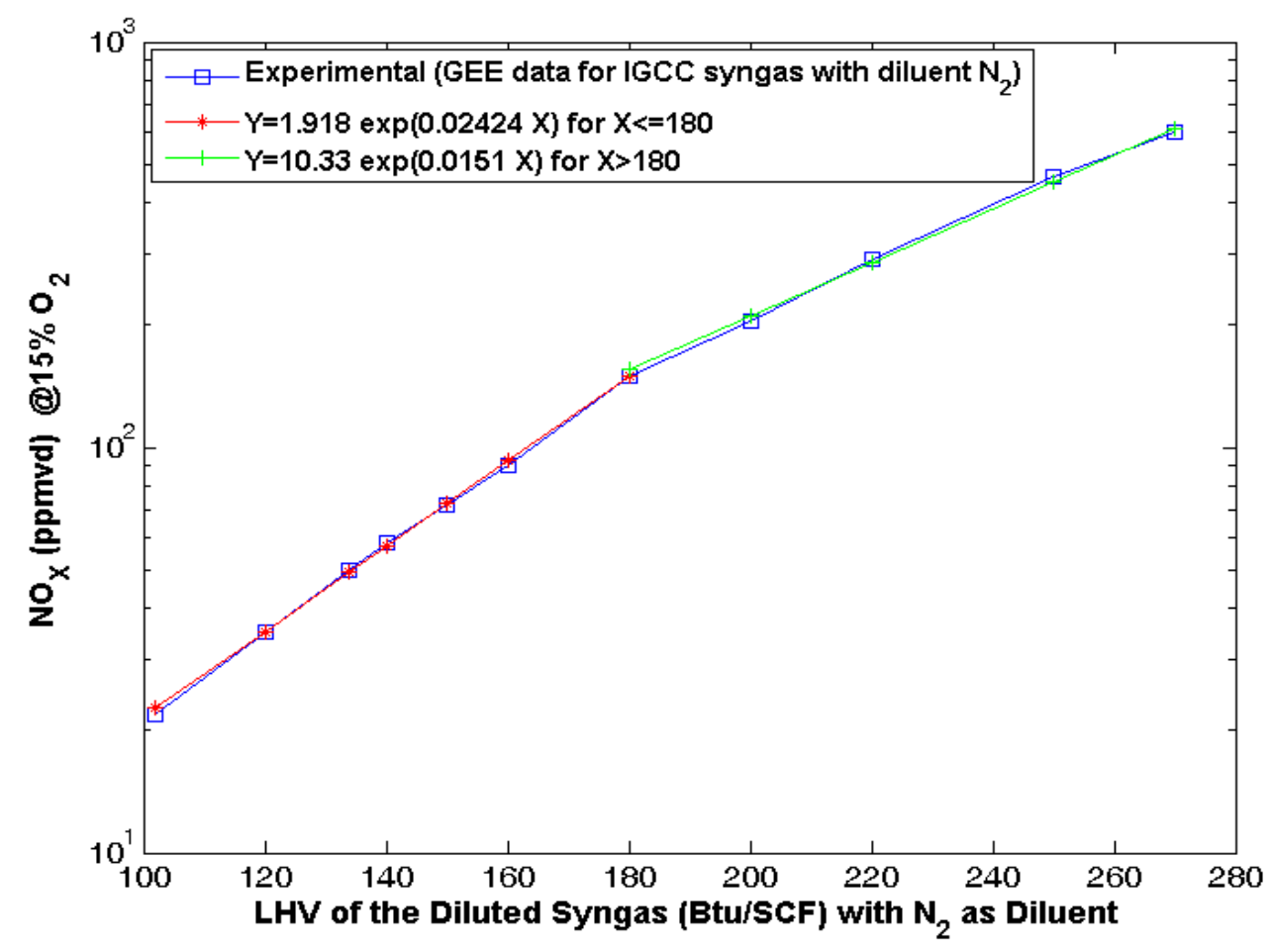

Figure 4: $\mathrm{NO}_{\mathrm{X}}$ (ppmvd) vs LHV of the Diluted Syngas (Btu/SCF) when $\mathrm{N}_{2}$ is used as a Diluent $[13,25]$

$$
\begin{aligned}
& \text { For } \mathrm{LHV} \leq 6.71 \frac{\mathrm{MJ}}{\mathrm{m}^{3}} ; \mathrm{NO}_{\mathrm{x}} \quad \text { ppmvd }=0.07787 \times \exp \left(0.001404 \times \mathrm{LHV}\left[\frac{\mathrm{MJ}}{\mathrm{m}^{3}}\right]\right) \\
& \text { For LHV }>6.71 \frac{\mathrm{MJ}}{\mathrm{m}^{3}} ; \mathrm{NO}_{\mathrm{x}} \quad \text { ppmvd }=0.6255 \times \exp \left(0.001 \times \mathrm{LHV}\left[\frac{\mathrm{MJ}}{\mathrm{m}^{3}}\right]\right)
\end{aligned}
$$




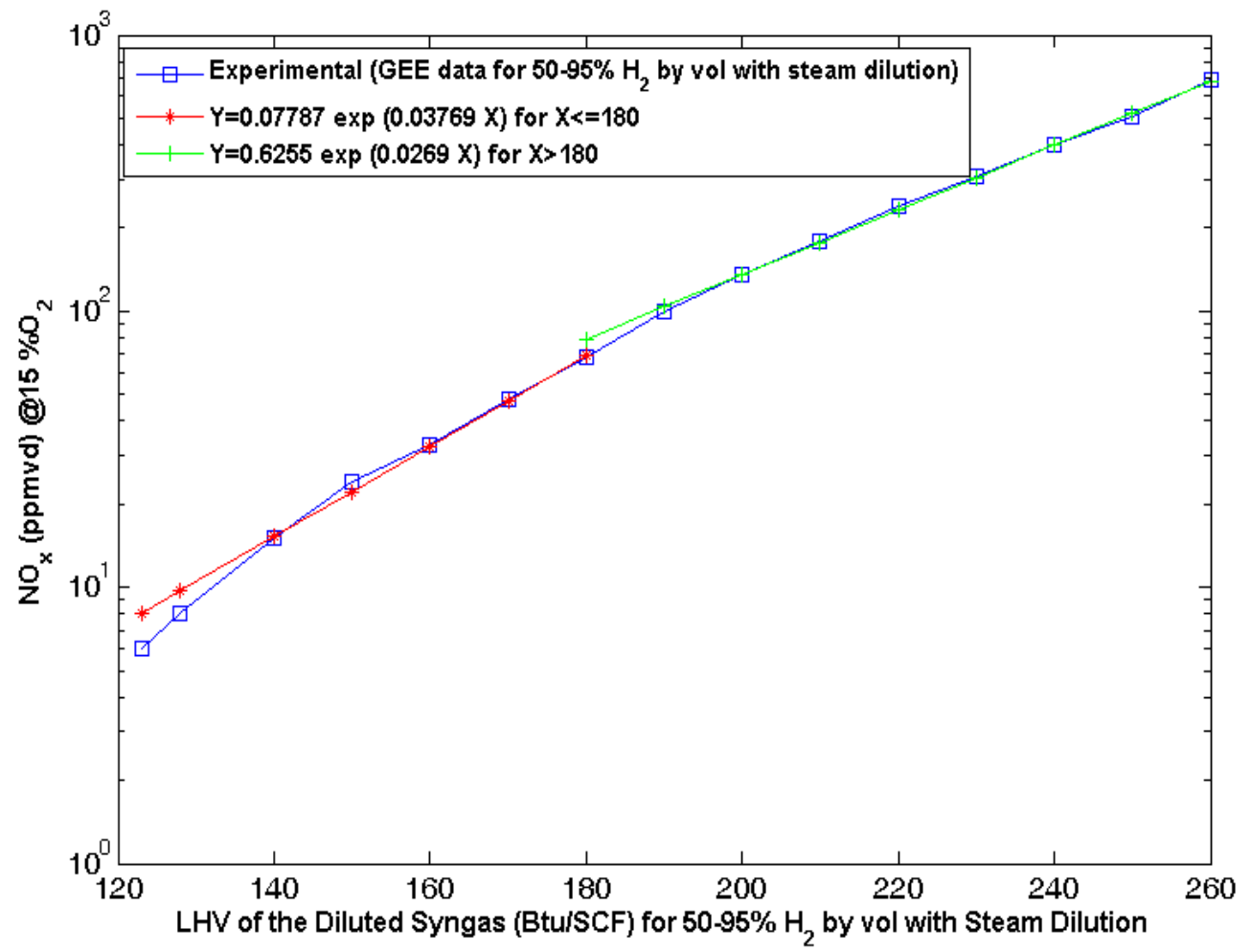

Figure 5: $\mathrm{NO}_{\mathrm{X}}$ (ppmvd) vs LHV of the Diluted Syngas (Btu/SCF) with 50-95\% $\mathrm{H}_{2}$ by volume when steam is used as a Diluent $[13,25]$

\section{Results and Discussion}

Configuration 1, described in Table 1, was simulated at an HP column operating pressure of $6.80 \mathrm{~atm}$ and a corresponding LP column operating pressure of $1.70 \mathrm{~atm}$. This configuration employs a PLOX cycle. Since, for all studies discussed in this paper, the number of stages for both the HP and LP columns were left constant and since the relative volatility of nitrogen and oxygen is higher for this configuration compared to the other configurations, which are run at elevated pressures, the low-pressure nitrogen purity is higher than specification. For this Configuration, low-pressure nitrogen purity is $99 \mathrm{~mol} \% \mathrm{~N}_{2}\left(1 \mathrm{~mol} \% \mathrm{O}_{2}\right)$. This configuration was run with a PLOX cycle which, without a high-pressure air source, was pumped to a pressure of $255 \mathrm{kPa}$. Further pumping of the liquid oxygen is possible if a booster compressor is used to compress the air to be 
liquefied. However, with this configuration, and all configurations with a PLOX cycle, as the pressure of the streams to be liquefied is increased, the flows of these streams must also be increased. As the pressure of the streams to be liquefied is increased, higher flows are required to maintain the same amount of heat exchange with the liquid oxygen. For example, when condensing saturated gaseous air, $76 \%$ more air at $29.6 \mathrm{~atm}$ is required for the same enthalpy change as compared to an air stream at 15.4 atm mainly because of an elevated condensation temperature due to increase in pressure. As shown in Table 4, although this configuration does not require nitrogen recycle, the power required to compress products to the delivery pressure is large, representing $59 \%$ of the total ASU power requirement.

Configuration 2, described in Table 1, was completed at an HP column operating pressure of 12.93 atm and a corresponding LP column operating pressure of $4.15 \mathrm{~atm}$. This configuration uses a gaseous oxygen cycle. This is a more conventional configuration with little or no integration with the GT and, as shown in Tables 1 and 4, requires neither a booster compressor nor nitrogen recycle. However, this cycle requires that all oxygen compression be accomplished through the oxygen compressors, which have safety and efficiency issues associated with them [20]. In addition, since hydrocarbons can accumulate within the liquid oxygen sump of the LP column, a liquid draw is often still required for safety reasons [26]. However, withdrawal of only gaseous oxygen from the LP column helps in generating more liquid and vapor traffic in both the HP and LP columns compared to a PLOX cycle.

Configuration 3 was simulated at an HP column operating pressure of 11.23 atm and a corresponding LP column operating pressure of $3.42 \mathrm{~atm}$. This configuration utilizes a PLOX cycle. This configuration splits the liquid air generated in the main heat exchanger between the HP column and LP column after subcooling in the nitrogen superheater. The operating pressure for this 
configuration is limited due to the medium used to recover the liquid oxygen refrigeration. As mentioned before, the increased liquid air flow to either column presents separation challenges. To overcome these issues, the operating pressure must be decreased to increase the relative volatility of nitrogen and oxygen. Due to the decreased operating pressure, the power required to compress products to delivery pressure increases, representing $53 \%$ of the total ASU power requirement. This configuration does yield a high power savings via pumping the liquid oxygen; however, the degree of pumping is limited, due to the high pressure to which the air to be liquefied must be compressed.

Configuration 4 was completed at an HP column operating pressure of 13.47 atm and a corresponding LP column operating pressure of $4.32 \mathrm{~atm}$. This configuration utilizes a PLOX cycle. The refrigeration of the liquid oxygen is recovered via a nitrogen stream which is then sent to the top of the LP column as reflux. This configuration allows higher ASU operating pressures, which decreases nitrogen compression costs, as shown in Table 4. However, little to no power savings are seen in pumping the liquid oxygen, as shown in Figure 6, as a nearly equivalent amount of power must be used to increase the pressure of the nitrogen recycle as that saved in the oxygen compressors.

Configuration 5 was completed at an HP column operating pressure of 12.93 atm and a corresponding LP column operating pressure of $4.15 \mathrm{~atm}$. This configuration again uses a PLOX cycle. Both liquid air and a nitrogen recycle are used to recover liquid oxygen refrigeration. By using both to recover refrigeration, the operating pressure of the ASU can be increased via the nitrogen recycle, and it is possible to achieve considerable power savings by pumping the liquid oxygen, as shown in Figure 6. A summary of the power requirements is shown in Table 4.

The nitrogen recycle can produce the desired nitrogen and oxygen purities required for an IGCC power plant even at high operating pressures; however, it is a 
very power intensive option [12]. Therefore Configuration 6 was considered in an attempt to maintain the high operating pressure of the ASU and decrease the quantity of nitrogen recycle required to maintain product purities. Configuration 6 was run at the same HP and LP column operating pressures as Configuration 5, but with the inclusion of the sidedraw, Stream 9 in Figure 2. The sidedraw takes liquid nitrogen from an intermediate stage in the HP column and sends it to an intermediate stage in the LP column. The effect of this sidedraw, in the region studied, helps to improve the crude oxygen purity from the HP column, as shown in Figure 7. This, in turn, helps to recover more refrigeration from the liquid oxygen via the liquid air, as shown in Figure 8. As the flow of the liquid air to the HP column increases, the heating duty of the reboiler/condenser is decreased, as shown in Figure 9, resulting in less boilup in the LP column. These advantages result in a 1.2 MW decrease in the ASU power requirement by decreasing the nitrogen recycle required to maintain product purities, as shown in Figure 10. However, as the sidedraw is increased further, the separation achieved in the LP column is reduced because of a reduced boilup ratio. Therefore, even though the crude oxygen purity keeps increasing with an increase in the sidedraw flow, the refrigeration recovered through the air needs to be decreased to increase the boilup ratio in the LP column that is required to achieve the desired separation. This study shows that there exists an optimum flowrate of the sidedraw for minimizing the auxiliary power consumption. 
Table 4: Power requirements for ASU configurations

\begin{tabular}{|c|c|c|c|c|c|c|}
\hline $\begin{array}{l}\text { Configuration } \\
\text { Number }\end{array}$ & $\begin{array}{l}\text { MAC } \\
{[\mathrm{MW}]}\end{array}$ & $\begin{array}{l}\mathrm{N}_{2} \\
{[\mathrm{MW}]}\end{array}$ & $\begin{array}{l}\mathrm{O}_{2} \\
{[\mathrm{MW}]}\end{array}$ & $\begin{array}{l}\text { Booster } \\
{[\mathrm{MW}]}\end{array}$ & $\begin{array}{l}\mathrm{N}_{2} \\
\text { Recycle } \\
{[\mathrm{MW}]}\end{array}$ & $\begin{array}{l}\text { Total } \\
\text { Power } \\
{[\mathrm{MW}]}\end{array}$ \\
\hline 1 & 55.10 & 58.32 & 19.84 & - & - & 133.26 \\
\hline 2 & 72.08 & 41.64 & 15.94 & - & - & 129.66 \\
\hline 3 & 66.23 & 57.81 & 15.30 & 1.49 & - & 140.83 \\
\hline 4 & 73.20 & 40.74 & 14.49 & - & 6.56 & 134.99 \\
\hline 5 & 72.08 & 41.64 & 12.83 & 0.59 & 3.99 & 131.13 \\
\hline 6 & 72.08 & 41.64 & 12.83 & 0.73 & 2.70 & 129.98 \\
\hline
\end{tabular}

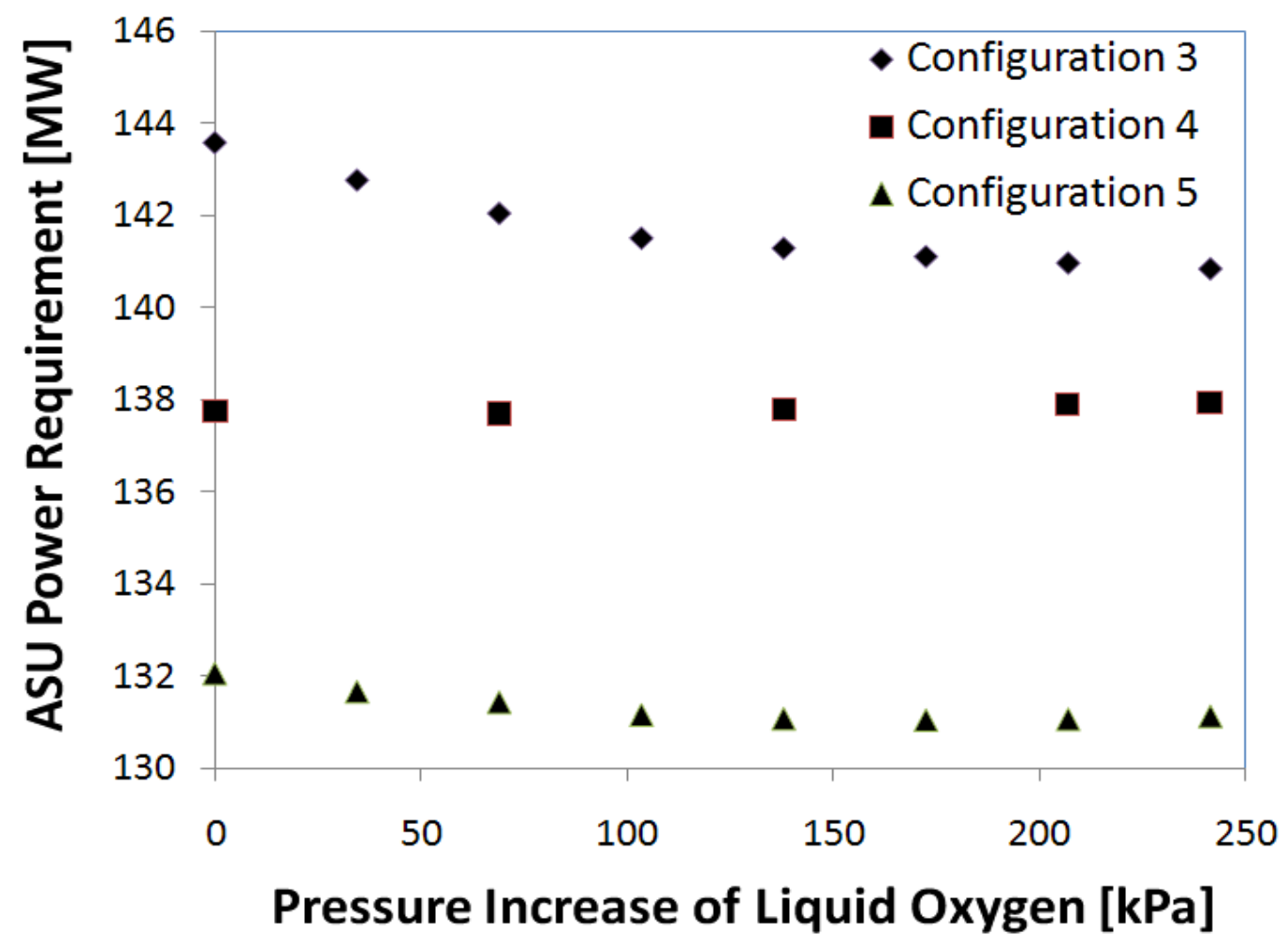

Figure 6. ASU power requirements for varying cycles and degree of liquid oxygen pumping 


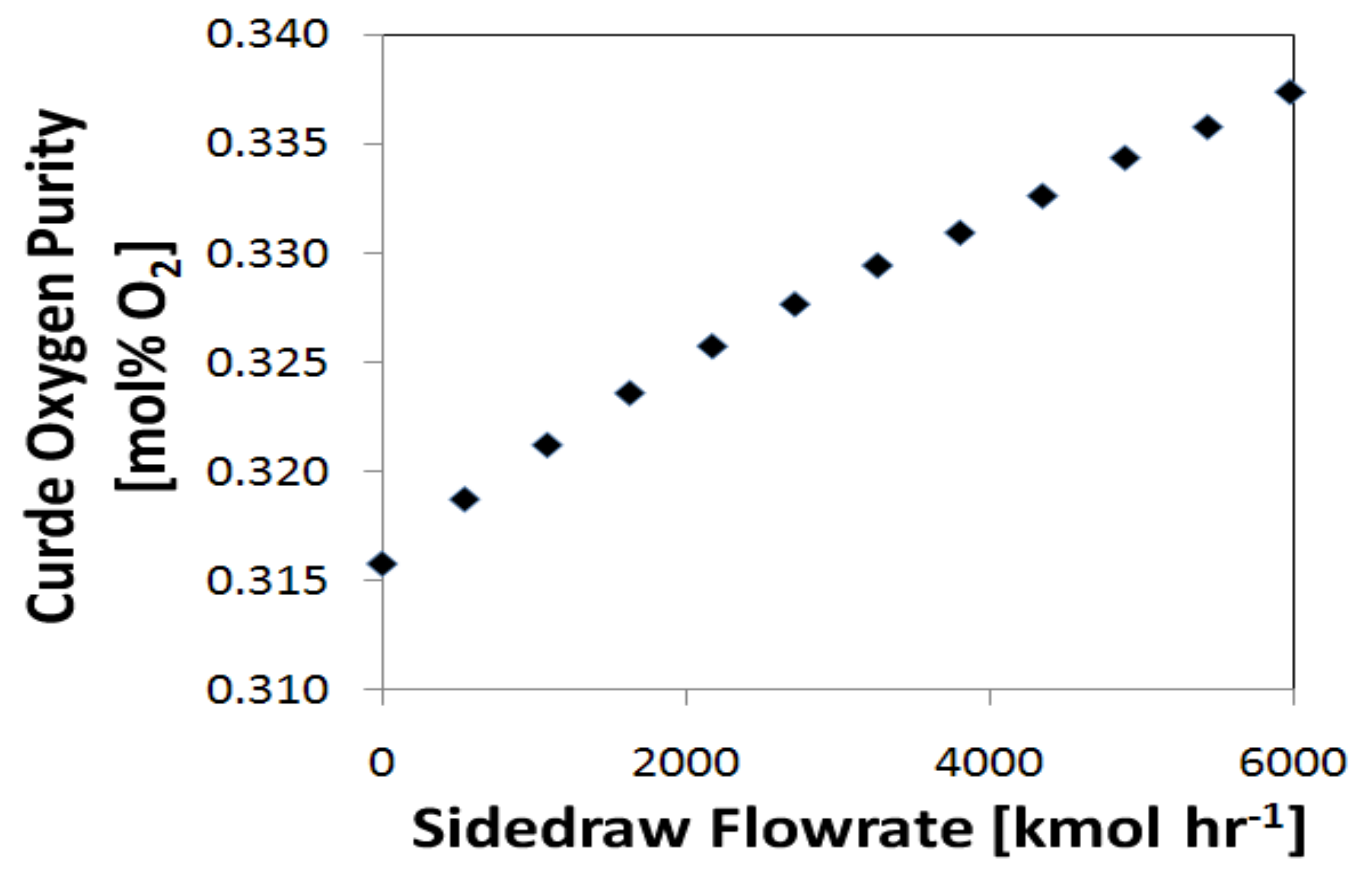

Figure 7. Sidedraw effect on crude oxygen purity

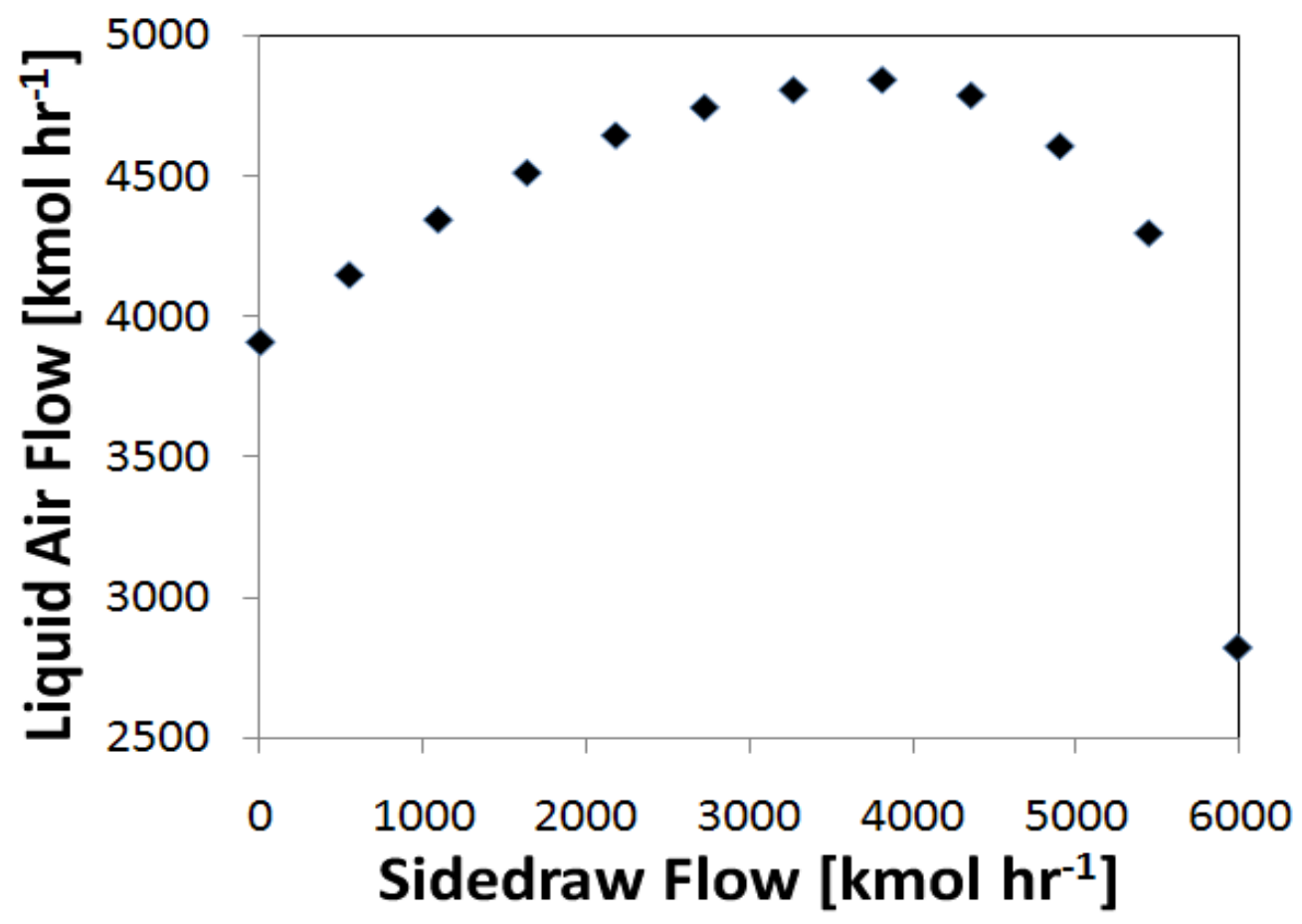

Figure 8. Sidedraw effect on liquid air flowrate 


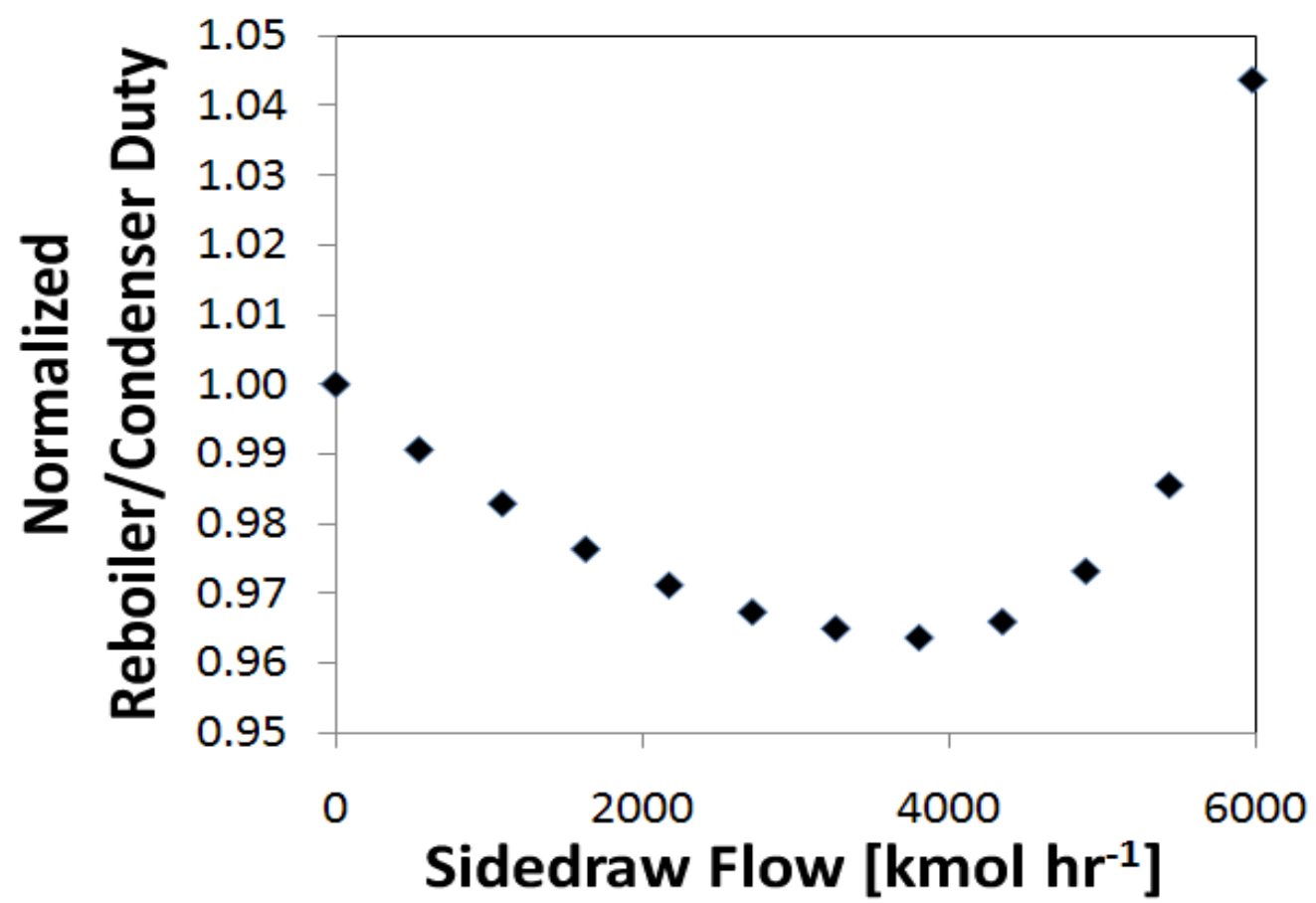

Figure 9. Sidedraw effect on reboiler/condenser duty

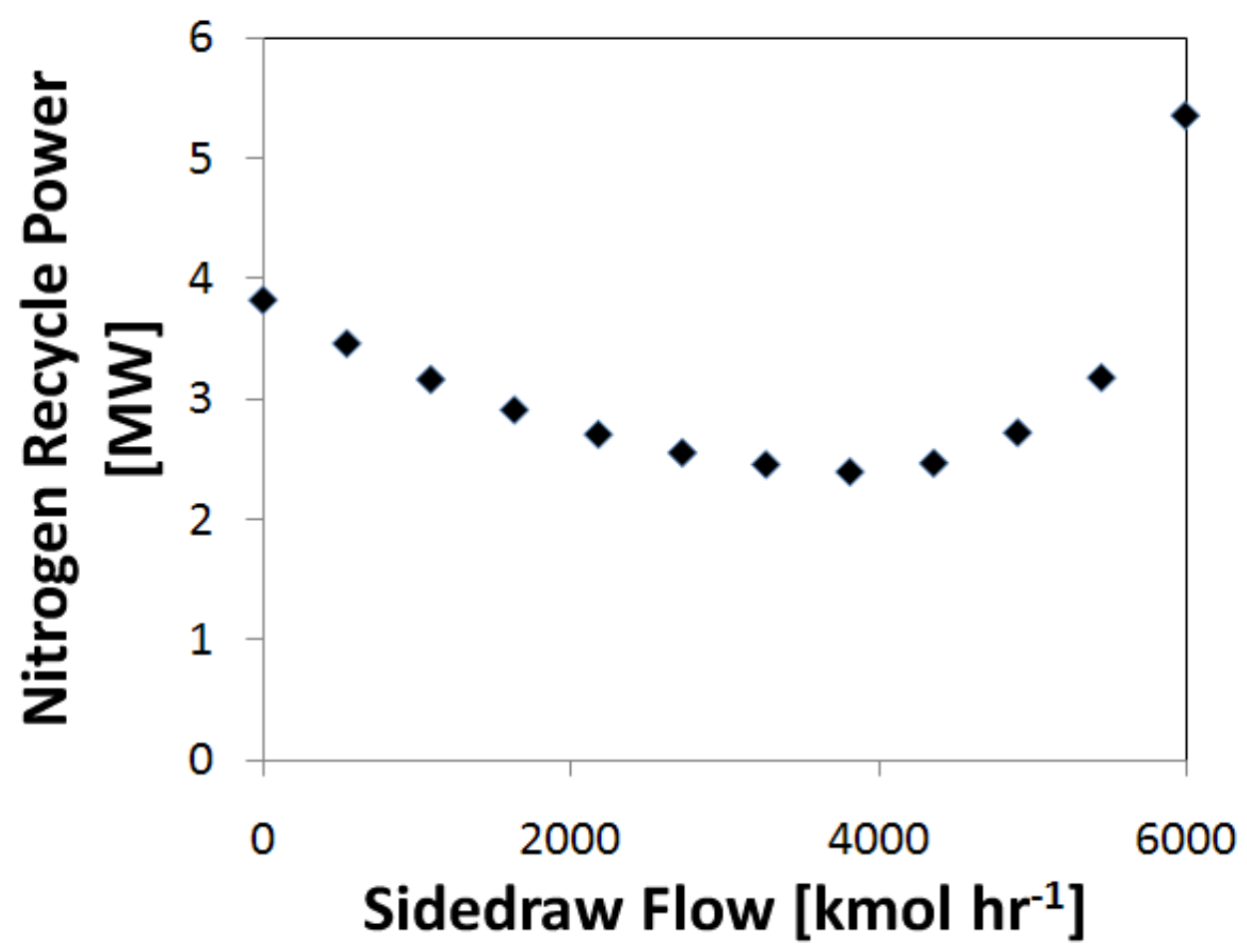

Figure 10. Sidedraw effect on nitrogen recycle power requirement 
The large differences in the power requirements of the different configurations is due to the operating pressure at which each configuration must be run in order to satisfy the product quality requirements. For example, as mentioned previously, the maximum operating pressure in Configuration 3 is limited because of using air for recovering the refrigeration. Whereas in Configuration 4 , the operating pressure of the ASU can be increased, yielding power savings in product compression. Additionally, Configurations 3 and 5 allow for higher degrees of liquid oxygen pumping and although little to no savings may be possible, this may still be desired in order to eliminate a stage in the oxygen compressors. However, for Configuration 3, increased degrees of liquid oxygen pumping would require a decrease in ASU operating pressure since the increasing pressure of the liquid air yields higher vapor fractions when flashed, resulting in insufficient reflux being provided to maintain product specifications.

This study shows that an ASU with PLOX cycle can have auxiliary power consumption similar to that of an ASU with GOX cycle, if optimally designed. The added advantages of the PLOX cycles are increased safety, and availability of the plant in addition to savings in the cost of the oxygen compressor.

\section{Integration}

\section{Higher Heating Value Fuels}

For the studies discussed in this section, two power producing gas turbines, with a frame similar to a GE $7 \mathrm{FB}$, are considered $[13,15]$. For the studies presented here, a shifted, hydrogen-rich syngas is considered, fuel properties are shown in Table 3. The composition is shown in Table 3. The fuel gas has an LHV of $43 \mathrm{MJ} \mathrm{kg}^{-1}$. Because this fuel has a calorific value near that of natural gas, mass and volumetric flow limitations are different than when using unshifted syngas. The main combustible component in the unshifted syngas is $\mathrm{CO}$ whereas the shifted syngas has mostly hydrogen. Even though pure hydrogen has lower LHV 
compared to $\mathrm{CO}$ on volumetric basis, the concentration of combustibles in an unshifted syngas is $64 \%$ compared to $93 \%$ in shifted syngas. This results in a higher volumetric LHV of the shifted syngas in comparison to the unshifted syngas. The assumed mass and volumetric flow limitations are presented in Table 5 [6]. Results of the study on the effect of the percent of air integration, defined as the percentage of the total ASU air supply requirement being provided by air extraction from the GT are presented in Figure 11 for ASU operating pressures of $12.24 \mathrm{~atm}, 12.93 \mathrm{~atm}$, and $13.95 \mathrm{~atm}$. This study was carried out with Configuration 5 with the addition of Stream 1 shown on Figure 2. A summary of the individual power requirement of the ASU at the operating pressure of 12.93 atm and power production in the power block are shown in Table 6 . Table 6 shows that the power consumption in the MAC monotonically decreases, as expected, with increase in air integration. As the nitrogen from the ASU gets completely depleted at about $9 \%$ integration, there is no more increase in the power consumption by the nitrogen compressor. As nitrogen gets depleted, the power produced by the GT keeps decreasing as more air is extracted beyond this level of integration. The extent of power saving in the MAC is less than the loss in the generated power from the GT as the level of air integration is increased further. This is in qualitative agreement with the literature $[6-11,19,21]$ where similar findings have been reported for lower energy fuels. Importantly, the ASU operating pressure has a negligible effect on power production. This is due to the cost of oxygen compression for all pressure cases being equivalent to pump the liquid oxygen to the same pressure. However, the pressure that the liquid oxygen can be pumped is determined by the pressure of the streams to be liquefied, and since the pressure of the extracted air is constant for all cases, the pressure of the oxygen sent to the oxygen compressors is constant [20]. The advantage of operating the ASU at a high pressure is in the decrease in nitrogen compression 
costs $[6-10,21]$. However, this effect is relatively small due to the need to reflux more nitrogen to maintain product purities. The optimal found here is lower than that found in other studies $[6-11,19,21]$ since the fuel considered is a higher energy fuel when compared to syngas. As a result, less fuel must be sent to the GT for the same power output, thereby making mass and volumetric flow limitations less of an issue. Since the hydrogen-rich fuel has a heating value, on a mass basis, close to that of natural gas, torque limitations due to increased mass flow through the turbine are less significant. However, as the hydrogen-rich fuel still has a lower heating value on a volumetric basis when compared to natural gas, so the surge problem may still be present for a hydrogen-rich fuel similar to unshifted syngas. However, the hydrogen-rich fuel considered here has an LHV of 9.4 MJ $\mathrm{m}^{-3}$, requiring only 3.7 times the volumetric flow of fuel as compared to natural gas. Compared to syngas, that has a LHV of $7.1-7.8 \mathrm{MJ} \mathrm{m}^{-3}$ [7], requiring 5 times the volumetric flow of fuel as compared to natural gas.

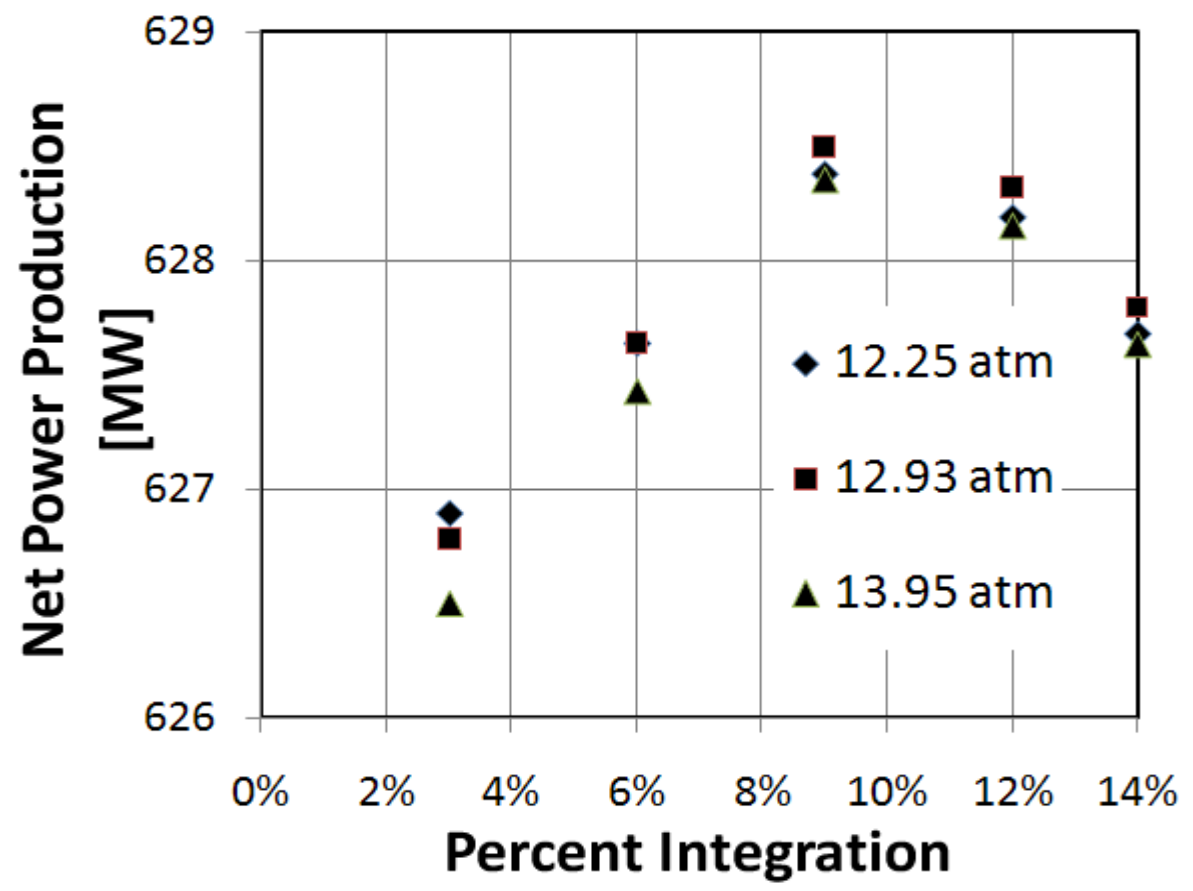

Figure 11. Power production with varying degrees of integration and ASU operating pressure for Configuration 5 with air integration 
Table 5. Assumed flow limitations for gas turbine

\begin{tabular}{|c|c|}
\hline Maximum mass flowrate $\left[\right.$ tonne $\left.\mathrm{hr}^{-1}\right]$ & 1,905 \\
\hline Maximum volumetric flowrate $\left[\mathrm{m}^{3} \mathrm{hr}^{-1}\right]$ & 244,900 \\
\hline
\end{tabular}

Table 6. Power summary for the 12.9 atm case using Configuration 5 with air integration

\begin{tabular}{|c|c|c|c|c|c|c|}
\hline $\begin{array}{c}\text { Percent } \\
\text { Air } \\
\text { Integration }\end{array}$ & $\begin{array}{c}\text { MAC } \\
{[\mathrm{MW}]}\end{array}$ & $\begin{array}{c}\text { Nitrogen } \\
\text { Compressors } \\
{[\mathrm{MW}]}\end{array}$ & $\begin{array}{c}\text { Oxygen } \\
\text { Compressors } \\
{[\mathrm{MW}]}\end{array}$ & $\begin{array}{c}\text { Booster } \\
\text { Compressor } \\
{[\mathrm{MW}]}\end{array}$ & $\begin{array}{c}\text { Nitrogen } \\
\text { Recycle } \\
{[\mathrm{MW}]}\end{array}$ & $\begin{array}{c}\text { Power } \\
\text { Block } \\
{[\mathrm{MW}]}\end{array}$ \\
\hline 3 & 69.9 & 38.1 & 13.4 & 0.3 & 3.8 & 752.3 \\
\hline 6 & 67.8 & 39.9 & 13.4 & 0.2 & 3.8 & 752.7 \\
\hline 9 & 65.6 & 41.7 & 13.4 & 0.1 & 3.8 & 753.0 \\
\hline 12 & 63.4 & 41.7 & 13.4 & 0.0 & 3.8 & 750.6 \\
\hline 14 & 62.0 & 41.7 & 13.4 & 0.0 & 3.8 & 748.6 \\
\hline
\end{tabular}

\section{Optimal ASU configuration at varying degrees of air integration}

There are several studies within the open literature that have shown that optimal air integration occurs at $25-50 \%$ with a low energy fuel such as syngas [6$11,19,21]$. In the study presented above for a shifted syngas, the optimal air integration is about $9 \%$. However the coal-fed IGCC plants in the USA, Polk and Wabash River, have $0 \%$ air integration [15]. Whereas, the coal-fed IGCC plants in Europe, Buggenum and Puertollano have 100\% air integration [7]. When 100\% integration is chosen, no MAC is required. In addition, the GT compressors are typically more efficient than the MAC [7]. However, 100\% integration results in longer start-up times and presents operability issues [7]. The studies in this section are intended to address optimal ASU configuration as the degrees of air integration are varied in from 10 to $100 \%$.

Smith et al. [8] have suggested that at degrees of air integration lower than $40 \%$, an LP-ASU with a PLOX cycle is comparable to an EP-ASU. Smith and Klosek [11] also suggested that at air integration levels less than $25 \%$, the operating pressure of the ASU can be set independently of the operating pressure 
of the GT. Air extraction, in the case of an EP-ASU, yields power savings via the decreased load on the MAC, which in the case of the EP-ASU can represent as much as $61 \%$ of the total ASU power requirement [15]. In the case of an LP-ASU, power savings are still seen in the decreased load on the MAC; however, the MAC power represents as little as $42.2 \%$ of the total power requirement. Since the pressure to which the liquid oxygen can be pumped is determined by the pressure of the streams to be liquefied, the pressure of the extracted air will set this pressure whether an EP or LP configuration is chosen [20], assuming that extracted air flow is sufficiently high to efficiently recover the liquid oxygen refrigeration or that a booster compressor is used to compress a portion of the MAC discharge to the pressure of the extracted air. However, if a configuration like that shown in Figure 2, Stream 2, is chosen, extracted airflow that is higher than the required liquid airflow, approximately $30 \%$ for the LP-ASU and $15 \%$ for the EP-ASU, can be sent through a turbine, discharged to the pressure of the MAC and used to power a compressor to compress the air stream that will be liquefied. With the higherpressure air stream available, pumping the oxygen to higher pressure is possible. With the operation of an LP-ASU, a larger pressure drop is attained in the turbine, further increasing the pressure of the air stream to be liquefied. It should be noted that in the studies considered here that the isentropic efficiency of both the compressor and turbine were assumed to be $72 \%$.

For this study, Configuration 1 is considered for the LP-ASU case, Configuration 5 with an HP column operating pressure of $12.25 \mathrm{~atm}$ is considered for the EP-ASU with PLOX, and Configuration 2 is considered for the EP-ASU with GOX. For all levels of integration investigated in this study, it is assumed all low-pressure nitrogen produced in the ASU can be sent to the GT without exceeding mass or volumetric flow limitations. At lower levels of air integration, where extracted air flow is less than that required to recover liquid oxygen 
refrigeration, a booster air compressor, Stream 3 in Figure 2, is used to further compress a portion of the MAC discharge to the pressure of the extracted air [12, 20]. At higher degrees of air integration, where extracted air flow is greater than that required to recover the liquid oxygen refrigeration, approximately $15-30 \%$ of the total air flow depending on the configuration, the extra air is sent to a turbine to further compress the flow that will be liquefied and then mixed with the MAC discharge. Figure 12 shows the result of this study where power savings is defined as the difference in the power requirement of each configuration from the base case values at $0 \%$ air integration. The total power requirement of each configuration at $0 \%, 30 \%, 60 \%$, and $100 \%$ air integration is provided in Table 7 . This Figure shows that at lower levels of air integration, the power savings are as much as 1.2 MW higher for Configuration 1 than for Configuration 2 and $0.5 \mathrm{MW}$ higher than Configuration 5. While at higher degrees of air integration of approximately 50 $60 \%$, all configurations yield nearly equivalent power savings. Above this level of integration, Configuration 2 yields up to $5.1 \mathrm{MW}$ more power savings than Configuration 1 and up to $2.2 \mathrm{MW}$ more power savings than Configuration 5 . Although the pressure of the liquid oxygen can always be increased past $20-30 \%$ integration for Configurations 1 and 5, as shown in Figure 13, the power savings in the oxygen compressors and MAC for Configuration 1 are not as large as the power savings in the MAC for Configuration 2. Additionally, beyond an air integration level of $40 \%$, the cost of increasing the pressure of the nitrogen recycle is higher than the power savings in the oxygen compressors which causes power savings to decrease with further liquid oxygen pumping. In addition, little additional increase in the liquid oxygen pressure is possible beyond $60 \%$ for Configuration 5 due to higher flows of liquid air being required as the pressure of the liquid air is increased, resulting in less extracted air being sent through the turbine, this can be seen in Table 8. Because of this, little increase in pressure of 
the liquid air is seen beyond $60 \%$ integration. A similar effect occurs in Configuration 1; however, since the relative volatility for this case is higher, the effect is smaller since less reflux is required.

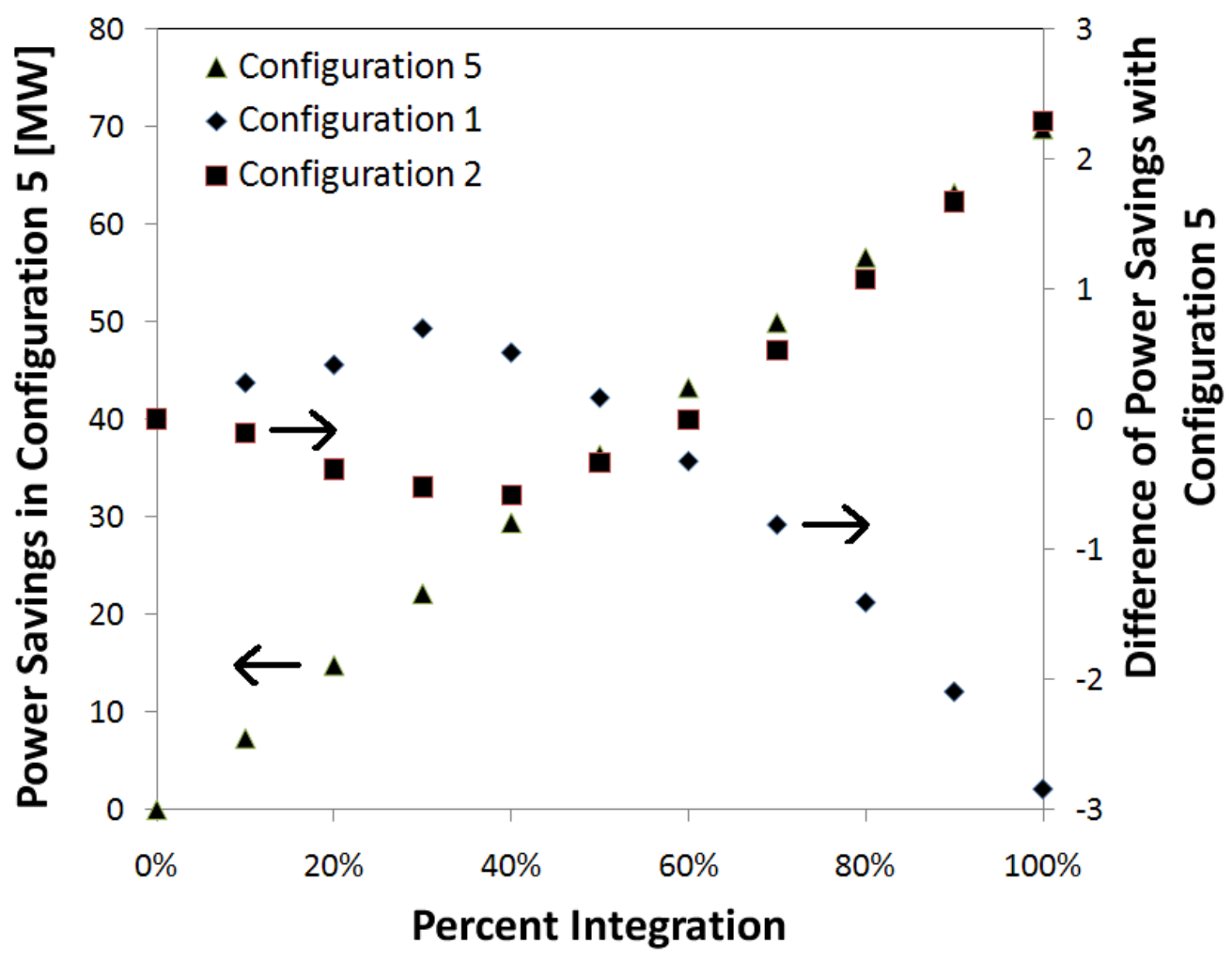

Figure 12: Power savings in the ASU as a function of increasing air integration with the gas turbine 


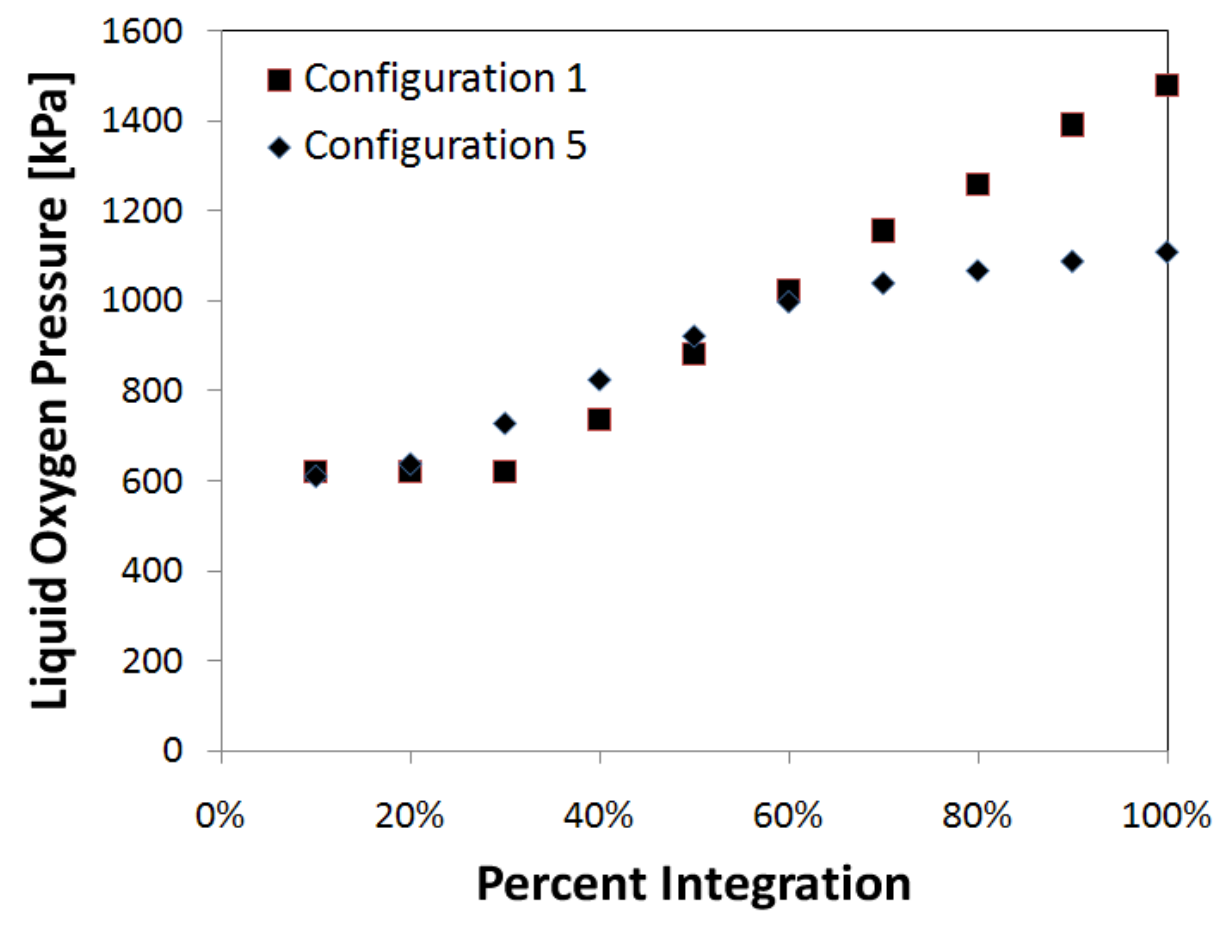

Figure 13: Liquid oxygen pressure as a function of percent integration

Table 7: Total ASU power requirement for each Configuration using varying degrees of air integration

\begin{tabular}{|c|c|c|c|c|c|}
\hline & $\begin{array}{c}\mathrm{N}_{2} \\
\text { Compressors } \\
{[\mathrm{MW}]}\end{array}$ & $0 \%$ & $30 \%$ & $60 \%$ & $100 \%$ \\
\hline $\begin{array}{c}\text { Configuration } \\
1\end{array}$ & 58.3 & 133.3 & 110.4 & 90.3 & 66.3 \\
\hline $\begin{array}{c}\text { Configuration } \\
2\end{array}$ & 41.6 & 129.7 & 108.0 & 86.4 & 57.6 \\
\hline $\begin{array}{c}\text { Configuration } \\
5\end{array}$ & 44.6 & 131.1 & 109.5 & 88.4 & 61.8 \\
\hline
\end{tabular}


Table 8: Results for Configuration 5 using varying degrees of air integration

\begin{tabular}{|c|c|c|c|c|c|c|c|}
\hline $\begin{array}{c}\text { Percent Air } \\
\text { Integration }\end{array}$ & $\begin{array}{c}\mathrm{MAC} \\
{[\mathrm{MW}]}\end{array}$ & $\begin{array}{c}\mathrm{N}_{2} \\
\text { Comp. } \\
{[\mathrm{MW}]}\end{array}$ & $\begin{array}{c}\mathrm{O}_{2} \\
\text { Comp. } \\
{[\mathrm{MW}]}\end{array}$ & $\begin{array}{c}\mathrm{N}_{2} \\
\text { Recycle } \\
{[\mathrm{MW}]}\end{array}$ & $\begin{array}{c}\text { Liquid } \\
\text { Air } \\
\text { Flow } \\
{[\mathrm{kmol}} \\
\left.\mathrm{hr}^{-1}\right]\end{array}$ & $\begin{array}{c}\text { Liquid } \\
\text { Air } \\
\text { Pressure } \\
{[\mathrm{kPa}]}\end{array}$ & $\begin{array}{c}\text { Liquid } \\
\mathrm{O}_{2} \\
\text { Pressure } \\
{[\mathrm{kPa}]}\end{array}$ \\
\hline 10 & 63.6 & 44.6 & 13.3 & 2.5 & 5053.9 & 1586 & 607 \\
\hline 20 & 56.5 & 44.6 & 13.1 & 2.6 & 5079.8 & 1635 & 641 \\
\hline 30 & 49.4 & 44.6 & 12.3 & 3.2 & 5184.1 & 1826 & 731 \\
\hline 40 & 42.4 & 44.6 & 11.5 & 3.7 & 5337.4 & 2016 & 827 \\
\hline 50 & 35.3 & 44.6 & 10.9 & 4.4 & 5448.1 & 2217 & 924 \\
\hline 60 & 28.3 & 44.6 & 10.4 & 5.1 & 5603.7 & 2412 & 1000 \\
\hline 70 & 21.2 & 44.6 & 10.2 & 5.7 & 5728.0 & 2612 & 1041 \\
\hline 80 & 14.1 & 44.6 & 10.1 & 6.2 & 5892.2 & 2803 & 1069 \\
\hline 90 & 7.1 & 44.6 & 9.9 & 6.8 & 6048.2 & 2990 & 1096 \\
\hline 100 & 0.0 & 44.6 & 9.9 & 7.3 & 6256.4 & 3167 & 1110 \\
\hline
\end{tabular}

\section{Fuel Diluent}

It has been suggested that the operating pressure of the GT, the degree of air integration, and the fraction of nitrogen injection (in the case where both nitrogen and steam are used as fuel diluents) determine optimal ASU operating pressure [68]. A study was carried out to determine the effect of the choice of fuel diluent and degree of nitrogen injection on the choice of ASU operating pressure. This study was carried out with a constant $\mathrm{NO}_{\mathrm{X}}$ concentration of 37 ppmvd in the gas turbine exhaust, using Equations 1a, 1b, 2a, and $2 \mathrm{~b}$ to predict concentration. The simplified configuration for the combined cycle unit used in this study is shown in Figure 3. ASU Configurations 1 and 5 were used for this study. At different nitrogen flows the diluent steam flow was manipulated to maintain the $\mathrm{NO}_{\mathrm{X}}$ concentration. The region in which these studies were carried out requires no air extraction, which is due to approximately half as much steam being needed as nitrogen for the same degree of $\mathrm{NO}_{\mathrm{X}}$ inhibition [10], and no PLOX cycle was 
considered for either configuration. As shown in Figure 14, the degree of nitrogen injection has a large influence on the optimal operating pressure and at a nitrogen injection rate beyond about $50 \%$, Configuration 5 becomes more advantageous than Configuration 1, which is in good agreement with the findings of Frey and Zhu [6], who considered syngas humidification and Smith et al. [8]. This finding is driven by the cost of nitrogen compression, which is determined by the ASU operating pressure and gas turbine operating pressure.

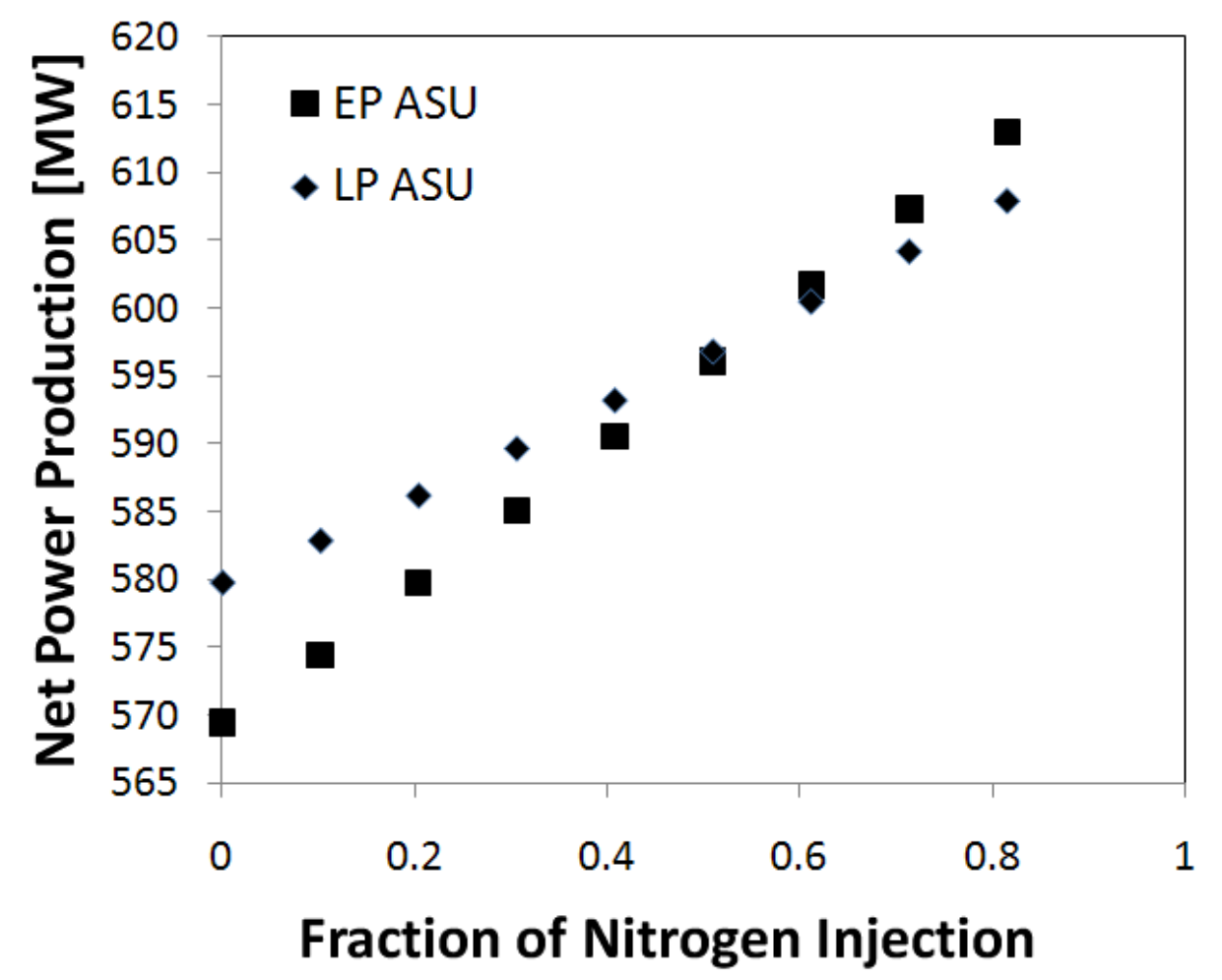

Figure 14: The effect of fuel diluent on the net power production for constant $\mathrm{NO}_{\mathrm{X}}$ concentration in GT exhaust

\section{Conclusions}

An EP-ASU with PLOX cycle can be a feasible alternative to the traditional GOX cycle for improving the safety and availability of an IGCC plant where the operating pressure of the gasifier is high. However, the refrigeration lost in the liquid oxygen must be efficiently recovered to avoid loss in the ASU efficiency. This paper has considered five different configurations with PLOX cycle for $100 \%$ 
nitrogen integration to improve the overall plant efficiency. In absence of a highpressure air stream in Configuration 1 which is an LP-ASU with PLOX cycle, the PLOX pressure could not be increased much. Therefore this configuration required a very high compression ratio for both LP nitrogen and oxygen, highest among all the configurations, resulting in $59 \%$ of the total ASU power consumption. Configuration 1 consumes higher power compared to an EP-ASU with GOX cycle which is Configuration 2. If a high-pressure air stream is used alone to recover the refrigeration from liquid oxygen, as in Configuration 3, the resulting liquid air creates significant separation challenges. As the operating pressure of the LP column is lowered to satisfy the product qualities, this configuration is found to consume the highest power among all the configurations considered in this paper. If a high-pressure nitrogen stream is used alone to recover the refrigeration, as in Configuration 4, a higher ASU pressure can be maintained without sacrificing product qualities. However, negligible power saving is achieved by pumping the liquid oxygen because of a nearly equivalent increase in power consumption in the recycle nitrogen compressor to that saved in the oxygen compressors. Configuration 5, a hybrid of Configuration 3 and 4, is found to have higher power savings because of the advantages of each configuration. The power requirement is further reduced by utilizing a sidedraw in Configuration 6 . The study shows that there is an optimum flowrate of the sidedraw that results in the minimum power consumption for an EP-ASU with PLOX cycle. The power consumption in Configuration 6 is similar to Configuration 2. This shows that an optimally designed EP-ASU with PLOX cycle can have similar efficiency to that of an EPASU with GOX cycle with other added advantages of using a PLOX cycle.

As found by others studies, optimal air integration occurs when air extracted from the GT can be replaced with nitrogen from the ASU without exceeding mass/volumetric flow limitations of the GT. In the case of an unshifted syngas, 
optimal integration is generally agreed to occur at approximately $25-50 \%$ integration. In the case of a shifted syngas where the LHV both on mass and volume basis is higher than the unshifted syngas, optimal air integration was found to be $9 \%$.

High-pressure air extracted from the GT, when used in an EP-ASU, yields power savings due to a decreased load on the MAC. It has been shown here that an LP-ASU with a cycle as shown in Figure 2 can yield greater power savings than is possible for an EP-ASU with GOX cycle or EP-ASU with PLOX cycle when air integration levels are less than $50-60 \%$. Above this range of integration levels, the power savings expected from an EP-ASU can be as much as 5.1 MW greater.

It has been determined that the major factors affecting the optimal ASU operating pressure are degree of nitrogen injection and gas turbine operating pressure. Since it is possible to see nearly equivalent or higher power savings from an LP-ASU with a pumped liquid oxygen cycle with degrees of air integration below $50-60 \%$, the degree of integration seems to have only minor effects on optimal ASU operating pressure below this range.

A study was carried out on how the net IGCC power is affected by the choice of fuel diluents in the GT. Nitrogen and steam were considered as fuel diluents and their concentrations were varied while maintaining the $\mathrm{NO}_{\mathrm{X}}$ level constant. The study shows that the degree of nitrogen injection has a strong influence on the optimal operating pressure of the ASU. Beyond about $50 \%$ nitrogen injection rate, an EP-ASU with PLOX cycle when both nitrogen and air are used as high-pressure streams becomes more advantageous than an LP-ASU with PLOX cycle.

This paper shows that an optimal integration between the ASU and GT and an optimal design of an ASU under various degrees of integration can help to increase the net power generation from an IGCC plant with $\mathrm{CO}_{2}$ capture. 


\section{$\underline{\text { References }}$}

(1) Cost and performance baseline for fossil energy power plants study, Volume 1: Bituminous coal and natural gas to electricity. National Energy Technology Laboratory, http://www.netl.doe.gov, DOE/NETL-2007/1281, August 2007

(2) Bhattacharyya, D.; Turton, R.; Zitney, S. Steady-state simulation and optimization of an integrated gasification combined cycle (IGCC) power plant with $\mathrm{CO}_{2}$ capture. Accepted, Ind. Eng. Chem Res (2010)

(3) Bhattacharyya, D.; Turton, R.; Zitney, S. Plant-wide Dynamic Simulation of an IGCC Plant with $\mathrm{CO}_{2}$ Capture. Proc. of the $26^{\text {th }}$ Annual International Pittsburgh Coal Conference, September 21-24, Pittsburgh, PA (2009)

(4) Encyclopedia of Energy Engineering and technology, Vol 2-3, Ed. B. L. Capehart, CRC Press, Boca Raton, FL, (2007)

(5) Allam, R. J.; Foster, E.; Stein, V. Improving gasification economics through ITM oxygen integration. $5^{\text {th }}$ (IChemE) European Gasification Conference, 8-10 April, 2002, Noordwijk, The Netherlands

(6) Frey, H.C.; Zhu, Y. Improved system integration for integrated gasification combined cycle systems. Environ. Sci. Technol. 2006, 40, 1693-1699.

(7) Wimer, J.G.; Keairns, D; Parsons, E.L.; Ruether, J.A.; Integration of gas turbines adapted for syngas fuel with cryogenic and membrane-based air separation units: Issues to consider for system studies. Journal of Engineering for Gas Turbines and Power, 2006, 128, 271-280

(8) Smith, A.R.; Klosek, J; Woodward, D.W. Next-generation integration concepts for air separation units and gas turbines. J.Eng. Gas Turbines Power 1997, 119, 298 - 304.

(9) Geosits, R. F.; Schmoe, L.A.; IGCC - The challenges of integration, ASME Turbo Expo 2005, June 6-9, Reno-Tahoe, Nevada

(10) Foster Wheeler. Optimizing IGCC Design, Foster Wheeler Review, 1999, Autumn, 17-21 
(11) Smith, A.R.; Klosek, J. A review of air separation technologies and their integration with energy conversion processes. Fuel Processing Technology, 2001, 70, 115-134.

(12) Smith, A.R.; Woodward, D.W. Operation flexibility considerations in the selection of a pumped LOX air separation process incorporating a source of high pressure feed air. Air Products research disclosure Oct. 1996.

(13) Todd, D.M. Gas turbine improvements enhance IGCC Viability. Gasification Technologies Conference, Oct. 8-11 2000, San Francisco, California

(14) Jonsson, M.; Yan, J. Humidified gas turbines - a review of proposed and implemented cycles. Energy, 2005, 30, 1013-1078

(15) Hornick, M. J.; McDaniel, J. E. TampaElectric Polk Power Station Integrated Gasification Combined Cycle Project; Final Technical Report, DE-FC-21-91MC27363; prepared for the U. S. Department of Energy, Office of Fossil Energy, National Energy Technology Laboratory (NETL): Morgantown,WV,August 2002.

(16) Anand, A.K.; Cook, C.S.; Corman, J.C.; Smith, A.R. New technology trends for improved IGCC systems performance. Journal of Engineering for Gas Turbines and Power, 1996, 118, 732-736.

(17) Brooks, F.J. GE gas turbine performance characteristics, GE Power Systems

(18) Beate Seliger; Richard Hanke-Rauschenbach; Frank Hannemann; Kai Sundmacher Modeling and dynamics of an air separation rectification column as part of an IGCC power plant. Seperation and Purification Technology, 2006, 49, 136-148.

(19) A.R. Smith; E.J. Noga; Air Separation Design for IGCC - Future Directions. EPRI Gasification Technologies Conference, Oct 1996, San Francisco, CA

(20) Bruce K. Dawson; Scott C. Siegmund; Zhang Yonggui; Flowsheet Optimization for Multi-Purpose Air Separation Units. The First Baosteel Annual Academic Conference, May 2004, Shanghai, China 
(21) R.J. Allam; H. Castle-Smith; Air Separation Units, Design and Future Development. Gasification of Coals, Biomass, and Oil EUROTHERM Seminar $N^{0}$ 65, July 2000, Enschede, The Netherlands

(22) B. Roffel; B.H.L Betlem; J.A.F. de Ruitjer; First principles dynamics modeling and multivariable control of a cryogenic distillation process. Computers and Chemical Engineering (2000) 111-123

(23) Jason Miller; William L. Luyben; Paul Belanger; Stephane Blouin; Larry Megan; Improving Agility of Cryogenic Air Separation Plants, Ind. Eng. Chem Res. (2008), 47, 394-404

(24) J.O. Trierweiler; S. Engell; A case study for control structure selection: air separation plant. Journal of Process Control 10 (2000), 237-243

(25) Raddings T, Jones R, and Scholz M. "Gas Turbine Flexibility for Low Turbine Fuels", Presented at IChemE Gasification 9, Dusseldorf, Germany, March 24, 2009

(26) Schmidt, W. "ASU Reboiler/Condenser Safety.” Presented at European Industrial Gas Association, Product Safety Seminar, February 2, 2006

(27) Jacobs Consultancy UK, "Impact of $\mathrm{CO}_{2}$ removal on coal gasification based fuel plants', Feb 2006

(28) Chan Lee, Seung Jong Lee, Yongseung Yun. "Effect of air separation unit integration on integrated gasification combined cycle performance and NOx emission characteristics" Korean J. Chem. Eng. 24(2) (2007), 368373

(29) Chan Lee, Hyung Taek Kim, Yongseung Yun. "Optimal integration condition between the gas turbine air compressor and the air separation unit of IGCC power plant" Energy Conversion Engineering Conference, 1997. IECEC-97., Proceedings of the 32nd Intersociety

(30) Ola Maursad, "An overview of coal based integrated gasification combined cycle (IGCC) technology" http://sequestration.mit.edu/pdf/LFEE_2005-002_WP.pdf

(31) Calin-Cristian Cormos. "Evaluation of energy integration aspects for IGCC-based hydrogen and electricity co-production with carbon capture 
and storage" International Journal of Hydrogen Energy 35 (2010) 7485 7497

(32) Marvin M. Schorr, Joel Chalfin. "Gas Turbine $\mathrm{NO}_{\mathrm{X}}$ Emissions Approaching Zero - Is it Worth the Price?", GE Power Systems 